\title{
Cochlear implantation : Surgical and audiological assessment of cochlear implantation techniques
}

Citation for published version (APA):

Postelmans, J. (2012). Cochlear implantation : Surgical and audiological assessment of cochlear implantation techniques. [Doctoral Thesis, Maastricht University]. Datawyse / Universitaire Pers Maastricht. https://doi.org/10.26481/dis.20121128jp

Document status and date:

Published: 01/01/2012

DOI:

10.26481/dis.20121128jp

Document Version:

Publisher's PDF, also known as Version of record

\section{Please check the document version of this publication:}

- A submitted manuscript is the version of the article upon submission and before peer-review. There can be important differences between the submitted version and the official published version of record.

People interested in the research are advised to contact the author for the final version of the publication, or visit the DOI to the publisher's website.

- The final author version and the galley proof are versions of the publication after peer review.

- The final published version features the final layout of the paper including the volume, issue and page numbers.

Link to publication

\footnotetext{
General rights rights.

- You may freely distribute the URL identifying the publication in the public portal. please follow below link for the End User Agreement:

www.umlib.nl/taverne-license

Take down policy

If you believe that this document breaches copyright please contact us at:

repository@maastrichtuniversity.nl

providing details and we will investigate your claim.
}

Copyright and moral rights for the publications made accessible in the public portal are retained by the authors and/or other copyright owners and it is a condition of accessing publications that users recognise and abide by the legal requirements associated with these

- Users may download and print one copy of any publication from the public portal for the purpose of private study or research.

- You may not further distribute the material or use it for any profit-making activity or commercial gain

If the publication is distributed under the terms of Article $25 \mathrm{fa}$ of the Dutch Copyright Act, indicated by the "Taverne" license above, 


\section{Cochlear Implantation}

Surgical and audiological assessment of cochlear implantation techniques 
(C) Job Postelmans, Maastricht 2012

ISBN 9789461591869

Financial support for the publication of this thesis was kindly provided by Advanced Bionics, ATOS medical, Beter Horen, Carl Zeiss, Cochlear Benelux, Olympus, Streukens, Daleco Pharma, Electro Medical Instruments, GloxoSmithKline and MSD Nederland. 


\title{
Cochlear Implantation
}

\section{Surgical and audiological assessment of cochlear implantation techniques}

\author{
Proefschrift \\ ter verkrijging van de graad van doctor \\ aan de Universiteit Maastricht, \\ op gezag van de Rector Magnificus, Prof. dr. L.L.G. Soete, \\ volgens het besluit van het College van Decanen, \\ in het openbaar te verdedigen \\ op woensdag 28 november 2012 om 14.00 uur
}

door

Job Postelmans

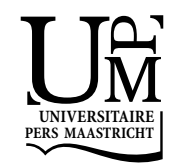




\section{Promotores}

Prof. dr. R.J. Stokroos

Prof. dr. B. Kremer

Prof. dr. W. Grolman, Universiteit Utrecht

\section{Beoordelingscommissie}

Prof. dr. H. Kingma, voorzitter

Prof. dr. ir. P. van Dijk

Prof. dr. ir. J.H.M. Frijns

Prof. dr. Y. Temel 


\section{Contents}

$\begin{array}{lll}\text { Chapter } 1 & \text { General introduction } & 7\end{array}$

Chapter 2 Post-operative complications of cochlear implantation in adults and children: five years' experience in Maastricht

Chapter 3 Cochlear implantation in patients with chronic otitis media:

7 years' experience in Maastricht

Chapter 4 The suprameatal approach: a safe alternative surgical technique for cochlear implantation

Chapter 5 Comparison of two approaches to the surgical management of cochlear implantation

Chapter 6 An evaluation of preservation of residual hearing using the suprameatal approach for cochlear implantation: Can this implantation technique be used for preservation of residual hearing?

Chapter 7 Residual hearing preservation after cochlear implantation: comparison between two surgical techniques

Chapter 8 General discussion

Samenvatting

List of publications

Dankwoord

Curriculum Vitae 

(ㄱ)

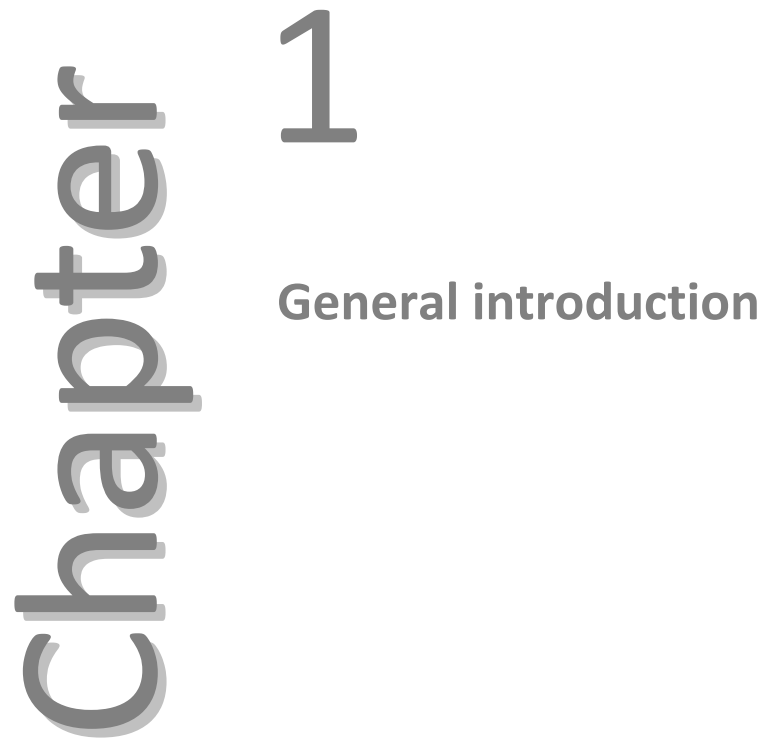


8 (1) Chapter 1 


\section{Normal hearing}

Hearing occurs when sound vibrations are transmitted through the outer ear canal, via the middle ear to the inner ear, where the vibrations result in neural excitation. The tympanic membrane separates the outer ear canal from the middle ear. Sound waves reaching the tympanic membrane cause oscillation of this membrane, which consequently sets up vibration of the malleus, incus and stapes (ossicular chain) in the middle ear (Figure 1.1). The lateral side of the ossicular chain is attached to the tympanic membrane via the malleus while its medial side communicates with the oval window via the stapes. Movement of the stapes footplate in the oval window transmits the sound vibrations from the middle ear to the inner ear. The inner ear, also known as the cochlea, is a very small fluid filled coiled snail-like structure embedded in bone that accommodates the sense organ of hearing (organ of Corti). The cochlea has a total length of approximately 35 millimeters. Three spiral compartments: the scala media, scala vestibuli and scala tympani constitute the cochlear turns. They are composed of windings around the modiolus which contains the spiral ganglion cells of the cochlear nerves. The scala tympani and vestibuli communicate with each other at the apex, with the scala media wedged in between. The scala media contains the organ of Corti, which rests on the basilar membrane and lies between the scala vestibuli and scala tympani.

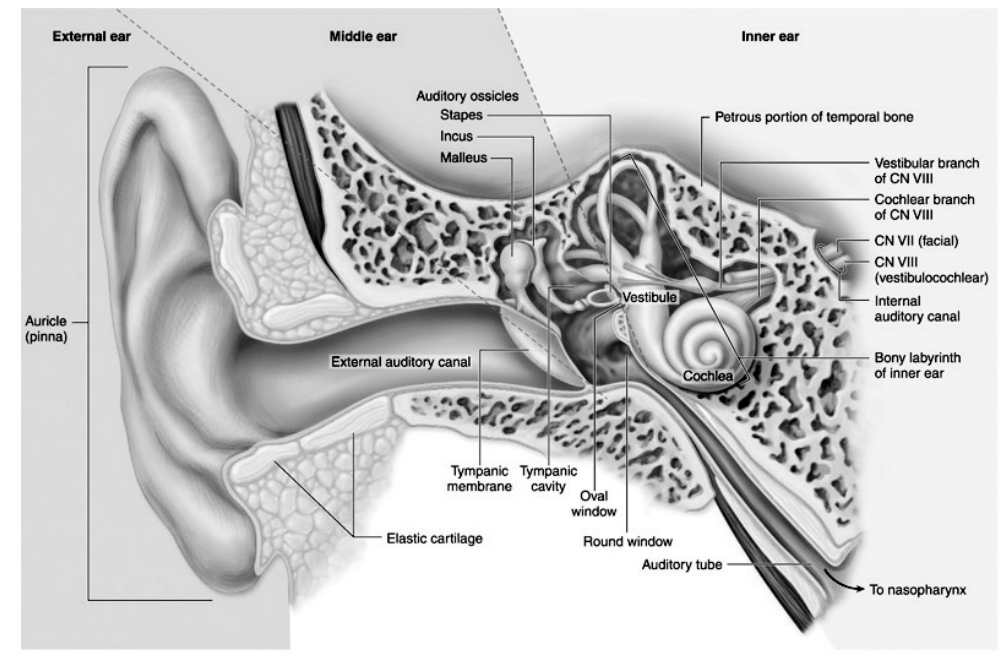

Figure 1.1 Overview of the middle- and inner ear contents. 
Vibration of the basilar membrane is caused by a fluid wave in the cochlea that travels in the direction of the apex, as a consequence of the movement of the stapes footplate at the oval window, in response to sound vibrations. This motion of the basal membrane induces hair cell movement within the organ of Corti. When these hairs move back and forth in response to vibration of the basilar membrane, the movement of the hair cells evokes action potentials that produce patterns of excitation. The evoked action potentials travel along the nerve fibers that connect the hair cells with the spiral ganglion cells located in the modiolus of the cochlea. From the spiral ganglion cells, the evoked action potentials are passed on to the cochlear nerve and brainstem to be projected and interpreted in the auditory cortex. The patterns of excitation passed along the auditory pathways encode information about the spectrum, amplitude and frequency of the sound that induced the excitation. This representation is facilitated by the tonotopic organization of the cochlea which refers to the fact the basilar membrane vibrates selectively to different sound frequencies, functioning as a sound filter. High frequencies produce maximal vibrations at the beginning of the basilar membrane at the beginning of the cochlear turn. Low frequencies produce maximal vibrations of the basilair membrane at the end of the cochlear turn. This spectral analysis is maintained within the subsequent transmission of compound action potentials, because the different nerve fibers that comprise the cochlear nerve each correspond with a specific location in the cochlea. ${ }^{1}$

\section{Cochlear implantation}

A cochlear implant is an electronic device that transforms acoustic vibrations electronically into an electrical current that directly stimulates the auditory nerve. This device has been developed for patients suffering from severe to profound sensorineural hearing loss for whom amplification of sounds with conventional hearing aids does not sufficient restore ability to understand speech. In these patients, the auditory nerves that lead to the brain centres cannot be stimulated as a consequence of loss of hair cells. The cochlear implant was therefore developed to bypass the hair cells to facilitate delivery of information to the hearing centres of the central nervous system.

A cochlear implant consists of an external and internal part of which the internal part is surgically implanted underneath the skin and in the cochlea. The external part is comprised of a microphone, speech processor and transmitter where sounds are received, analyzed and transformed into electric pulses. The speech processor with the microphone is commonly worn behind the ear as a conventional hearing aid. The electrical pulses are transmitted using a coil worn on the outside of the head, and coupled via FM transduction, to a receiver placed under the skin. From the receiver, the decoded pulses are transmitted to the electrode array that is placed into the scala tympani of the cochlea. Electrode arrays may comprise up to 22 stimulating 
electrodes. The different frequency bands of an incoming sound are first processed and then divided over the appropriate electrodes of the inserted electrode array. Each electrode array stimulates a specific location along the cochlea by producing electric pulses that spread to the auditory nerve fibers, thereby using the natural tonotopic organization of the cochlea. In this way cochlear implants can provide auditory input even when the organ of Corti itself is non-functional.

\section{History of cochlear implantation}

The history of cochlear implantation started with the use of electricity to stimulate the ear in an attempt to produce a sensation of sound. This discovery was made by Alessandro Volta who placed metal rods in his own ears and connected them to an electrical source. This caused him to lose consciousness, but he also remembered hearing a noise "like a thick boiling soup" in his ears. ${ }^{2}$ Almost two centuries later, around 1957, André Djourno and Charles Eyriès were the first to directly stimulate an acoustic nerve with an electrode by means of a single copper wire. ${ }^{3,4}$ After placing a copper wire on the auditory nerve during an operation, they reported that the patient was able to hear heard sounds like " a roulette wheel" and "a cricket" when current was applied. This event is considered the seminal observation that paved the way for modern cochlear implantation.

Despite the scepticism of many scientists about the feasibility of a cochlear implant in the 1960s, the field of cochlear implantation has grown from a small number of isolated experimental studies, to a diverse discipline subject to extensive and diverse research. ${ }^{5}$ This has resulted in the introduction of several types of cochlear implant devices which can basically be classified into extracochlear and intracochlear systems which were further divided into single-channel and multi-channel stems in the 1960s. Until now, surgeons have been concerned that the placement of intracochlear devices would cause even more damage to the refined hearing organ in the cochlea. In addition to the potential risk of insertion trauma, other objections to intracochlear systems were the potential lack of biocompatibility of the device and, especially in children, the risk of middle ear infection spreading to the cochlea and meninges via the intracochlear array. These objections resulted in the development of extracochlear systems, in which the electrode was placed outside the cochlea, in the round window niche or on the promontory.

Despite the risks of insertion trauma and meningitis after placement of an electrode into the cochlea, animal studies showed that the scala tympani was the best place to stimulate the auditory nerve fibers connected to the different frequency regions of the brain. ${ }^{6-8}$ Furthermore, it was shown that injury to the nerve fibers could be prevented when the electrode arrays with the correct mechanical properties were placed into the cochlea without extensive force. ${ }^{9}$ It was also shown that current was not harmful to the nerve fibers. ${ }^{9}$ These findings led to the development of the first cochlear implant in 
1972 by William House and Jack Urban. ${ }^{10}$ With this device, the entire speech signal was delivered to a single electrode located in the scala tympani. This single-channel implant permitted adequate stimulation of the cochlear nerve. ${ }^{11,12}$ Although the results of initial cochlear implants were encouraging; by allowing patients to pick up ambient sounds, the implant served as an aid to lip-reading. It became apparent that just one electrode was unable to transfer the spectral information needed to enable speech recognition. Therefore, Graeme Clark took the development of cochlear implants in a new direction by stimulating the cochlea at multiple points in the 1970 s. $^{13}$ The development of multichannel cochlear implants, which became widely available in the 1980s, supported significantly higher levels of speech reception than their singlechannel predecessors. ${ }^{13}$ Clark first implanted a human subject in 1978, and in 1981, he showed that patients were able to understand some open-set speech with their implants and without the aid of lip-reading. ${ }^{14,15}$ The Food and Drugs Administration (FDA) approval for the multichannel implant was approved for adult patients in 1985 and children as young as 2 years in 1990. Almost three decades after the approval of the FDA, the first multichannel cochlear implant devices underwent multiple advancements regarding hardware and software related issues.

\section{Preservation of residual hearing}

Due to the rapid and continuous evolution of cochlear implant technology during the last three decades both prelingual deafened children and postlingually deafened adults and children have acquired new levels of hearing performance. In fact, cochlear implant users have now started to outperform many patients with less severe forms of hearing loss aided with hearing aids. ${ }^{16}$ The significant improvements of these devices have broadened criteria for eligibility to include patients with some degree of residual hearing. The rationale behind the preservation of residual hearing is based on several clinical findings: 1) better performance of recipients in difficult or noisy listening environments, 2) improvement of music perception and appreciation, and 3) sound and voices have a more natural quality. ${ }^{17-23}$ Preservation of residual hearing is therefore presently one of the highest priorities of the cochlear implant surgeon.

Prior to the institution of hearing preserving surgical cochlear implantation techniques, reports demonstrated some postoperative hearing remnants in the implanted ear of up to $50 \%$ of conventional cochlear implant recipients. ${ }^{24,25}$ The introduction of meticulous surgical techniques preservation of residual hearing has contributed to further improvement after cochlear implantation. ${ }^{26}$ In fact, several clinical studies have shown that it is possible to preserve residual hearing in roughly $90 \%$ of cases. ${ }^{19-23}$ However, complete preservation of preoperative hearing abilities is only possible in $50 \%$ of individuals in most studies, thus leaving much room for improvement of the surgical technique. ${ }^{22,23}$ 


\section{Surgical technique for cochlear implantation}

The surgical goal of cochlear implant surgery is to maximize the contact between the electrodes and the modiolus as atraumatically as possible. This goal is usually achieved by performing a canal wall up mastoidectomy and exposing the facial recess to facilitate the insertion of the electrode array into the scala tympani. Since the first implantation of a single electrode cochlear implant into the scala tympani in 1961 by House, this particular surgical approach has proven to be efficient and safe in the majority of cases. ${ }^{27-32}$

The surgical technique for cochlear implant surgery consists of several steps including:

1) Facial nerve monitoring electrodes are placed at the beginning of the procedure, and facial nerve monitoring occurs until the implant electrodes are in place. The procedure is performed in the conventional otologic position using routine aseptic techniques, under general anesthesia. Muscle relaxants agents must not be used during the drilling of the mastoid and/or facial recess as they may disrupt monitoring of the facial nerve. The use of perioperative antimicrobial prophylaxis is recommended in order to cover skin and middle ear flora; the most frequently used agents mentioned in literature are first- or second generation cephalosporines. ${ }^{33-35}$

2) An "inverted J" incision is used to expose the mastoid cortex, linea temporalis, mastoid tip, and at least $3 \mathrm{~cm}$ of bone above and beyond the mastoid. The "inverted J" incision creates a posteriorly and inferiorly based retroauricular scalp flap by extending the retroauricular incision superiorly and inferiorly to create an "inverted J" incision. This particular incision allows the preservation of blood supply in the superficial temporal artery and thus helps overcome flap related complications. In the early days of cochlear implant surgery flap-related complications were often reported as a consequence of the frequently used "Cshaped" incision. Introduction of the "inverted J" incision has reduced flap-related complications as the design of the "inverted J" incision does not compromise vascular supply to the skin flap. A disadvantage of the "inverted J" incision is that the incision crosses the electrode lead as it enters the mastoid cavity without ensuring electrode coverage. Therefore an anteriorly based musculofascial flap (Palva flap) under the scalp flap is recommended in using the "inverted-J incision" to guarantee coverage of the electrode. Figure 1.2 gives an overview of the historically used incisions for cochlear implant surgery.

3) A template of the receiver-stimulator is used to mark the location of the receiverstimulator with an 18-gauge needle dipped in methyl blue before incision. It is mandatory that the position of the receiver-stimulator on the skull is far enough away from the pinna to facilitate future behind-the-ear housing. 


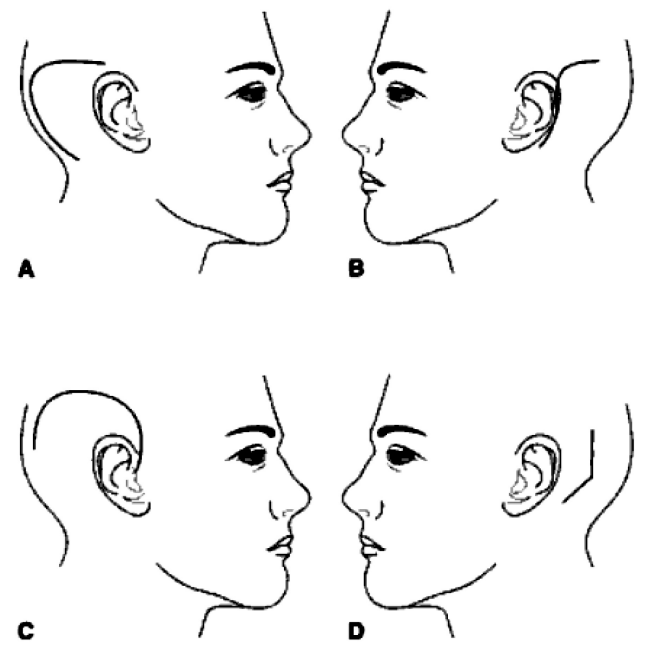

Figure 1.2 Illustrates the various incisions and flap designs historically used for cochlear implantation. A) Anteriorly based or C-shaped flap. B) Posteriorly based or inverted J-shaped flap. C) Inferiorly based flap or extended endaural incision. D) Superiorly and anteriorly based flap. (Illustration is from Cochlear Implant, Principles \& Practices, Second Edition 2009, by John K. Niparko)

4) After exposing the landmarks a simple mastoidectomy is performed, with care taken not to saucerize the superior and posterior bony margins. Moreover, the bone at the margins of the mastoid cavity can offer protection for connecting leads and a platform for stabilizing the receiver-stimulator. Subsequently, the antrum is opened and the lateral semicircular canal and the short process of the incus can then be identified.

5) Approaching the facial recess is achieved by using strategies optimizing visualization including 1 ) adequate maximal thinning of the posterior external auditory canal, 2) systemic exposure of the horizontal semicircular canal, fossa incudis and chorda-facial angle. When performing the posterior tympanotomy, the facial recess is opened widely, with care taken to preserve a layer of bone overlying the facial nerve. An adequate facial recess facilitates good visualization of the stapedial tendon, the round window, and the cochlear promontory. To properly visualize and gain access to the cochlear promontory for the cochleostomy, the facial recess must be enlarged inferiorly and the bone anterior to the facial nerve and inferior to the stapedial tendon must be removed. Copious irrigation should occur to avoid thermal damage to the facial nerve in case of skeletonizing and when the facial recess is open. The chorda tympani can be spared in nearly all cases. When the facial recess is very small, the nerve can be sacrificed in order to obtain better visualization of the round window. In this case, 
care should be taken not to injure the annular ligament of the tympanic membrane, as the chorda enters the middle ear at the level of the annulus. An adequate facial recess approach to the middle ear requires full access to the round window and the inferior cochlea. If the anatomy of the round window is obscured, the surgeon should always remember that the round window is never more than 2 $\mathrm{mm}$ from the inferior margin of the oval window and usually directly inferior in orientation. ${ }^{36-38}$ Misinterpretation of the anatomy may lead the surgeon to insert the tip of the electrode array into a hypotympanic air cell.

6) The well to accommodate the receiver-stimulator is created as previously marked, just posterior and superior to the mastoid area. It should be snug enough to prevent migration of the receiver-stimulator and deep enough to prevent extrusion of the device through the skin flap. The floor of the well may need to be thin like an eggshell in children. Complete bone removal to accommodate the receiver-stimulator directly to the dura mater is not necessary. Great care must be taken with children not to injure the dura mater. Subsequently, a narrow groove is drilled leading to the mastoidectomy cavity that will later accommodate the leading wire from the device onto the facial recess.

7) The scala tympani must be opened which can only be done after obtaining full access to the round window and the surrounding structures by means of the posterior tympanotomy. Opening the scala tympani can be done in two ways: either directly using a round window approach, or indirectly by drilling a cochleostomy through the promontory. The most frequently used approach to enter the scala tympani is drilling a cochleostomy. Since preservation of residual hearing has become clinically relevant, guidelines for inserting the electrode array into the scala tympani have been modified, according to the soft surgery protocol which was introduced by Lenhardt in $1993 .^{26}$

In summary, it is recommended that the following steps should occur: identification of the cochleostomy site, anterior-inferiorly to the round window, and as close as possible to the round window; controlled opening of the endostium as late as possible; keeping aspiration of the perilymphatic fluid to a minimum; apply Healon as a sealant to the endostial opening and as a lubricant on the electrode array; closure of the endostium as soon as possible and avoiding bone dust contamination of the perilymphatic fluid throughout. In addition, corticosteroids are recommended postsurgically.

8) The receiver-stimulator is placed and secured into the well. The electrode array is led via the facial recess towards the promontory and inserted into the scala tympani under direct visualization, using methods designed to minimize trauma to the membranous components of the cochlea. After insertion of the electrode array into the scala tympani, the cochlea is sealed around the electrode array with temporalis fascia to minimize the risk of meningitis. 
9) Excess lead wire is coiled and packed into the mastoid cavity. Subsequently, tissue coil is used to prevent migration of the lead wire in the mastoid cavity. If, present the ground electrode is placed under the temporal muscle.

10) The incision is closed in three layers beginning with the periosteum for a complete covering, the electrode leads are extended from the receiver-stimulator into the mastoid cavity.

\section{Alternative surgical implantation techniques}

In spite of the fact that the mastoidectomy with posterior tympanotomy approach (MPTA) continues to be the gold standard and most commonly used surgical technique for cochlear implant surgery, a number of alternative techniques have been developed which are described in literature. Several alternative implantation techniques have been studied including the suprameatal approach (SMA), the transcanal wall ("Veria") technique, the pericanal electrode insertion technique (PEIT), and the transmastoid labyrinthomy technique. ${ }^{39-44}$ Among these alternative techniques, the SMA technique appears to be the most often used according to the literature. ${ }^{42-46}$ The SMA technique was introduced by Kronenberg in 1999, to prevent facial paralysis and injury to the chorda tympani. ${ }^{42,43}$ The SMA technique is based on a retroauricular tympanotomy approach to the middle ear and cochleostomy site. The electrode is introduced into the middle ear via a suprameatal route thus avoiding mastoidectomy and posterior tympanotomy. By drilling the suprameatal tunnel the facial nerve is protected by the body of the incus when the middle ear is entered. Up till now, there are no available published reports which document the occurrence of facial paralysis when using the SMA technique for cochlear implantation.

Only a few studies have reported on the occurrence of postoperative complications after cochlear implantation using the SMA technique. ${ }^{42-46}$ In general the incidences of major and minor complications reported in these studies are in line with studies regarding the MPTA technique. ${ }^{47-49}$ Major complications are defined as those requiring further surgery and/or hospitalization for treatment. Minor complications are defined as those which can be treated by medical or audiological management and cause little distress to the patient. The most relevant and frequent major and minor complications which have been described in literature are summarized below.

\section{Major complications}

\section{Flap-related complications}

Several studies have shown that the most frequently identified complications, both major and minor complications, are related to the incision and postauricular flap 
design. ${ }^{50-53}$ These particular flap related complications vary in severity from minor wound dehiscence or infections to major loss of tissue requiring that the device be explanted. Numerous surgeons emphasize the importance of a good flap design and technical skill to prevent these complications. ${ }^{54,55}$ It is mandatory that the flap has adequate blood supply and venous drainage, and that adequate exposure of the operative site with adequate coverage of the device is maintained, and be carefully closed in layers without tension. For the event that potential extrusion of the device occurs as a consequence of local flap necrosis, the device can be rotated superior under the temporal muscle where intact skin covers the device.

\section{Device failure}

Device failure is another frequently described complication after cochlear implant surgery which can be divided into "hard failures" and "soft failures". Most cochlear implant failures are exactly that: the device ceases to function and the recipient no longer derives any benefit from the device. These "hard failures" are dramatic, straightforward, and easy to diagnose, and usually result in an abnormal integrity test. "Hard failures" may be caused by external trauma or by failure of internal components such as an integrated circuit, leakage of fluid into the case, short-circuits, or a variety of other modes. The occurrence of a "hard" failure clearly requires re-implantation, and the recipient fares well with this replacement.

On the other hand, "soft" failures are characterized by excessive loudness of sound, harsh noises, or intermittent signals which are experienced by the recipient as unpleasant while at the same time trouble-shooting the device indicates it to be functioning properly. Another even more difficult scenario is one in which the recipient does not experience any unpleasant sounds, but the performance on speech testing declines from a previous higher level. Also, the integrity test in these cases is usually normal. These events are also considered as "soft" failures, and are appropriately treated by replacement of the device. It is mandatory that a thorough medical and radiographic workup be performed before making the diagnosis of device failure. All explanted devices are returned to the manufacturer for analysis. Unfortunately, the integrity test by the manufacturer is just as often unable to provide reasons for failure.

\section{Facial nerve injury}

Facial nerve injury is a serious major complication after cochlear implant surgery and has been reported to occur rarely. ${ }^{56-58}$ In the early days of cochlear implantation, incidences of injury to the facial nerve ranging from 1.7 to $2.0 \%$ were not uncommon. $^{56-58}$ The most frequent mode of injury was a consequence of the heat generated with the burr shaft rotating over the facial nerve in the facial recess. To prevent facial nerve injury during cochlear implantation it is strongly recommended to maintain copious irrigation during drilling. Furthermore, the thin sheet of bone that covers the facial nerve must be maintained in this location along with an angle of 
drilling that keeps the bur shaft lateral and away from the floor of the facial nerve. To minimize facial nerve injury due to heat generated by the bur special burs have been designed in which the bur shaft is covered.

\section{Minor complications}

Minor complications appear usually immediately after cochlear implant surgery and tend to disappear over time. The most commonly reported minor complications include tinnitus, vertigo, facial nerve stimulation and taste disturbances.

\section{Tinnitus}

The prevalence of tinnitus has been noted to be extremely high in the cochlear implant population. In addition, $80-90 \%$ of $\mathrm{Cl}$ candidates have tinnitus prior cochlear implantation. ${ }^{59}$ In most patients the tinnitus increases only for a few days after cochlear implantation and normally subsides without any treatment. It has been reported that tinnitus is either suppressed or subsides on use of the implant in a large number of cochlear implant users. ${ }^{60}$

\section{Postoperative vertigo}

Recent studies have shown that cochlear implantation postoperative vertigo is not an uncommon minor complication. ${ }^{61-65}$ Transient nonspecific dizziness in the first several hours after cochlear implant surgery often requires no further intervention beyond supplemental doses of prophylactic antiemetic agents already given in the operating room. In the majority of patients the degree of nausea declines sufficiently to tolerate oral input and to be discharged the day after surgery. However, patients with acute severe unilateral vestibular sensory loss (for example, due to malpositioning of the electrode array or other causes of acute labyrinthine injury) may experience severe vertigo and exhibit an obvious nystagmus.

\section{Taste disturbance}

Identification of patients who experience taste disturbances may take various forms, such as reduced sensation, complete loss of taste, or numbness of the tongue. To prevent taste disturbances care must be taken not to injure the chorda tympanic nerve during the facial recess approach, nevertheless, minor damage is sometimes inevitable. In the majority of patients the symptoms tend to subside within a few weeks, and ongoing complaints of such taste disturbances are very rare.

\section{Facial nerve stimulation}

Facial nerve stimulation with device activation occurs in a considerable number of patients, although its incidence varies from 0.31 to $14 \% .{ }^{66-68}$ Certain conditions such as cochlear malformation, otosclerosis and cochlear ossification have been associated 
with substantially higher incidences of facial nerve stimulation. ${ }^{69-71}$ Facial twitching may appear immediately after switching on the device as consequence of deficient partition between the facial canal and superior segment of the cochlear basal turn. Studies have reported an incidence of facial nerve stimulation as high as $75 \%$ in patients with otosclerosis. $^{72}$

Proposed etiology for facial nerve simulation, are twofold: the pressure elicited by the straight electrode array on the outer wall of the scale tympani and the existence of an electrical current shunt in the otosclerotic bone. In the first case, facial nerve stimulation occurs several months after the use of cochlear implantation and sometimes even after a few years. The electrodes located beneath the tympanic portion of the facial nerve are the most likely source of stimulation. Facial nerve stimulation can be resolved by switching off the electrodes located in the superior segment. If speech perception deteriorates, replacement with a modiolar hugging electrode may provide satisfactory resolution.

\section{Cochlear implant surgery in patients with chronic otitis media (COM)}

Although cochlear implantation has become a routine surgical procedure and incidences of the above described complications are within acceptable levels, special attention is paid to patients who have become deaf as a result of chronic otitis media (COM). In particular, it is these patients who present a significant challenge to safe cochlear implantation. In the early days of cochlear implantation COM was a contraindication to cochlear implantation. Nowadays, however, recognition of the potential benefits of cochlear implantation in patients with COM has stimulated the development of innovative surgical approaches to overcome the potential risks of postoperative complications. ${ }^{73-77}$

Hypothetically, cochlear implantation in a chronic diseased ear may lead to implant colonization and subsequent implant extrusion or meningitis as a consequence of inserting an electrode through an infected mastoid or middle ear cavity into a space with intracranial communication. In order to justify cochlear implantation in a specific patient with COM, there must be focus on accurate assessment of the risk to the patient and anticipated benefit.

The primary purpose of cochlear implantation in patients with COM is twofold, namely elimination of infection and creation of a closed environment to reduce the risk of infection associated with the placement of foreign material. A various number of surgical approaches have been developed to facilitate cochlear implantation in a COM setting. These surgical approaches include: i) radical mastoidectomy with eustachian 
tube occlusion, ii) mastoid obliteration using abdominal fat or temporal muscle flap and blind sac closure of the external ear canal (EAC), iii) blind sac EAC closure without cavity obliteration or other manipulations to protect the electrode array, including retrofacial placement of the electrode array with a cartilage or vascularized flap. iiii) additional techniques, including reconstruction of the posterior canal wall or partial obliteration of the cavity, have also been described. ${ }^{73-77}$ It is important to note that COM disease activity has to be respected. In other words, in case of an active infection of COM, all above described surgical approaches need to be performed as a twostaged procedure. In case of an inactive COM, surgical approaches can be performed in a one stage procedure. Thus, the inflammation is eradicated and simultaneously the device is implanted. As no single surgical approach has been shown to be superior, it is often customized to the individual patient as well as to the clinical experience and first choice of the surgeon.

\section{Aim of this thesis}

In recent years cochlear implantation has become a routine surgical procedure as a consequence of an increasing number of cochlear implant candidates. Review of the latest literature on the topic of cochlear implantation outcome, gives the impression that complications seldom occur. A more detailed search of literature from the past two decades, however, reveals reports of both minor and major complications occurring after cochlear implantation. Such complications are a concern to patients and their families, and to the healthcare staff involved in their care, and prompt identification of such complications is thus essential. In chapter 2, the incidence of major and minor complications is evaluated and compared to rates from other studies. Furthermore it is investigated whether the surgical technique at our department can be improved. The incidences of complications are used to optimize counselling of the patients who will undergo cochlear implantation at our department. In order to achieve optimal hearing revalidation following cochlear implantation, careful patient selection and monitoring is mandatory. In this process, patients are informed of the possible benefits of cochlear implantation, versus the possibility of intra- and postoperative complication, and especially, the risk of re-exploration being required as a consequence of device failure.

Evaluation of postoperative complication after cochlear implantation has accounted for modification of our surgical approach in patients with COM. In chapter 3, we report surgical complications occurring after cochlear implantation in recipients who suffer from a sensorineural hearing loss due to COM. Second, we substantiate our algorithm which we use for managing cochlear implantation in the setting of COM. This particular algorithm has evolved in our five years' gained experience with cochlear implantation together with outcomes published in the setting of COM. The starting point of this algorithm is based on the assessment of the activity of COM. The inactive forms of 
COM were defined as having a history of COM with otoscopic evidence, e.g. myringosclerosis or tympanic membrane perforation, but no clinical or radiological evidence of any infectious activity 6 months prior to implantation. The active forms of COM were defined as those with a history of COM with clinical and radiological signs of either a recent or recurrent infection with or without a cholesteatoma 6 months prior to implantation. In case of an active infection, cochlear implantation was performed as a staged procedure 3-6 months after subtotal petrosectomy or a combined approach tympanotomy. With respect to inactive disease, patients underwent cochlear implantation and simultaneously closure of the tympanic membrane or a subtotal petrosectomy as a single stage procedure.

Besides the MPTA technique, which has proven to be efficient for the vast majority of cases, alternative implantation techniques have been developed as a consequence of uneasiness of some surgeons to drill near the facial nerve. This development has been prompted further by the fact that in some cases temporary injury to both the facial and chorda tympani nerves were described during drilling of the facial recess. In the early days of cochlear implantation, incidences of injury to the facial and chorda tympani nerve from 1.7 to 2.0 percent cochlear implantation were not uncommon. Most alternative surgical techniques have not been demonstrated to have clear advantages to the MPTA technique as a consequence of their limited feasibility. This is not the case for the SMA technique, however, which has been demonstrated as having several advantages relative to the MPTA technique such as 1) better exposure of the middle ear contents, 2) avoidance of a mastoidectomy and posterior tympanotomy which accounts for a decline of duration of surgery, and most importantly 3 ) by drilling the suprameatal tunnel to enter the middle ear cavity the facial nerve is protected by the body of the incus. In our opinion, these positive findings needed to be further substantiated as there are only a few reports available in literature describing the surgical outcome of this technique.

In chapter 4, we report our experience with the SMA technique as an implantation technique for cochlear implantation in 104 patients. Two modifications were made to the original SMA technique which was introduced by Kronenberg et al. Rather than one large inverted J-shaped incision, we perform a small retroauricular skin incision, followed by a small temporopartial skin incision. Connection of the two incisions results in a subperiostal tunnel in which the electrode array is guided towards the suprameatal tunnel. Another modification was made concerning the creation of the atticoantrostomy. Instead of opening the attic transmeatally as done by Kronenberg, we drill a groove lateral to the incus through the suprameatal tunnel. In our opinion, these two modifications contribute to a more delicate tissue handling in applying the SMA technique.

In chapter 5, we compare the incidence of postoperative complication between the SMA and MPTA technique. In addition, the duration of surgery for the two surgical techniques are compared with each other. One would expect the SMA technique to be more time efficient because it consists of less surgical steps. Besides reduced duration 
of surgery, there are several reports that the SMA technique has advantages relative to the MPTA technique. Surprisingly, these reports do not mention any clear disadvantages of the SMA technique. Therefore, we have reported some disadvantages we have experienced with the SMA technique. One of these disadvantages is that the SMA might be less applicable for the preservation of residual hearing based on the different course of the electrode in the middle ear.

In chapter 6, we evaluate the alteration of pre-and postoperative thresholds in patients who underwent cochlear implantation using the SMA technique. By means of this study we are able to show whether the SMA technique can be used in the conservation of residual hearing. In all study patients, pre-and postoperative thresholds were near the maximum capacity of the audiometer which resulted in a ceiling effect precluding the possibility to observe the true preservation of residual hearing. To overcome this ceiling effect, three independent calculation methods were used. Two of these methods had already frequently been described in literature. These calculation methods assess the conservation of hearing according to the median or mean deterioration of the residual hearing. Unfortunately, both calculation methods might overestimate the degree of preservation of hearing as a consequence of the inability of both techniques to overcome the ceiling effect. We therefore introduced an alternative method to obtain a more accurate measure of conservation of residual hearing.

In chapter 7, we focus on comparing the SMA and MPTA techniques regarding the conservation of hearing whereby our alternative method of determining conserved residual hearing was applied. With this alternative method, the preservation of residual hearing can only be assessed in patients with measurable pre-and postoperative thresholds at the frequencies of interest. In our opinion this is the only way to bypass the ceiling effect and allows a more adequate and accurate comparison of the two techniques regarding residual hearing preservation. In chapter $\mathbf{8}$, a general discussion is provided regarding the findings of the preceding chapters. Chapter $\mathbf{9}$ is a Dutch summary of the main contents of this thesis. 


\section{References}

1. Cummings CW, Haughey BH, Thomas JR, Harker LA, Flint PW. Cummings Otolaryngology, Head and Neck Surgery. 4th ed. Elsevier, 2004.

2. Clark G.M, Tong Y.C, Patrick J.F Cochlear prosthesis. Melbourne: Churchill Livingstone;1990.

3. Djourno $A$, Eyriès $C$. Prosthèse auditive par excitation électrique à distance du nerf sensorielà l'aide d'un bobinage inclus à demeure. Presse Médicale 1957;65: 1417.

4. Djourno A, Eyriès $C$, Vallancien B. De l'excitation électrique du nerf cochléaire chezl'homme par induction à distance, à l'aide d'un micro-bobinage inclus à demeure. Comptesrendus de la Societe de Biologie et ses filiales 1957;151: 423-5.

5. Doyle J, Doyle D. Electrical stimulation of the nerve deafness. Bulletin of the Los Angeles Neurological Society. 1963;28:148-50.

6. Simmons FB. Permanent intracochlear electrodes in cats, tissue tolerance and cochlear microphonics. Laryngoscope 1967;77:171-86.

7. Clark GM. Hearing due to electrical excitation of the auditory nerve. J Acoust Sco Am 1980;67:868-74.

8. Black RC, Clark GM. Differential electrical excitation of the auditory nerve. J Acoust Soc Am 1980;67:868-74.

9. Shepherd RK, Clark GM, Black RC. Chronic electrical stimulation of the auditory nerve: the effect of electrode position on neural excitation. Hear Res 1993;66:108-20.

10. House WF, Urban J. Long term results of electrode implantation and electronic stimulation of the cochlea in man. Ann Otol Rhinol Laryngol. 1973;82:504-17.

11. House LR. Cochlear implant: the beginning. Alryngoscope 1987(8 pt 1):996-7.

12. House W. Cochlear implants: past, present and future. Adv Otorhinolaryngol 1993;48:1-3.

13. Clark GM, Hallworth RJ. A multiple-electrode array for a cochlear implant. J Laryngol Otol 1976;90: 623-7.

14. Clark GM, Tong YC, Martin LF. A multiple-channel cochlear implant: an evaluation using open-set CID sentences. Laryngoscope 1981;91:628-34.

15. Clark GM, Blamey PJ, Brown AM, Gusby PA, Dowell RC, Franz BK, Pyman BC, Shepherd RK, Tong YC, Webb RL, et al. The University of Melbourne--nucleus multi-electrode cochlear implant. Adv Otorhinolaryngol. 1987;38:V-IX, 1-181.

16. Linthicum FH, Fayad J, Otto SR, et al. Cochlear implant histopathology. Am J Otol 1991;12:245-311.

17. Copeland BJ, Pillsbury $\mathrm{HC} 3^{\text {rd }}$. Cochlear implantation for the treatment of deafness. Annu Rev Med 2004;55:157-67.

18. Fraysse B, Dillier N, Klenzner T, Laszig R, Manrique M, Morera Perez C, Morgon AH, Müller-Deile J, Ramos Macias A. Cochlear implants for adults obtaining marginal benefit from acoustic amplification: a European study. Am J Otol 1998;19:591-7.

19. Fraysse B, Macías AR, Sterkers O, Burdo S, Ramsden R, Deguine O, Klenzner T, Lenarz T, Rodriguez MM, Von Wallenberg E, James C. Combined electro-acoustic stimulation in conventional candidates for cochlear implantation. Otol Neurotol 2006;27:624-33.

20. James C, Albegger K, Battmer R, Burdo S, Deggouj N, Deguine O, Dillier N, Gersdorff M, Laszig R, Lenarz $T$, Rodriguez MM, Mondain M, Offeciers E, Macías AR, Ramsden R, Sterkers O, Von Wallenberg E, Weber B, Fraysse B. Preservation of residual hearing with cochlear implantation: how and why. Acta Otolaryngol 2005;125:481-91.

21. Gstoettner W, Kiefer J, Baumgartner WD, Pok S, Peters S, Adunka O. Hearing preservation in cochlear implantation for electric acoustic stimulation. Acta Otolaryngol 2004;124:348-52.

22. Skarzyński H, Lorens A, D'Haese P, Walkowiak A, Piotrowska A, Sliwa L, Anderson I. Preservation of residual hearing in children and post-lingually deafened adults after cochlear implantation: an initial study. ORL J Otorhinolaryngol Relat Spec 2002;64:247-53.

23. Gantz B, Turner C, Gfeller K, Lowder M. Preservation of hearing in cochlear implant surgery: advantages of combined electrical and acoustical speech processing. Laryngoscope. 2005;115:796-802.

24. Hodges AV, Schloffman J, Balkany T. Conservation of residual hearing with cochlear implantation. Am J Otol 1997;18:179-83. 
25. Kiefer J, von Ilberg C, Reimer B, Knecht R, Gall V, Diller G, Stürzebecher E, Pfennigdorff T, Spelsberg A. Results of cochlear implantation in patients with severe to profound hearing loss- implications for the indications. Audiology 1998; 37:382-95.

26. Lehnhardt E. Intracochlear placement of cochlear implant electrodes in soft surgery technique HNO. 1993;41:356-9.

27. House WF. Cochlear implants, Ann. Otol. Rhinol. Laryngol. 1976;85:1-93.

28. Proops DW, Stoddart RL, Donaldson I. Medical, surgical and audiological complications of the first 100 adult cochlear implant patients in Birmingham. J Laryngol Otol 1999;113:14-24.

29. Arnoldner C, Baumgartner WD, Gstoettner W, Hamzavi J. Surgical considerations in cochlear implantation in children and adults: a review of 342 cases in Vienna. Acta Otolaryngol 2005;125: 228-34.

30. Bhatia K, Gibbin KP, Nikolopoulos TP, O'Donoghue GM. Surgical complications and their management in a series of 300 consecutive pediatric cochlear implantations. Otol Neurotol 2004;25:730-9.

31. Dutt SN, Ray J, Hadjihannas E, Cooper H, Donaldson I, Proops DW. Medical and surgical complications of the second 100 adult cochlear implant patients in Birmingham. J Laryngol Otol 2005;119:759-64.

32. Gysin C, Papsin BC, Daya H, Nedzelski J. Surgical outcome after paediatric cochlear implantation: diminution of complications with the evolution of new surgical techniques. J Otolaryngol 2000;29: 285-89.

33. Arnold W, Bredberg G, Gstottner W, et al. Meningitis following cochlear implantation: pathomechanisms, clinical symptoms, conservative and surgical treatments. J Oto-Rhino-Laryngol and Its Related Specialties 2002;64:382-9.

34. Hirsch BE, Blikas A, Whitaker M. Antibiotic prophylaxis in cochlear implant surgery. Laryngoscope 2007;117:864-7.

35. Lalani T, Sexton DJ, Tucci DL. Cochlear implant infections. In: RoseBD, ed. Up to date. Waltham, MA: UptoDate, 2007.

36. Proctor B, Bollobass B, Niparko J. Anatomy of the round window niche. Ann Otol Rhinol Laryngol 1986;95:444-6.

37. Takahashi H, Sando I. Computer-aided 3-D temporal bone anatomy for cochlear implant surgery. Laryngoscope 1990;100:417-21.

38. Takahashi H, Honjo I, Sando I, et al. Orientation for cochlear implant surgery in case with round window obstruction: a computer reconstruction study. Eur Arch Otorhinolaryngol 1995;252:102-5.

39. Colletti V, Fiorino FG, Carner M, Pacini L. Basal turn cochleostomy via the middle fossa route for cochlear implant insertion, Am. J. Otol. 1998;19:778-84.

40. Kiratzidis T. 'Veria operation': cochlear implantation without a mastoidectomy and a posterior tympanotomy. A new surgical technique, Adv. Otorhinolaryngol. 2000;57:127-30.

41. Hausler R. Cochlear implantation without mastoidectomy: the pericanal electrode insertion technique, Acta Otolaryngol. 2002;122:715-9.

42. Kronenberg J, Migirov L, Dagan T. Suprameatal approach: new surgical approach for cochlear implantation, J. Laryngol. Otol. 2001;115:283-5.

43. Kronenberg J, Migirov L, Baumgartner WD. The suprameatal approach in cochlear implant surgery: our experience with 80 patients, ORL J. Otorhinolaryngol. Relat. Spec. 2002;64: 403-5.

44. Kronenberg J, Baumgartner WD, Migirov L, Dagan T, Hildesheimer M. The suprameatal approach: an alternative surgical approach to cochlear implantation, Otol. Neurotol. 2004;25:41-5.

45. Postelmans JT, Grolman W, Tange RA, Stokroos RJ. Comparison of two approaches to the surgical management of cochlear implantation. Laryngoscope. 2009 ;119:1571-8.

46. Postelmans JT, Tange RA, Stokroos RJ, Grolman W. The suprameatal approach: a safe alternative surgical technique for cochlear implantation. Otol Neurotol. 2010 ;31:196-203.

47. Arnoldner C, Baumgartner WD, Gstoettner W, Hamzavi J. Surgical considerations in cochlear implantation in children and adults: review of 342 cases in Vienna. Acta Otolaryngol 2005;125: 228-34.

48. Migirov L, Yakirevitch A, Kronenberg J. Surgical and medical complications following cochlear implantation: comparison of two surgical approaches. J Otorhinolaryngol Relat Spec 2006;68: 213-9.

49. Yin S, Chen Z, Wu Y, Wang L, Zhang J, Zhou W, Zhou W, Huang J, Shen Z, Qiu J. Suprameatal approach for cochlear implantation in 45 Chinese children. Int J Pediatric Otorhinolaryngol 2008;72:397-403.

50. Green KMJ, Bhatt YM, Saeed SR, Ramsden RT. Complications following adult cochlear implantation: experience in Manchester. J Laryngol Otol 2004;118:417-20. 
51. Proops DW, Stoddart RL, Donaldson I. Medical, surgical and audiological complications of the first 100 adult cochlear implant patients in Birmingham. J Laryngol Otol 1999;113:14-7.

52. Arnoldner C, Baumgartner WD, Gstoettner W, Hamzavi J. Surgical considerations in cochlear implanation in children and adults: a review of 342 cases in Vienna. Acta Otolaryngol (Stockh) 2005;125:228-34.

53. Cohen NL, Hoffman R. Complications of cochlear implant surgery in adults and children. Ann Otol Rhinol Laryngol 1991;100:708-11.

54. Wang RC, Parisier SC, Weiss $\mathrm{MH}$, et al. Cochlear implant flap complications. Ann Otol Rhinol laryngol 1990;99:791-5.

55. Cohen NL. Surgical techniques to avoid complications of cochlear implants in children. Adv Otorhinolaryngol 1997;52:161-3.

56. Cohen NL, Hoffman RA. Complications of cochlear implant surgery in adults and children, Ann. Otol. Rhinol. Laryngol. 1991;100:708-11.

57. Cohen NL. Medical or surgical complications related to the Nucleus Multichannel Cochlear Implant, Ann. Otol. Rhinol. Laryngol. 1989;98:754.

58. Webb RL, Lehnhardt E, Clark GM, Laszig R, Pyman BC, Franz BK. Surgical complications with the cochlear multiple-channel intracochlear implant: experience at Hannover and Melbourne, Ann. Otol. Rhinol. Laryngol. 1991;100:131-6.

59. Miyamoto RT, Bichey BG. Cochlear implantation for tinnitus suppression. Otolaryngol Clin North Am 2003;36:345-52.

60. Ito J, Sakakihara J. Tinnitus suppression by electrical stimulation of the cochlear wall and by cochlear implantation. Laryngoscope 1994;104:752-4.

61. Brey $\mathrm{RH}$, Facer GW, Trine $\mathrm{MB}$, et al. Vestibular effects associated with implantation of a multiple channel cochlear prosthesis. Am J Otol 1995;16:424-30.

62. Huygen PL, van den Broek P, Spies TH, et al. Does intracochlear implantation jeopardize vestibular function? Ann Otol Rhinol Laryngol 1994;103:609-14.

63. Fina $M$, Skinner $M$, Goebel JA, et al. Vestibular dysfunction after cochlear implantation. Otol Neurotol 2003;24:234-42.

64. Handzel O, Burgess BJ, Nadol JB. Histopathology of the peripheral vestibular system after cochlear implantation in the human. Otol Neurotol 2006;27:57-64.

65. Buchman CA, Joy J, Hodges A, et al. Vestibular effects of cochlear implantation. Laryngoscope 2004;114(Suppl 103):1-22.

66. Web RL, Lehnhardt E, Clark GM, et al: Surgical complications with the cochlear multiple-channel intracochlear implant: Experience at Hannover and Melbourne. Ann Otol Rhinol Laryngol 1991;100:131-6.

67. Kempf HG, Johann K, Lenarz T: Complications in pediatric cochlear implant surgery. Eur Arch Otorhinolaryngol 1999;256:128-32.

68. Bigelow DC, Kay DJ, Rafter KO, et al: Facial nerve stimulation from cochlear implant. Am J Otol 1998; 19:163-9.

69. Iwasaki S, Atsumi K, Ocho S, Mizuta K. Facial nerve stimulation by a cochlear implant in a hemodialysis patient with bone of low mineral density. Eur Arch Otorhinolaryngol 1998;255:352-4.

70. Papsin BC. Cochlear implantation in children with anomalous cochleovestibular anatomy. Laryngoscope 2005;115(suppl 106):1-26.

71. Smullen JL, Polak M, Hodges AV, Payne SB, Telischi FF, Balkany TJ. Facial nerve stimulation after cochlear implantation. Laryngoscope 2005;115:977-82.

72. Quaranta N, Bartoli R, Priore A, et al Cochlear implantation in otosclerosis. Otol Neurotol 2005;26: 983-7.

73. Gray RF, Irving RM. Cochlear implants in chronic suppurative otitis media. Am J Otol. 1995;16:682-6.

74. Meyerhoff WL, Stringer SP, Roland PS. Rambo procedure: modification and application. Laryngoscope. 1988;98:795-6.

75. Axon PR, Mawman DJ, Upile T, Ramsden RT. Cochlear implantation in the presence of chronic suppurative otitis media. J.Laryngol Otol. 1997;111:228-32.

76. Hamzavi J, Baumgartner W, Franz P, Plenk H. Radical cavities and cochlear implantation. Acta Otolaryngol 2001;121:607-9. 
26 (3) Chapter 1

77. Issing PR, Schönermark MP, Winkelmann S, Kempf HG, Ernst A. Cochlear implantation in patients with chronic otitis: Indications for subtotal petrosectomy and obliteration of the middle ear. Skull base surg. 1998;8: 127-31. 
(2) 27

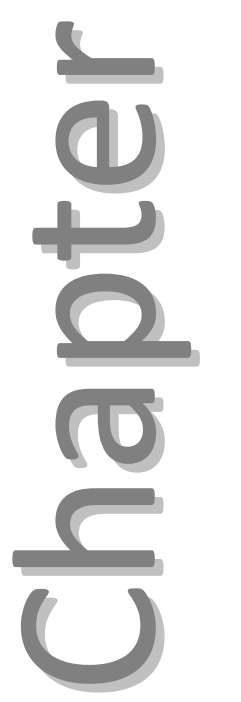

\section{Post-operative complications of cochlear} implantation in adults and children: five years' experience in Maastricht

JTF Postelmans, B Cleffken, RJ Stokroos

The Journal of Laryngology \& Otology 2007; 121:318-323 


\section{Abstract}

Although cochlear implantation is considered as a safe method of rehabilitation for profoundly deaf individuals, a number of these patients suffer complications after surgery. To evaluate postoperative complications after cochlear implantation, a retrospective chart review was performed for 112 patients who had undergone implantation in the Maastricht Academic Hospital. Minor complications were defined as those that could be overcome by medical or audiological management. These occurred in 36 patients $(32.1 \%)$ and all were managed successfully. Major complications were defined as device extrusion and those requiring further surgery, and these were identified in 4 patients (3.6\%). These complications included wound infection and device failure mediated by middle-ear pathology. In cases of chronic otitis media, we recommend performance of cochlear implantation as a staged procedure. In order to reduce the post-operative incidence of acute otitis media, we recommend an adenotomy, placement of ventilation tubes and early antibiotic treatment. 


\section{Introduction}

Over the past three decades, cochlear implantation has come to be accepted as a safe and effective method of audiological rehabilitation for profoundly hearing-impaired deaf adults and children who derive insufficient benefit from conventional hearing aids. Several previous studies have reported improvement of hearing in the majority of cochlear implant users. Post-operative audiometric outcome have ranged from little improvement to open set speech discrimination. The factors described in previous studies as influencing outcome have related to the duration of deafness, neuronal survival and central processing and cognitive abilities, as well as to factors inherent in the device, especially the extent of insertion, programming strategies and limitations of stimulation frequency. ${ }^{1}$

In 2000, the department of Otorhinolaryngology- Head and Neck surgery of the Maastricht University Hospital established its adult and paediatric cochlear implant programme. The first patient was implanted in September 2000, and over a five year period 112 patients underwent successful cochlear implantation. Four patients were identified with a major complication, an incidence of $3.6 \%$ (4/112). Major complications have been defined in prior studies as electrode failure, problems requiring revision surgery and other complications (such as haemorrhage, permanent facial palsy and persistent perilymph leak). ${ }^{2,3}$ Our major complication rate compared well with recently published studies, which reported rates of between 5 and $6 \%{ }^{2,4}$ Minor complications comprised those managed conservatively by either medical or audiological interventions (e.g. tinnitus, vertigo and non-auditory stimulation). ${ }^{2,3}$ We found a minor complication incidence of $32.1 \%$ (36/112). This figure is in keeping with those reported by previous studies, which have ranged from 4.1 to $47.5 \%$. $^{2-4}$

To achieve optimal hearing revalidation following cochlear implantation, careful patient selection is necessary. In this process, patients are informed of the possible benefits of the procedure, versus the possibility of intra- and post-operative complication and, especially, the risk of re-operation being required due to device failure. To optimize such counselling, we evaluated post-operative complications in the first 80 adults and 32 children who had undergone cochlear implantation in the Maastricht Academic Hospital between September 2000 and June 2005.

\section{Materials and methods}

A retrospective chart review was performed, identifying surgical and medical complications in 80 adult and 32 paediatric patients who had undergone cochlear implantation at the Maastricht Academic Hospital between September 2000 and June 2005. In keeping with the classification of Cohen and Hofmann ${ }^{5}$, major complications were defined as those requiring further surgery and/or hospitalization for treatment. 
Minor complications were defined as those that could be overcome by medical or audiological management and that caused little distress to the patient. All operations had been carried out by the same ear surgeon (RJS) using standard techniques.

The following data were entered into a patient database: age, pre- or postlingual deafness, age at onset of deafness, duration of profound hearing loss before surgery, mean age at implantation, etiology of deafness, type of implant, evaluation of preoperative high resolution computed tomography (HRCT) and magnetic resonance imaging (MRI) scans, full or partial electrode insertion, major complications, and minor complications. The results were analyzed. The performance of each patient's electrodes was documented and possible reasons for any malfunction were analyzed.

\section{Pre- and post-operative assessments}

The patients' pre- and post-operative assessments had included medical, audiological and psychological evaluation. Candidate selection had been comparable for adults and children. The initial part of evaluation had comprised a standard ENT examination and psychological assessments, the latter examining whether the patient's expectations and motivations were realistic. Audiological assessments in adult candidates had comprised audiometry, tympanometry, speech perception tests and audiovisual performance tests. In the case of young children, audiological assessment had comprised play audiometry or visual reinforcement audiometry, auditory brainstem response audiometry, tympanometry and speech perception tests. Audiological assessment tests had been carried out by dedicated audiologists nine months before implantation and during the rehabilitation programme. During the last decade, the audiological criteria assessing eligibility for cochlear implantation changed, such that patients with limited speech discrimination were accepted for cochlear surgery.

\section{Results}

This study assessed 116 patients who had been treated by our rehabilitative cochlear programme. Four patients were excluded from the study: three patients had been operated upon elsewhere, and one paediatric case was excluded as no pre- or postoperative data were available. This series, thus, contained 112 successful cochlear implantations carried out in 80 adults and 32 children. Post-operative complications were analyzed within the paediatric group (i.e. $\leq 14$ years old) and the adult group (i.e. $\geq 14$ years old).

\section{Clinical characteristics of adult and paediatric groups}

The adult group contained 40 males and 40 females. The mean age at onset of deafness had been 23.6 years (range $0-72.0$ years). The mean age at implantation had 
been 53.4 years (range 14.7-82.0 years). The overall mean duration of deafness prior to surgery had been 28.3 years (range $1.7-78.4$ years). The paediatric group contained 19 males and 13 females. The mean age at onset of deafness had been 0.3 years (range 0-2 years). The mean age at implantation had been 4.3 years (range 1.6-11.4 years). The overall mean duration of deafness prior to surgery in this group had been 4.1 years (range $0.8-11.4$ ). The incidence of prelingual deafness had been $96.9 \%$.

\section{Etiology}

The etiological factors accounting for deafness in the adult and paediatric groups are summarized in Tables 2.1 and 2.2, respectively. The etiology of deafness in the adult group had been unknown in $28.75 \%$. Congenital deafness and otosclerosis had been the next commonest causes, at $17.5 \%$ and $16.25 \%$, respectively. Deafness had been caused by meningitis in $10.0 \%$ of adult patients. Compared with the adult group, congenital deafness in children had been particularly prevalent (68.75\%). Meningitis had been the second largest cause of deafness in the paediatric group $12.50 \%$, comparable to the adult group). Other diagnoses in the adult and paediatric groups are shown in Tables 2.1 and 2.2.

Table 2.1 Etiology of deafness in adults.

$\begin{array}{lll}\text { Cause } & \mathrm{N} & \%^{1} \\ \text { Idiopathic } & 23 & 28.75 \\ \text { Congenital } & 14 & 17.5 \\ \text { Otosclerosis } & 13 & 16.25 \\ \text { Meningitis } & 7 & 8.75 \\ \text { Maternal rubella infection } & 3 & 3.75 \\ \text { Mèniere's disease } & 2 & 2.5 \\ \text { Middle-ear surgery } & 2 & 2.5 \\ \text { Trauma } & 2 & 2.5 \\ \text { Large Vestibular Aqueduct Syndrome } & 2 & 2.5 \\ \text { Chronic otitis media } & 2 & 2.5 \\ \text { Status after cholesteatoma } & 2 & 2.5 \\ \text { Auto-immune } & 1 & 1.25 \\ \text { Radiotherapy } & 1 & 1.25 \\ \text { Goltz-Gorin's syndrome } & 1 & 1.25 \\ \text { Melas' syndrome } & 1 & 1.25 \\ \text { Waardenburg's syndrome } & 1 & 1.25 \\ \text { Borrelia burgdorferi infection } & 1 & 1.25 \\ \text { Mastoidectomy } & 1 & 1.25 \\ \text { Charcot-Marie-Tooth's disease } & 1 & 1.25\end{array}$

${ }^{1}$ Of total 
Table $2.2 \quad$ Etiology of deafness in children.

\begin{tabular}{lrc} 
Cause & N & $\%^{1}$ \\
\hline Congenital & 22 & 68.75 \\
Meningitis & 4 & 12.5 \\
Pendred's syndrome & 2 & 6.25 \\
Connexine 26 mutatie & 2 & 6.25 \\
Autosomal recessive deafness & 1 & 3.12 \\
Large vestibular aqueduct syndrome & 1 & 3.12
\end{tabular}

${ }^{1}$ Of total

\section{Electrode insertion}

\section{Adults}

In three adults (3.75\%), electrode insertion had been difficult to achieve. In two of these three, deafness had been due to meningitis. In only one of these cases had preoperative HRCT images shown ossification of the cochlea. In both post-meningitis cases, it had been possible to achieve full insertion of all electrodes, with no dysfunctional electrodes after surgery. The third patient with a difficult insertion had suffered a possible autoimmune mediated perceptive hearing loss. This patient's medical history reported Crohn's disease. ${ }^{6}$ Electrode insertion had been achieved with slight difficulty in one adult. In the remaining 76 adults (76/80, 95.0\%), electrode insertion had presented no difficulty.

\section{Children}

Electrode insertion had been achieved with great difficulty in two children (2/30, $6.25 \%)$. In the first case, dysplasia of the cochlea attributed to Pendred's syndrome had been present; full electrode insertion had eventually been achieved. In the second case, only partial electrode insertion had been possible due to severe ossification of the cochlea, attributed to meningitis; only 12 of 22 electrode arrays had been implanted and only eight electrodes had responded post-operatively. In the 30 remaining paediatric cases (30/32, 93.75 per cent), full electrode insertion had been successfully achieved.

\section{Implants}

A total of 114 implants had been used, comprising 112 primary implantations and two re-implantations. Nucleus multi-channel implants (Nucleus (Cochlear Corp, Lane Cove, Australia) had been implanted in 101 cases. In 13 adults, an Advanced Bionics cochlear implant (Advanced Bionics Corp, Sylmar USA) had been used. 


\section{Follow up}

The average duration of follow up for the adults had been 16.9 months (range 1.0-47.5 months). The average duration of follow-up for children had been 26.7 months (range 1.0-48.2 months). Two patients had been lost to follow up as they had returned to their home countries (Indonesia and Germany).

\section{Complications in the adult group}

Two adult patients $(2 / 80,2.5 \%)$ had experienced major complications following cochlear implantation; these are reviewed in Table 2.3. The first major complication had been in a 70-year-old woman suffering perceptive deafness caused by chronic middle-ear disease. She had been audiometrically deaf in both ears since 1993. Cochlear implantation had been performed in January 2003. Three months after surgery, the patient had complained of pain over the implant site, attributed to a skin infection. Initially, the skin infection had been treated with antibiotics. When this failed, exploration had been performed. The cochlear implant had been rotated cranially under the temporalis muscle. Due to persistent wound infection, mediated by chronic middle-ear disease, wound dehiscence had occurred and the implant package had been extruded. In agreement with the patient, the implant had been explanted and no re-implantation performed.

Table 2.3 Major complication in adults.

$\begin{array}{lcc}\text { Complication } & \text { N } & \%^{1} \\ \text { Wound infection \& device extrusion } & 1 & 1.25 \\ \text { Device failure } & 1 & 1.25\end{array}$

${ }^{1}$ Of total.

The second major complication had been a device failure two years after implantation. This patient had reported a sudden electrical shock in his upper body after switching on the processor, experienced as a combination of a loud noise, light flashes and pain. Re-implantation of a new Nucleus cochlear implant device was carried out successfully. The minor complications in the adult group are listed in Table 2.4 . Overall, $40.0 \%$ $(32 / 80)$ of the adult group had suffered minor complications within three months of surgery. Eleven adult patients had reported transient vertigo sensations that had resolved spontaneously; however, hospital admission was required in one case because of severe, continuous vertigo. Five adults had experienced wound infection near the implant site, requiring antibiotic therapy in three cases (other wound infections had healed spontaneously without the need for antibiotics). Six patients had complained of transient tinnitus. 


$\begin{array}{lcc}\text { Complication } & \mathrm{N} & \%^{1} \\ \text { Vertigo } & 11 & 34.37 \\ \text { Tinnitus } & 6 & 18.75 \\ \text { Wound infection } & 5 & 15.62 \\ \text { Pain } & 4 & 12.50 \\ \text { Retro-auricular emphysema } & 2 & 6.25 \\ \text { Transient facial palsy } & 1 & 3.12 \\ \text { Processor dysfunction } & 1 & 3.12 \\ \text { Perforated ear drum } & 1 & 3.12 \\ \text { Haematoma } & 1 & 3.12 \\ { }^{1} \text { Of total. } & & \end{array}$

\section{Complications in children}

Two of 32 children had suffered a major complication after cochlear implantation. Major complications in the paediatric group are listed in Table 2.5. The first major complication had involved cochlear device failure. The child had not shown good audiometric progress. The etiology of deafness had been a heterozygote mutation of the connexine 26 and connexine 30 genes. Forty-three months after surgery, the Nucleus cochlear implant had been explanted and an identical one re-implanted, with improved hearing results.

The second major complication in the pediatric group had included abscess formation near the implant site, mediated by acute otitis media, with mastoiditis that had required surgical drainage and intravenous antibiotic therapy. Complete resolution had been achieved and the Nucleus implant had continued to function normally.

Table $2.5 \quad$ Major complications in children.

\begin{tabular}{lll} 
Complication & $\mathrm{N}$ & $\%^{1}$ \\
\hline Abscess formation near implant site & 1 & 3.12 \\
Device failure & 1 & 3.12
\end{tabular}

${ }^{1}$ Of total.

In the paediatric group, four patients $(4 / 32,15.6 \%)$ had suffered minor complications following cochlear implantation as listed in Table 2.6. One patient had suffered a postoperative fever for three days. Blood cultures had remained sterile. Antibiotic therapy had been continued for a week, with complete recovery.

In another case, a mild wound infection had occurred over the implant side, not requiring antibiotic therapy. In one child, two electrodes had malfunctioned. Perioperative full insertion of all electrode arrays had initially been achieved in this child, and no cochlear ossification had been encountered during surgery or noted on HRCT scanning. Implant reprogramming had not been successful. 
In one child, the cochlear implant had unfortunately not been used because of unforeseen family problems which had interfered with participation in the rehabilitation programme.

Table 2.6 Minor complications in children.

$\begin{array}{lll}\text { Complication } & \mathrm{N} & \%^{1} \\ \text { Fever } & 1 & 3.12 \\ \text { Wound infection } & 1 & 3.12 \\ \text { Electrode malfunction } & 1 & 3.12 \\ \text { Not using implant } & 1 & 3.12\end{array}$

${ }^{1}$ Of total.

\section{Discussion}

\section{Post-operative complications}

In this study, the surgical and medical complication rate after two years of cochlear implantation had been low and had been accompanied by a satisfactory audiometric outcome.

The rate of major complications had been $2.5 \%(2 / 80)$ in the adult group and $6.3 \%$ $(2 / 32)$ in the paediatric group, with an overall major complication rate of $3.6 \%$. Two of the four major complications encountered had been device failure, resulting in explantation and re-implantation. The remaining two major complications (in an adult and a child) had both been mediated by middle-ear pathology. In the adult case, chronic otitis media had led to secondary infection of the implant site, with device exposure, three months after surgery. Explantation had followed and subsequent reimplantation had been refused. In the paediatric case, acute otitis media had led to abscess formation over the implant site, requiring drainage of the abscess, with preservation of the cochlear implant. All patients who had received a new cochlear implant after explantation of a former implant had shown an improved audiometric outcome. Minor medical complications had occurred in $40.0 \%(32 / 80)$ of the adult group and $12.5 \%$ (4/32) of the pediatric group. All minor complications had been reported within one year of surgery and treated satisfactorily. None of the major or the minor complications had interfered with patients' participation in the rehabilitation programme.

In this study, the overall post-operative complication rate was $36.6 \%$. This percentage is in keeping with the findings of Proops et al. (Birmingham) ${ }^{3}$ and Green et al. (Manchester) $^{2}$ who reported overall complication rates of $42 \%$ and $54 \%$, respectively. In our study, complications had not been more common in the first period of the cochlear implant programme than in the latter two years. From the start of the 
programme, we had periodically evaluated the cochlear implant protocol and had found no significant decline in postoperative complications. This is in contradiction to the findings of Dutt et al., ${ }^{7}$ who reported a halving of the minor complication rate (from 39 to 18\%) in the second 100 patients of the Birmingham series undergoing cochlear implantation, due to surgical experience (suggesting a learning curve). Unfortunately, Dutt et al. ${ }^{7}$ reported no decline in their major complication rate.

In the present study, in otitis media-prone children, we noticed that the incidence of secretory otitis media had decreased after cochlear implantation when adenotomy had been performed and ventilation tubes placed before cochlear implantation. Most authors agree that the incidence and severity of chronic otitis media in children with cochlear implants are the same or less after implantation compared with before. Migirov et al. ${ }^{8}$ demonstrated that mastoidectomy in itself does not influence the natural history of serous otitis media in cochlear implanted children. The placement of ventilation tubes has been studied by various authors. Lin et al. ${ }^{9}$ recommended early placement of ventilation tubes in order to prevent retraction pocket formation and infection in cochlear-implanted children with otitis media. Kennedy and Shelton ${ }^{10}$ recommended placement of ventilation tubes in otitis media-prone children with cochlear implants, based on a survey of members of the American Neurotological Society. Kempf et al. ${ }^{11}$ pointed out that the incidence of otitis media in children after implantation can be reduced by the use of ventilation tubes and adenotomy before implantation. Luntz et al. ${ }^{12,13}$ recommended the continuous use of a ventilation tube in otitis media-prone pediatric implantees until they outgrow their susceptibility to otitis media.

When post-operative otitis media has not been prevented by means of ventilation tubes and adenotomy, it must be treated immediately with intravenous high dose antibiotics.

Cochlear implantation in a patient with ongoing chronic otitis media can be challenging. In cases of inactive infection, repair of the dry tympanic membrane perforation and placement of the cochlear implant can be performed in a single stage procedure. In cases of active infection, a two stage procedure is required. In the first stage, the infection is eradicated by opening all the cells in the mastoid bone and middle ear, followed by cavity obliteration using autologous abdominal fat graft and temporal muscle. Cochlear implantation is performed as a second stage procedure after three to six months. Staging confers the advantage of a 'second look' during cochlear implantation and also avoids insertion of a foreign body into an infected mastoid cavity. We performed staged surgery in one patient with deafness caused by chronic otitis media; we noticed no postoperative complications, and the patient's audiometric results improved significantly after surgery. 


\section{Non-auditory stimulation}

In this study, we identified only one case of non-auditory stimulation in a patient with cochleo-labyrinthine otosclerosis. Green et al. ${ }^{2}$ reported non-auditory stimulation as a minor complication occurring in 53 cases involving 240 adults. Non-auditory stimulation manifests as pain in the throat or ear and as facial nerve stimulation. Otosclerosis, ${ }^{14,15}$ otitic syphilis, ${ }^{16}$ institution of haemodialysis or other bone-depleting conditions, ${ }^{17}$ cochlear malformation, ${ }^{18}$ head trauma, ${ }^{19}$ and temporal bone fractures ${ }^{19}$ have been previously reported as possible risk factors for the post-operative development of non-auditory stimulation. The phenomenon of non-auditory stimulation could be related to decreased resistance to electric stimuli of the facial nerve and the implant electrode(s). In our patient, facial nerve stimulation disappeared when three apical electrodes were switched off. The incidence of non-auditory stimulation has varied amongst several studies, from $0.9 \%$ in our study up to $75 \%,{ }^{15}$ therefore, the cause may be multifactorial. The application of modiolus proximal electrodes in most of our patients, not in contact with the outer wall of the scala tympani, might also contribute to this finding.

\section{Device failure}

The most common non-surgical complication of cochlear implantation described in literature is device failure. Previous investigations of cochlear implantation described unequal but relatively high percentages of device failure. The incidences of device failure reported by other centres have varied between $10.2 \%$ (in a series of 342 patients, Arnoldner et al.), ${ }^{4} 7.1 \%$ (in 53 patients, Collins et al.) ${ }^{20}$ and $1.0 \%$ (in 100 patients, Proops et al.). ${ }^{3}$ Surprisingly, Green et al. ${ }^{2}$ reported no device failures in a series of 214 patients. In our study, device failure occurred in one adult and one child. In the adult case, damage of the integrated circuits occurred due to electrostatic discharge. In the paediatric case, an integrity test was carried out and showed short circuits on three electrodes. All other electrode impedances were found to be normal. During analysis of failure, the device passed all tests conducted to verify the proper operation of the stimulator. The manufacturer could not rule out damage to the electrode array occurring during implantation. Previous investigators have identified the main causes of device failure as being: fracture of the central pin feed-through for the antenna coil; damage of the integrated circuits due to electrostatic discharges; damage of the electrode array by kinking or manipulation peri-operatively; damage to the electrode as it exits the internal receiver; and capacitor failure. ${ }^{21-24}$

\section{Conclusion and recommendations}

Wound infections and device failure were equally responsible for all the major complications of cochlear implantation observed in this series. In cases of chronic otitis media, we recommend that cochlear implantation be performed as a staged procedure 
to prevent possible post-operative wound infection. Complete eradication of the middle-ear infection avoids implantation of the cochlear implant into an infected mastoid cavity. After eradication of the infection, we advise an observation period of six months before cochlear implantation is performed. To reduce acute otitis media following cochlear implantation in otitis media-prone children, we recommend an adenotomy, pre-operative placement of ventilation tubes, and prompt treatment of acute otitis media. 


\section{References}

1. Maas S, Bance M, O'Driscoll M, Mawman D, Ramsden RT. Explantation of a nucleus multichannel cochlear implant and a re-implantation into the contralateral ear. A case report of a new strategy. J Laryngol Otol 1996;110:881-3.

2. Green KMJ, Bhatt YM, Saeed SR, Ramsden RT. Complications following adult cochlear implantation: experience in Manchester. J Laryngol Otol 2004;118:417-20.

3. Proops DW, Stoddart RL, Donaldson I. Medical, surgical and audiological complications of the first 100 adult cochlear implant patients in Birmingham. J Laryngol Otol 1999;113:14-17.

4. Arnoldner C, Baumgartner WD, Gstoettner W, Hamzavi J. Surgical considerations in cochlear implanation in children and adults: a review of 342 cases in Vienna. Acta Otolaryngol (Stockh) 2005;125:228-34.

5. Cohen NL, Hoffman R. Complications of cochlear implant surgery in adults and children. Ann Otol Rhinol Laryngol 1991;100:708-11.

6. Bachmeyer C, Leclerc-Landgraf N, Laurette F, Coutarel P, Cadranel JF, Médioni J, Dhôte R, MougeotMartin M. Acute autoimmune sensorineural hearing loss associated with Crohn's disease. Am J Gastroenterol 1998;93:2565-7.

7. Dutt SN, Ray J, Hadjihannas EH, Cooper H, Donaldson I, Proops DW. Medical and surgical complications of the second 100 adult cochlear implant patients in Birmingham. J Laryngol Otol 2005;119:759-64.

8. Migirov L, Amir A, Kronenberg J. The influence of mastoidectomy on natural history of secretory otitis media in cochlear implant children. ORL J Otorhinolaryngol Relat Spec 2006;68:156-8.

9. Lin OYS, Lee FP, Peng SC. Complications in children with long term cochlear implants. ORL J Otorhinolaryngol Relat Spec 2006;68:237-42.

10. Kennedy RJ, Shelton C. Ventilation tubes and cochlear implants: what do we do? Otol Neurotol 2005; 26:438-41.

11. Kempf HG, Stover T, Lenarz T. Mastoiditis and acute otitis media in children with cochlear implants: recommendations for medical management. Ann Otol Rhinol Laryngol Suppl 2000;185:25-7.

12. Luntz M, Hodges AV, Balkany T, Dolan-Ash S, Schloffman J. Otitis media in children with cochlear implants. Laryngoscope 1996;106:1403-5.

13. Luntz M, Teszler CB, Shpak T. Cochlear implantation in children with otitis media: second stage of a long-term prospective study. Int J Pediatric Otorhinolaryngol 2004;68:272-80.

14. Weber BP, Lenarz T, Battmer RD, Hartrampf R, Dahm MC, Dietrich B. Otosclerosis and facial nerve stimulation. Ann Otol Rhinol Laryngol Suppl 1995;166:445-7

15. Muckle RP, Levine SG. Facial nerve stimulation produced by cochlear implants in patients with cochlear otosclerosis. Am J Otol 1994;15:394-8.

16. Bigelow DC, Kay DJ, Rafter KO, Montes M, Knox GW, Yousem DM. Facial nerve stimulation from cochlear implants. Am J Otol 1998;19:163-9.

17. Iwasaki S, Atsumi K, Ocho S, Mizuta K. Facial nerve stimulation by a cochlear implant in a hemodialysis patient with bone of low mineral density. Eur Arch Otorhinolaryngol 1998;255:352-4.

18. Papsin BC. Cochlear implantation in children with anomalous cochleovestibular anatomy. Laryngoscope 2005;115(suppl 106):1-26.

19. Smullen JL, Polak M, Hodges AV, Payne SB, Telischi FF, Balkany TJ. Facial nerve stimulation after cochlear implantation. Laryngoscope 2005;115:977-82.

20. Collins MM, Hawthorne MH, El-Hmd K. Cochlear implantation in a district general hospital: problems and complications in the first five years. J Laryngol Otol 1997; 111:325-32.

21. Cohen NL, Hoffman RA. Surgical complications of multichannel cochlear implants in North America. Adv Otorhinolaryngol 1993;48:70-4.

22. Parisier SC, Chute PM, Popp MS. Cochlear implant mechanical failures. Am J Otol 1996;17:730-4.

23. Saeed SR, Ramsden RT, Hartley C, Woolford TJ, Boyd P. Cochlear reimplantation. J Laryngol Otol 1995;109:980-5.

24. Thomas DM, Abramovich S, Rakkar-Thomas S. An unusual cause of cochlear implant failure. J Laryngol Otol 1995;109:542-4. 

(2) 41

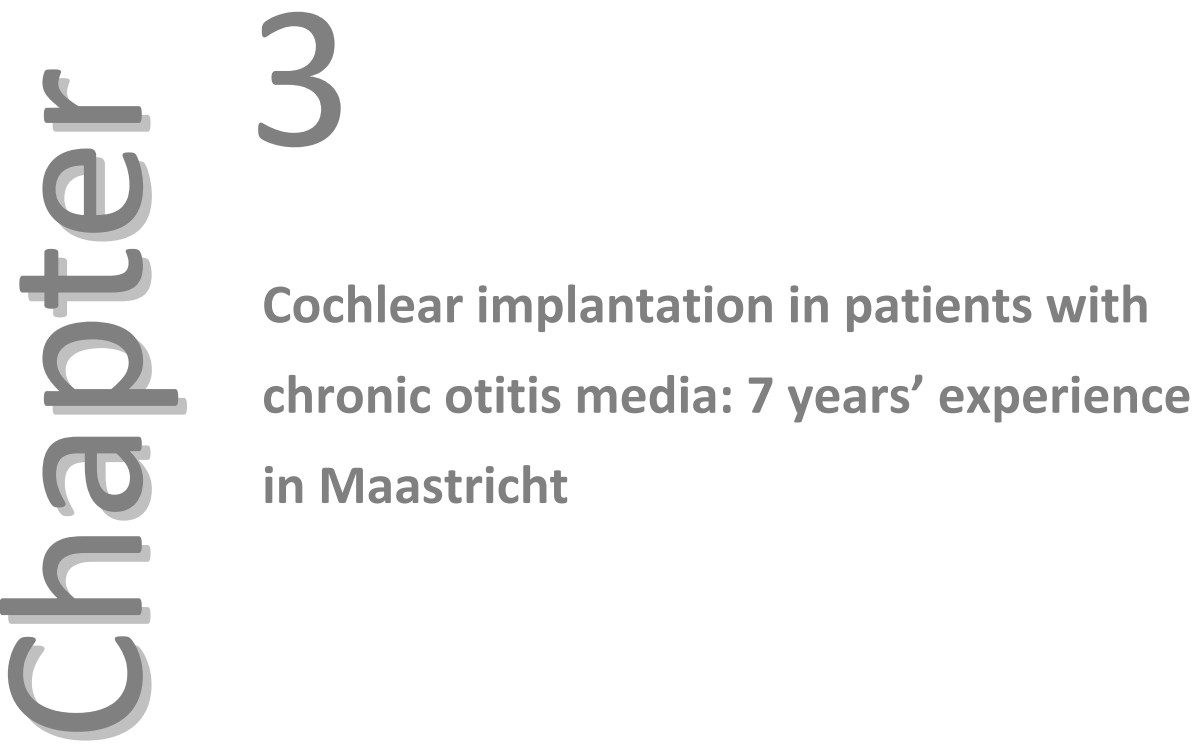

JTF Postelmans, RJ Stokroos, JJ Linmans, B Kremer

The European Archives of Otorhinolaryngology 2009;266:1159-1165 
42 () Chapter 3

\section{Abstract}

The purpose of this paper is to propose management options for cochlear implantation in chronic otitis media (COM) based on our 7-year experience. Thirteen patients with COM who were candidates for cochlear implantation were identified. COM was divided in an inactive and an active form based on clinical and radiological findings. One major complications and one minor complication were identified in the study group. In case of an active infection or in case of an unstable cavity we advise cochlear implantation as a staged procedure. A single stage procedure is recommended in case of patients with COM presenting with a dry perforation or a stable cavity. 


\section{Introduction}

During the past three decades cochlear implantation is accepted as a safe and effective method of audiological rehabilitation for the profoundly hearing-impaired deaf adult or child, who derives insufficient benefit from conventional hearing aids. Some patients suffering severe to profound sensorineural hearing loss as a result of chronic otitis media (COM) might be candidates for cochlear implantation. In these patients, COM plays a role in the etiology of the hearing loss but may limit possibilities for hearing rehabilitation at the same time. Cochlear implantation in a chronic diseased ear may lead to implant colonization and subsequent implant extrusion or meningitis as a consequence of inserting an electrode through an infected mastoid or middle ear cavity into a space with intracranial communication.

The degree of the activity of the disease has influence on the cochlear implant strategy in patients with a chronic diseased ear. COM can be distinguished on clinical and radiological characteristics into an active (with or without cholesteatoma) or an inactive form. Regarding the inactive form with a simple dry perforation, placement of the cochlear implant and closing of the dry tympanic membrane perforation can be performed as a single stage procedure. In case of an active infection (with or without cholesteatoma), it is debated in the literature whether a single stage or a two-stage procedure is preferable and which surgical technique should be used. In all patients with $\mathrm{COM}$, recurrence of a cholesteatoma and/or flairing-up of the infection are the main concern.

In this paper we report our surgical complications after cochlear implantation in patients with a history of COM. Secondly; we describe an algorithm which we used for managing cochlear implantation in patients with COM in this study.

\section{Materials and methods}

The charts of all 156 consecutive patients who underwent cochlear implantation between January 2000 and January 2007 at our tertiary referral hospital in Maastricht were retrospectively reviewed after institutional review board approval was obtained. An assessment of all 156 patients showed that there was an overlap of the patient population which was discussed in our former paper. ${ }^{1}$ From June 2005 till January 2007 we collected another 44 patients, which underwent cochlear implantation. Regarding our former paper, there is an overlap of 44 patients in which three patients were identified suffering from COM. All implantations were performed by the same surgeon (RJS). Candidates for cochlear implantation were evaluated for COM by a careful review of their otological case history, by otoscopy, by tympanometry and actual imaging (CT and/or MRI). All patients had a double sided progressive hearing loss with PTA $\geq 90 \mathrm{~dB}$ and SDT $\leq 30 \%$, therefore all patients were not considered as candidates for 
middle ear prosthesis due to their lack of residual hearing. Patients who were found to have a history of COM preceding cochlear implantation were enrolled in this study. The inactive forms of COM were defined as having a history of COM with otoscopic evidence, e.q. myringosclerosis or tympanic membrane perforation, but no clinical or radiological evidence of any infectious activity six months prior to implantation. Active forms of COM were defined as having a history of COM with clinical and radiological signs of either a recent or current infection with or without a cholesteatoma six months prior to implantation.

Clinical charts were reviewed for medical history, aetiology of hearing loss, type of cochlear implant and electrode, surgical management of the implanted ear and postoperative complications. In keeping with the classification of Cohen and Hofmann ${ }^{2}$ "Major" complications were defined as those requiring further surgery, and/or hospitalization for treatment. "Minor" complications were identified as those that can be overcome by medical or audiological management and cause little distress to the patient.

Preoperative audiological assessment included pure-tone audiometry (PTA) and speech discrimination tests (SDT) by means of a monosyllabic word list in Dutch. Puretone average (PTA) was calculated as the average of the thresholds at $0.5,1$, and $2 \mathrm{kHz}$.

\section{Surgical management}

All study patients received antibiotic therapy based on ear swabs preoperatively and were postoperatively continued for seven till ten days. Cases with an inactive or active COM with or without cholesteatoma were identified and treated according to the following algorithm (Figure 3.1)

- In patients presenting with an inactive form with a simple dry perforation, placement of the cochlear implant and closing of the dry tympanic membrane perforation was performed as a single stage procedure.

- In patients having a pre-existing radical mastoid cavity (RMC) without (a history of) evidence for an active inflammation, cochlear implantation was performed with a subtotal petrosectomy as a single stage procedure.

- In patients having a pre-existing RMC with evidence for an active inflammation, cochlear implantation was performed as a staged procedure 3 till 6 months after subtotal petrosectomy.

- In patients presenting with an active COM with or without cholesteatoma, cochlear implantation was performed as a staged procedure 3 till 6 months after either a combined approach tympanotomy with posterior tympanotomy or subtotal petrosectomy. 


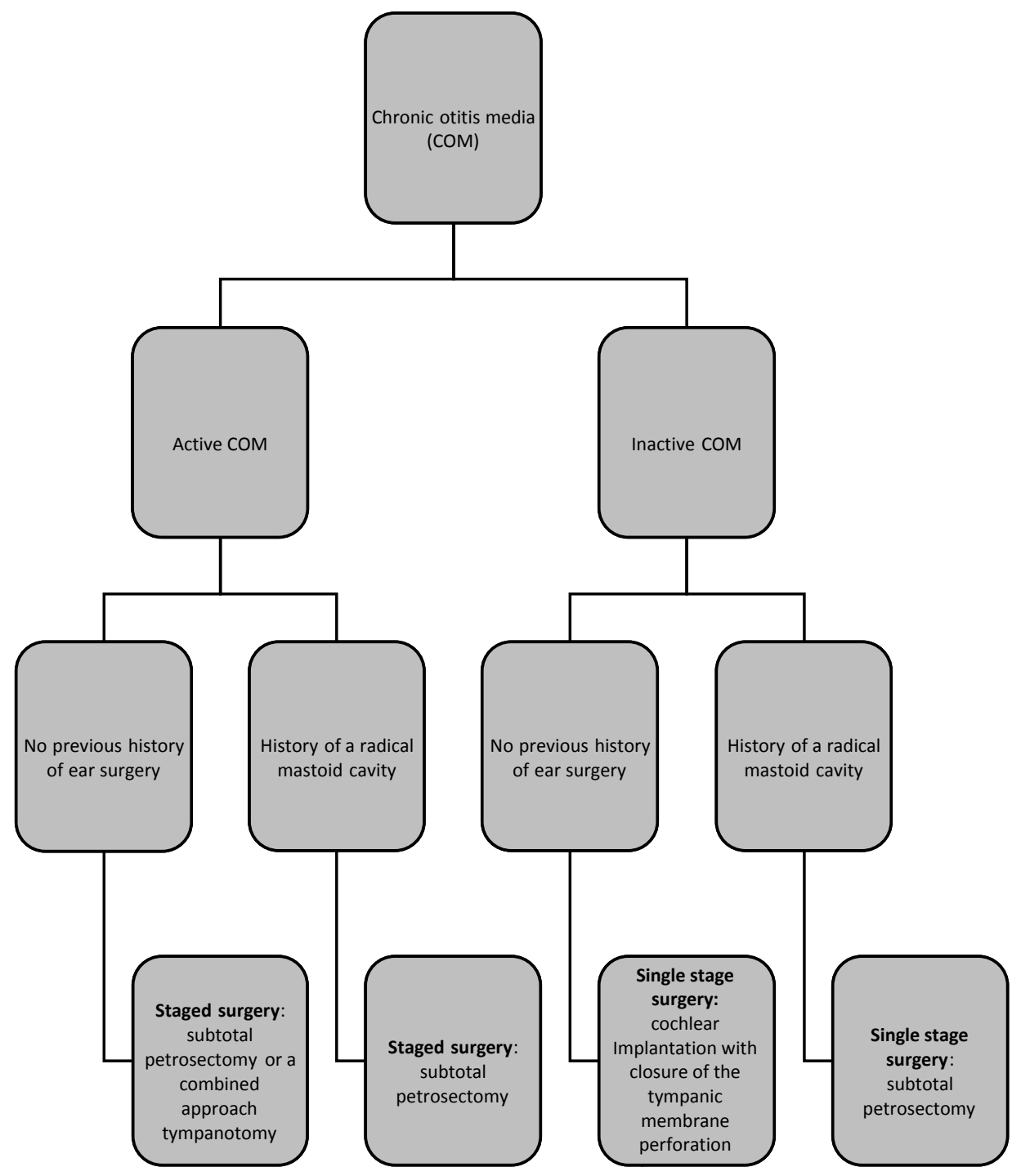

Figure 3.1 Depicts the algorithm which was used in case of cochlear implantation in patients with or without active chronic otitis media

\section{Surgical technique}

All cochlear implants were implanted by the posterior tympanotomy approach using standard surgical techniques in case of an inactive COM with a dry tympanic membrane perforation. With respect to patients with a pre-existing RMC or an active COM (with or without cholesteatoma) a subtotal petrosectomy was performed. A 
subtotal petrosectomy is a complete eradication of all pneumatic cell tracts of the temporal bone, except a few remnants of the apical cells when present, with obliteration of the isthmus of the Eustachian tube and blind sac closure of the external canal. Obliteration of the tympanomastoid cavity is performed with abdominal fat or a pedicled temporalis muscle flap.

In this study the surgical procedure of is performed in the following order in case of patients with a pre-existing RMC or an active COM:

(1) retroauricular incision with development of a musculo-periosteal flap, (2) subtotal petrosectomy, (3) obliteration of the Eustachian tube opening, (4) blind sac closure of the external auditory canal, (5) drilling the well to accommodate the receiverstimulator package, (6) cochleostomy, (7) insertion and fixation of the cochlear implant using muscle flaps and fibrin glue at cochleostomy. Furthermore, fibrin glue is used to fixate the electrode near the posterior wall of the mastoid cavity. (8) The tympanomastoid cavity is filled with abdominal fat to cover the electrode. (9) The musculo-periosteal flap is sutured over the receiver-stimulator and petrosectomy cavity so that the receiver is fixated and the fat is contained under the flap. (10) Finally, the subcutaneous soft tissue and skin are closed in two layers.

\section{Results}

From January 2000 till January 2007, one hundred fifty-six patients underwent cochlear implantation. Thirteen patients $(8.3 \% 13 / 156)$ were identified with COM.

This study group consisted of 6 males and 7 females. Mean age at implantation was 60.9 years (range 29-77 years). The demographic characteristics of patients with COM receiving a cochlear implant are summarized in Table 3.1 and 3.2. Five patients were identified with COM without a history of prior ear surgery. Two of them had an active inflammation with cholesteatoma. Both patients underwent a combined approach tympanotomy with posterior tympanotomy to eradicate the cholesteatoma prior to cochlear implantation. The remaining three patients had a clinical and radiological inactive form of COM. In those three patients, a single staged cochlear implantation and closure of the tympanic membrane perforation was carried out via a standard combined approach/facial recess technique.

Eight patients with COM presenting with a RMC were enrolled in this study. Six patients without active COM underwent a subtotal petrosectomy and cochlear implantation as a single stage procedure. Two patients presented with a clinical and radiological active inflammation and received their cochlear implant six months after performing a subtotal petrosectomy. In one case a cholesteatoma was identified during surgery. In all patients with a RMC, no intra- or postoperative complications were encountered. 
Table 3.1 Shows the characteristics of the number of study patients.

\begin{tabular}{|c|c|c|c|c|c|c|c|c|c|c|}
\hline Patients & Sex & Age & $\begin{array}{l}\text { Medical } \\
\text { history }\end{array}$ & $\begin{array}{c}\text { Active } \\
\text { or inactive }\end{array}$ & Cholesteatoma & Staged & CAT & $\begin{array}{c}\text { Subtotal } \\
\text { petrosectomy }\end{array}$ & $\begin{array}{c}\text { Major } \\
\text { complication }\end{array}$ & $\begin{array}{c}\text { Minor } \\
\text { complications }\end{array}$ \\
\hline 1 & Female & 71 & COM & Inactive & No & No & No & No & Yes & No \\
\hline 2 & Male & 56 & COM & Active & Yes & Yes & Yes & No & No & No \\
\hline 3 & Female & 44 & COM & Inactive & No & No & No & No & No & No \\
\hline 4 & Male & 71 & COM & Active & Yes & Yes & Yes & No & No & No \\
\hline 5 & Female & 67 & COM & Inactive & No & No & No & No & No & Yes \\
\hline 6 & Male & 46 & $\mathrm{RMC}$ & Inactive & No & No & No & Yes & No & No \\
\hline 7 & Male & 52 & RMC & Inactive & No & No & No & Yes & No & No \\
\hline 8 & Female & 29 & RMC & Inactive & No & No & No & Yes & No & No \\
\hline 9 & Female & 76 & RMC & Inactive & No & No & No & Yes & No & No \\
\hline 10 & Male & 77 & RMC & Inactive & No & No & No & Yes & No & No \\
\hline 11 & Female & 62 & $\mathrm{RMC}$ & Active & Yes & Yes & No & Yes & No & No \\
\hline 12 & Female & 74 & RMC & Inactive & No & No & No & Yes & No & No \\
\hline 13 & Male & 63 & RMC & Active & No & Yes & No & Yes & No & No \\
\hline
\end{tabular}

Table 3.2 Shows the characteristics of the number of study patients with respect to preoperative audiological assessments and type of implants.

\begin{tabular}{|c|c|c|c|c|c|c|c|c|c|}
\hline Patients & Sex & Age & $\begin{array}{c}\text { Medical } \\
\text { history }\end{array}$ & $\begin{array}{l}\text { Type of } \\
\text { implant }\end{array}$ & Array design & $\begin{array}{c}\text { PTA } \\
\text { operated } \\
\text { ear }(d B)\end{array}$ & $\begin{array}{c}\text { PTA } \\
\text { contra-lateral } \\
\text { ear }(\mathrm{dB})\end{array}$ & $\begin{array}{c}\text { SDT } \\
\text { operated } \\
\text { ear (\%) }\end{array}$ & $\begin{array}{c}\text { SDT } \\
\text { contra-lateral } \\
\text { ear (\%) }\end{array}$ \\
\hline 1 & Female & 71 & COM & $\mathrm{Cl} 24 \mathrm{R}$ & Perimodiolar & NR & 95 & 0 & 20 \\
\hline 2 & Male & 56 & COM & $\mathrm{Cl} 24 \mathrm{R}$ & Perimodiolar & NR & 100 & 0 & 18 \\
\hline 3 & Female & 44 & COM & Helix $90 \mathrm{~K}$ & Perimodiolar & NR & 110 & 0 & 10 \\
\hline 4 & Male & 71 & COM & Cl24RCA & Perimodiolar & NR & NR & 0 & 0 \\
\hline 5 & Female & 67 & COM & Cl24RCA & Perimodiolar & NR & 98 & 0 & 16 \\
\hline 6 & Male & 46 & RMC & Helix $90 \mathrm{~K}$ & Perimodiolar & NR & 100 & 0 & 15 \\
\hline 7 & Male & 52 & RMC & Cl24RCA & Perimodiolar & NR & NR & 0 & NR \\
\hline 8 & Female & 29 & RMC & Cl24RCA & Perimodiolar & NR & NR & 0 & NR \\
\hline 9 & Female & 76 & RMC & Helix $90 \mathrm{~K}$ & Perimodiolar & 100 & 95 & 15 & 20 \\
\hline 10 & Male & 77 & RMC & Cl24RECA & Perimodiolar & NR & 97 & 0 & 18 \\
\hline 11 & Female & 62 & RMC & Cl24RECA & Perimodiolar & 105 & NR & 0 & 0 \\
\hline 12 & Female & 74 & RMC & $\mathrm{Cl} 24 \mathrm{RECA}$ & Perimodiolar & NR & 90 & 0 & 23 \\
\hline 13 & Male & 63 & RMC & $\mathrm{Cl} 24 \mathrm{RECA}$ & Perimodiolar & NR & 100 & 0 & 20 \\
\hline
\end{tabular}

$N R$ no response

\section{Major complications}

One major complication (7.7\% 1/13) was identified in one patient who received the cochlear implant during a single stage procedure. This patient had no clinical or radiological evidence for an active inflammation in the last six months prior to cochlear implantation.

The patient identified with a major complication was a 70-year-old woman who had a perceptive deafness due to COM. Since 1993 she has been audiometric deaf bilaterally. Subsequently, cochlear implantation and closure of the tympanic membrane perforation was performed as a single stage procedure. Pre- and intra-operatively, no active 
inflammation or cholesteatoma was present. Three months after cochlear implantation this patient complained about pain over the implant site attributed to a skin infection. Initially, the skin infection was treated with intravenous antibiotics. Exploration was done when antibiotic therapy failed. The cochlear implant was rotated cranially under the temporalis muscle. Due to persistent wound infection in combination with flairing up of the COM, wound dehiscence occurred and the implant package extruded. In agreement with the patient, the implant was explanted. No reimplantation has been carried out so far.

One patient needed six months after cochlear implantation further surgery due to a luxation of the implant induced by a fall of this patient. Replacement of the implant was carried out accompanied with no postoperative complications. Audiometric outcome was retained. This incident was not interpreted as a surgical complication because of it's traumatic origin.

\section{Minor complications}

In one case, a minor complication developed which revealed an otitis externa. A 67-year-old female with an inactive COM, who had no clinical or radiological evidence for an active inflammation at time of operation, received their cochlear implant by means of a single stage procedure. She suffered from otitis externa one year after cochlear implantation. Local antibiotic therapy was required to break down the infection.

\section{Discussion}

The question whether cochlear implantation, in patients with an inactive COM with or without previous ear surgery, has to be performed as a staged or single staged procedure remains still unanswered. All surgeons fear a severe infection by inserting an electrode into the cochlea through a potentially infected field and thereby infecting a space which communicates intracranially. Reports on complications which required surgical treatment after cochlear implantation in patients with a stable COM are rare although some cases can be found. ${ }^{3-5}$ The complications include recurrence of cholesteatoma, ${ }^{3}$ explantation of the implant due to severe inflammation, ${ }^{3,4}$ wound breakdown, ${ }^{5}$ retraction pocket exposing the electrode array $^{3}$ or extrusion of the implant side due to flap difficulties. ${ }^{5}$ All of these cases were as a consequence of flairing up of the infection which all required subsequent surgical treatment. Interestingly, all complications occurred after either single staged or staged procedures. In this study, the low complication rate in this group is in keeping with the results reported in literature. ${ }^{6-10}$ One of nine patients developed a major complication in this group. This patient had prior to cochlear implantation no clinical or radiological 
signs of inflammation. Six months after surgery a skin infection occurred, induced by flairing up of the inflammation. This case illustrates that there is still a possibility of serious complications and subsequent explantation which can develop in patients with an inactive COM. Although one major complication developed in this group, in our opinion it is still relatively safe to implant a cochlear implant as a single stage procedure in patients with an inactive COM.

In contrast, cochlear implantation as a single staged procedure in patients with an active COM is in our opinion obsolete. This is substantiated in literature where all authors plead for a staged procedure concerning this issue..$^{2-7}$ In this study, all patients with an active COM with or without previous ear surgery underwent complete eradication of the inflammation focus six months prior implantation by means of a combined approach tympanotomy with posterior tympanotomy in the latter. With respect to patients with an active COM accompanied known with previous ear surgery underwent a subtotal petrosectomy six months prior to cochlear implantation.

A subtotal petrosectomy implies the complete exenteration of all accessible air-cell tracts of the temporal bone, sealing the Eustachian tube orifice and closure of the external meatus. This may be followed by obliteration of the tympanomastoid cleft with a pedicled temporalis flap or with abdominal fat. ${ }^{11,12}$ In this study, lack of complications using a subtotal petrosectomy in patients with a pre-existing radical mastoid cavity is in keeping with other published data. Gray et al. ( $n=4)$, Axon et al. $(n=4)$, and Hamzavi et al. $(n=8)$ reported no major complications after obliteration of the middle ear cleft with blind pit closure of the ear canal after 5 years. ${ }^{11,13,14}$ Gray reported a residue of cholesteatoma which was removed during the second operation. Eventually the cochlear implant could be implanted safely without further evidence for relapse of cholesteatoma. In contrast, Issing et al. ( $n=12)$ reported inadequate closure of a retroauricular fistula over the mastoid cavity in 2 cases (14.2 \%) and an inflammatory reaction in the implanted ear at two months in 1 case (7.1\%) after cochlear implantation. ${ }^{15}$ The inflammatory reaction was induced by a tumefactive inflammatory pseudotumor. Furthermore, Issing et al reported one patient with a temporary facial palsy for two weeks. ${ }^{15}$ The occurrence of a retroauricular fistula might be a consequence of impaired blood flow induced by prior retroauricular incisions or recurrence of cholesteatoma. Therefore this complication is not specific with respect to a subtotal petrosectomy.

Although the number of studied patients in literature are too small to have strong implications on the role of a subtotal petrosectomy in patients with COM undergoing cochlear implantation, the overall results in literature with respect to the combination cochlear implantation and subtotal petrosectomy are encouraging ${ }^{11,13-15 .}$

In this study, the tympanomastoid cleft of all patients that underwent a subtotal petrosectomy was obliterated with abdominal fat. Fat has a low metabolic rate and 
will undergo fibrosis easier than necrosis. Because it is a large single mass it is easy to be lift off the promotorium in case of a second look which can be difficult after the use of other materials. The aim of obliterating the tympanomastoid cleft is to create a closed and sterile cavity reducing the risk of infection associated with inserting a foreign body. Furthermore, obliteration of the tympanomastoid cleft provides the patient with an isolated and sterile environment which lowers the risk of an infection induced by insertion of a foreign body. Another advantage of this procedure is that no life-long care of the particular ear is necessary and swimming is allowed. However, the procedure has to be carried out with utmost care to prevent a residue of epithelial cells in the tympanomastoid cavity which can cause a recurrence of cholesteatoma inducing an asymptomatic destruction of the temporal bone with consecutive device failure. Secondly, if not all mucosa is removed a mucocele may develop, neccesating re-exploration. Major drawback of this technique is the difficulty to facilitate radiological imaging and a second look to detect a recurrent cholesteatoma. To overcome this issue the tympanomastoid cavity can be left open.

Besides the subtotal petrosectomy, several surgical techniques to insert a cochlear implant in patients with COM with a RMC are described in literature. ${ }^{11,12,16-18}$ Three other alternative surgical approaches are reported in literature which can be carried out either combined with cochlear implantation, as a single stage procedure or as a staged procedure. First, a revision mastoidectomy with eradication of active inflammation from the mastoid bowl and obliteration of the mastoid bowl with bone chips, with reconstruction of the bony posterior wall. ${ }^{17}$ This technique contributes to the anatomic rehabilitation of the cavity if there is no protection of the electrode array by the tympanic membrane and bony posterior wall of the external auditory canal. The advantages of this procedure are (i) the electrode is protected from cavity problems such as chronic infection or erosion of the epithelium in the open mastoid cavity, and (ii) reconstruction of the new tympanic cavity and tympanic membrane is beneficial to avoid electrode exposure in the mastoid and tympanic cavity. Regarding postoperative complications, inclusion of epithelial debris, necrosis of the cutaneous layer or obliteration material and electrode migration in the cavity can develop. Therefore, this technique is not included in our algorithm.

Secondly, a revision mastoidectomy with removal of all epithelium from the mastoid bowl with creating a periosteal flap to cover the electrode. This is often combined with drilling a groove in the mastoid cavity to stabilize the electrodes, and cochlear implantation with stabilization of electrodes to the facial ridge with either bone cement or cartilage. ${ }^{12}$ Advantages of this technique are (1) relapsing cholesteatoma can be effectively monitored, because of the benefits of an open technique. (2) The cement provides stabilization of the electrode array and the periosteal flaps provide a total covering of the electrode array, keeping it isolated from possible external contamination. However, this technique is not without risk of electrode exposure or migration, and is therefore also not included in our algorithm. 
Third, using a middle fossa approach access to the cochlea bypassing the possible infected conventional route for cochlear implantation. ${ }^{19}$ The electrode is inserted through a basal turn cochleostomy created in the floor of the middle cranial fossa. In this approach the cochleostomy is created further along the basal turn and the electrode may be inserted deeper in the cochlea. If this has a negative effect on hearing outcome remains to be demonstrated. Possible drawbacks of this procedure are the inherent risks of a craniotomy and compression of the temporal lobe.

\section{Conclusion}

In our opinion, patients with evidence for an active COM with or without cholesteatoma cochlear implantation have to be performed as a staged procedure. In patients with COM with a dry perforation or an stable cavity, cochlear implantation can be performed as a single stage procedure. Although it is accepted that cochlear implantation is relatively safe, especially in patients with a stable COM, our results illustrate that there is still a chance for serious complications in which subsequent explantation of the cochlear implant is desired. 


\section{References}

1. Postelmans JT, Cleffken B, Stokroos RJ. Postoperative complications of cochlear implantation in adults and children: five years' experience in Maastricht. J Laryngol Otol 2007;121:318-23.

2. Cohen NL, Hoffman R. Complications of cochlear implant surgery in adults and children. Ann Otol Rhinol Laryngol. 1991;100:708-11.

3. Bhatia K, Gibbin KP, Nikolopoulos TP, O'Donoghue GM. Surgical complications and their management in a series of 300 consecutive pediatric cochlear implantations. Otol Neurotol. 2004;25:730-9.

4. Harada T, Ishida K, Endo M, Takahashi M, Sakai M. Recurrent extrusion of cochlear implant at an interval of 5 years. Otol Neurotol. 2003;24:83-5.

5. Donnelly MJ, Pyman BC, Clark GM. Chronic middle ear disease and cochlear implantation. Ann Otol Rhinol Laryngol Suppl. 1995;166:406-8.

6. Syms MJ, Luxford WM. Management of cholesteatoma: status of the canal wall. Laryngoscope. 2003;113:443-8.

7. Roberson JB, Jr., Mason TP, Stidham KR. Mastoid obliteration: autogenous cranial bone pate reconstruction. Otol Neurotol. 2003;24:132-40.

8. Mills RP. Surgical management of the discharging mastoid cavity. J Laryngol Otol Suppl. 1988;16:1-6.

9. Palva T. Surgical treatment of chronic middle ear disease. III. Revisions after tympanomastoid surgery. Acta Otolaryngol. 1988;105:82-9.

10. Sheehy JL. Cholesteatoma surgery: canal wall down procedures. Ann Otol Rhinol Laryngol. 1988;97: 30-5.

11. Gray RF, Irving RM. Cochlear implants in chronic suppurative otitis media. Am J Otol. 1995;16:682-6.

12. Meyerhoff WL, Stringer SP, Roland PS. Rambo procedure: modification and application. Laryngoscope. 1988;98:795-6.

13. Axon PR, Mawman DJ, Upile T, Ramsden RT. Cochlear implantation in the presence of chronic suppurative otitis media. J.Laryngol Otol. 1997;111:228-32.

14. Hamzavi J, Baumgartner W, Franz P, Plenk H. Radical cavities and cochlear implantation. Acta Otolaryngol 2001;121:607-9.

15. Issing PR, Schönermark MP, Winkelmann S, Kempf HG, Ernst A. Cochlear implantation in patients with chronic otitis: Indications for subtotal petrosectomy and obliteration of the middle ear. Skull base surg. 1998;8:127-31.

16. El-Kashlan HK, Arts HA, Telian SA. Cochlear implantation in chronic suppurative otitis media. Otol Neurotol. 2002;23:53-5.

17. Tamura Y, Shinkawa A, Ishida K, Sakai M. Cochlear implant after reconstruction of the external bony canal wall and tympanic cavity in radically mastoidectomized patients with cholesteatoma. Auris Nasus Larynx. 1997;24:361-6.

18. Manrique M, Cervera-Paz FJ, Espinosa JM, Perez N, Garcia-Tapia R. Cochlear implantation in radical cavities of mastoidectomy. Laryngoscope. 1996;106:1562-5.

19. Colletti V, Fiorino FG, Carner M, Pacini L. Basal turn cochleostomy via the middle fossa route for cochlear implant insertion. Am J Otol. 1998;19:778-84. 
(2) 53

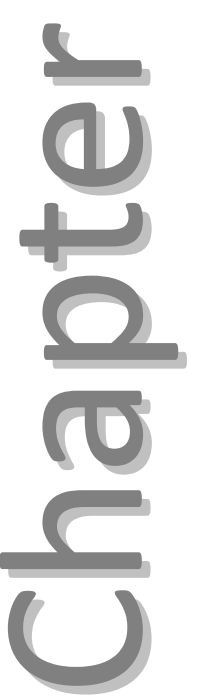

\section{The suprameatal approach: a safe alternative surgical technique for cochlear implantation}

JTF Postelmans, RA Tange, RJ Stokroos, W Grolman

Otology and Neurotology 2010;31:196-203 


\section{Abstract}

\section{Objective}

To report the surgical postoperative complications encountered in 104 patients undergoing cochlear implantation surgery using the suprameatal approach (SMA). Second, we want to substantiate the advantages and disadvantages of the SMA technique to the classic mastoidectomy with posterior tympanotomy approach (MPTA).

\section{Study design}

Retrospective study assessing the surgical postoperative complications of deaf adults and children undergoing cochlear implantation.

\section{Setting}

Tertiary referral centre for cochlear implantation

\section{Patients}

The mean age for the time of surgery was 39.6 years (1.0-82.3 years) and the mean duration of deafness was 26.3 years (0.3-66.0 years). The main etiology was a congenital hearing loss

$(31.4 \%)$ and a progressive sensorineural hearing loss e.c.i. $(24.8 \%)$ followed by meningitis $(13.3 \%)$ and otosclerosis (6.7\%). The mean duration of follow up after surgery was 25.7 months (range, 3.0-59.0 months).

\section{Results}

The overall major complication rate was 3.7\% (4/107). All complications developed postoperatively. The major complications consisted of extrusion of the implant due to wound infection $(n=2)$, a fausse route of the electrode $(n=1)$, and device failure $(n=1)$. Subsequently, the minor complication rate was $23.4 \%(25 / 107)$. The mean duration of cochlear implantation was 111.7 minutes (range, 60.0-261.1 minutes)

\section{Conclusions}

This study confirms the SMA is a safe, simple and quick technique feasible for cochlear implantation in most cases. Although a stretching over of the electrode array when it enters the scala tympani and a low lying dura might be potential restrictions of the SMA technique this can not be supported by our results however. 


\section{Introduction}

Since its introduction in 1961 by House ${ }^{1}$, the classic mastoidectomy with posterior tympanotomy approach (MPTA) has become the most common surgical technique for cochlear implantation. After the mastoidectomy, a posterior tympanotomy is performed to open the facial recess and to expose the round window via the triangular space between the facial nerve, the floor of the fossa incudis, and the chorda tympani. In experienced hands, a posterior tympanotomy has been shown to be a relatively easy procedure to perform. However, because of the close proximity of the facial nerve, this nerve might be injured during the drilling of the facial recess. Furthermore, in some cases, the chorda tympani might be sacrificed when the facial recess is narrow to enhance exposure at the cochleostomy site. Unsurprisingly, several cases of facial nerve paralysis associated with the MPTA procedure have been described in the literature both in the early days of cochlear implantation and recently. ${ }^{2-6}$ Permanent facial nerve paralysis after cochlear implantation is a major surgical complication. To prevent facial paralysis and injury to the chorda tympani, Kronenberg et al. ${ }^{7,8}$ developed an alternative technique in which the electrode of the cochlear implant is introduced into the middle ear via a suprameatal route. This suprameatal approach (SMA) differs from the classic approach in avoiding a mastoidectomy. The facial nerve is protected by the body of the incus when the middle ear is entered by drilling the suprameatal tunnel. Recent reports from Kronenberg et al. (Israel) and Arnoldner et al. (Vienna) show that, compared with the classic technique, there are fewer complications in terms of facial nerve paralysis and postoperative infections of the mastoid. $^{7-10}$ In light of these favorable preliminary results, we adopted the SMA procedure as the strategy for cochlear implantation. In this article, we report on the surgical complications after cochlear implantation in 104 patients with the SMA technique from 2003 till 2008. Second, we look at the benefits and drawbacks of this alternative surgical approach.

\section{Materials and methods}

We started our cochlear implant program in 2003, and, to date, 108 patients have received their cochlear implant at the Department of Otorhinolaryngology-Head and Neck Surgery of the Academic Medical Centre, University of Amsterdam. Initially, we used the MPTA technique but switched to the SMA procedure after 4 patients. All patients who underwent the MPTA technique were excluded from further analysis in this study. All data collection and analysis were performed by a trained unbiased observer with no connections to our Department. All cochlear implantations were performed by Authors 2 and 4. Only patients who underwent the SMA procedure were reviewed to identify postoperative surgical complications. In all, 104 consecutive patients who underwent cochlear implantation were included in this retrospective 
study between January 2003 and December 2007. The study group consisted of 85 adults and 19 children. The total number of procedures undertaken in these patients was 115. Of these, 107 were for implantation (including 101 unilateral and 3 simultaneous bilateral procedures), 4 for explantation, and 4 were for reimplantation.

\section{Patient characteristics}

The mean age at the time of surgery was 39.6 years $(1.0-82.3 \mathrm{yr})$, and the mean duration of deafness was 26.3 years (0.3-66.0 yr). Prelingual deafness and postlingual deafness accounted for 51.0 (53 of 104) and 49.0\% (51 of 104), respectively (Table 4.1). The main cause was a congenital hearing loss (30.8\%) and a progressive sensorineural hearing loss e.c.i. (25.0\%), followed by meningitis (12.5\%) and otosclerosis $(6.7 \%)$. Figure 4.1 provides a detailed breakdown of the various causes of the deafness and shows the distribution of prelingual and postlingual deafness among the various causes. The mean duration of follow-up after surgery was 25.7 months, with a minimum of 3.0 and a maximum of 59.0 months.

Table 4.1 Shows the patients' characteristics in this study.

$\begin{array}{ll}\text { Study patients } & \mathrm{n}=104 \\ & (85 \text { adults and } 19 \text { children) } \\ & 39.6 \text { years } \\ \text { Mean age at implantation } & (1.0-82.3) \\ & 26.3 \text { years } \\ \text { Mean duration of deafness } & (0.3-66.0) \\ \text { Prelingual deafness } & 51.0 \% \\ & (n=53) \\ \text { Postlingual deafness } & 49.0 \% \\ & (n=51) \\ \text { Mean follow-up } & 25.7 \text { months } \\ & (3.0-59.0)\end{array}$

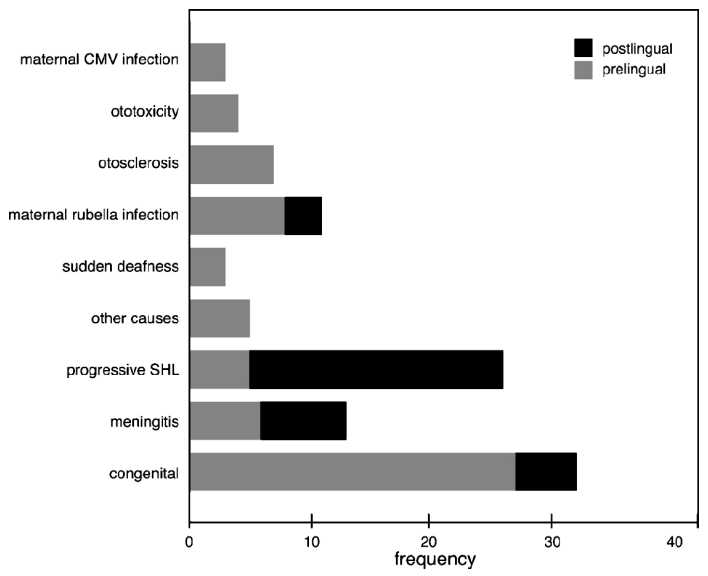

Figure 4.1 Distribution of prelingual and postlingual deafness with respect to the cause of deafness. 


\section{Surgical Procedure}

All cochlear implantation patients in this study underwent the SMA procedure, which consists of the following steps.

First, after placing the patient in a supine position, we make a retroauricular incision of $3 \mathrm{~cm}$. Subsequently, an endaural tympanotomy is used to approach and examine the middle ear contents. The tympanomeatal flap is raised, with elevation of the tympanic ring. Incidentally, a small part of the medial bony external auditory canal has to be drilled away to optimize visualization of the stapes and round window to determine the position of the cochleostomy.

Second, a tunnel is drilled supraposteriorly to the suprameatal spina (Henle spine) toward the posterior part of the aditus ad antrum at approximately a 1 o'clock position (in the left ear) and approximately an 11 o'clock position (in the right ear) of the external auditory canal (Figure 4.2). Packing is placed in the external auditory canal to prevent irritation by bone dust induced by the drilling. Determination of the optimal direction for the antrostomy is based on imaging of the temporal bone, especially the middle fossa dura and the course of the posterior part of the external auditory canal. During the drilling, the surgical landmarks are the lateral semicircular canal and the body of the incus. Drilling is stopped when the body of the incus is visualized. Subsequently, lateral to the body of the incus, a passage is drilled to connect the antrum with the middle ear, avoiding drilling contact with the incus itself.

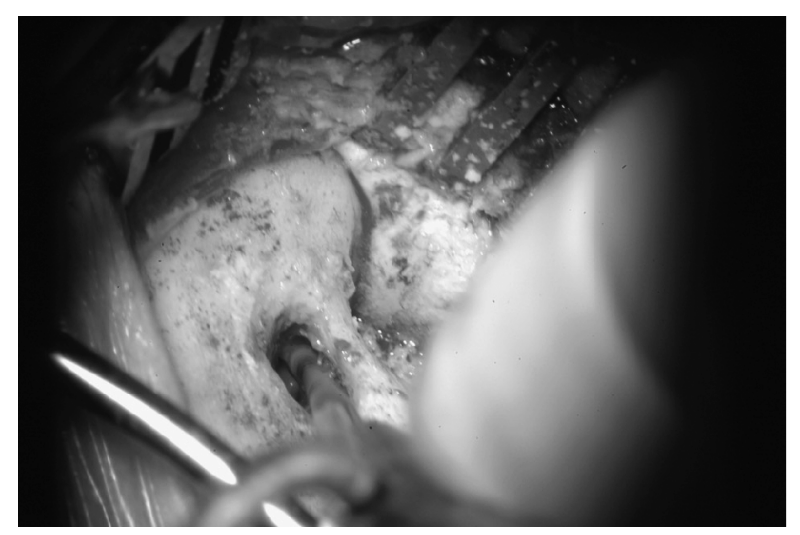

Figure 4.2 Photograph through the microscope of a right ear. The SMA tunnel is being drilled.

Third, a second small semicircular temporoparietal incision of $2.5 \mathrm{~cm}$ is made to visualize the myoperiosteal layer. This second incision is made in the myoperiosteal layer to drill a well in the temporoparietal calvaria to fixate the receiver-stimulator of the implant and to cover the receiver-stimulator package. The location of the well is the same as in the MPTA procedure. A subperiostal tunnel is formed, which allows the 
2 incisions to communicate, leaving the skin intact. The electrode of the implant is led via the subperiostal tunnel to the suprameatal tunnel before entering the middle ear. The ground electrode (if present) is fixated under the musculus temporalis.

Fourth, the cochleostomy is drilled anteroinferiorly to the oval window in the promontory, close to the overhang of the round window (Figure 4.3). The scala tympani is opened. The electrodes are now passed via the subperiostal tunnel through the suprameatal tunnel and groove into the cochleostomy (Figure 4.4). The cochleostomy is not sealed with temporal muscle or other material because the cochleostomy is so small that there is no space for additional material. In children, extra attention is paid to the positioning of the lead of the electrode to allow sufficient leeway for growth. The tympanomeatal flap is placed back and the external ear canal is packed with gauze. The 2 incisions are closed in 3 layers.

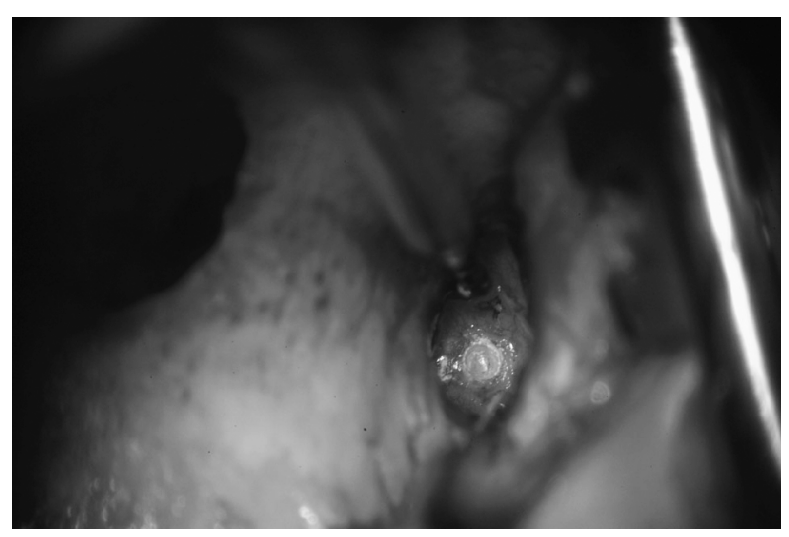

Figure 4.3 Photograph through the microscope of a right ear. The cochleostomy is drilled through the external auditory canal.

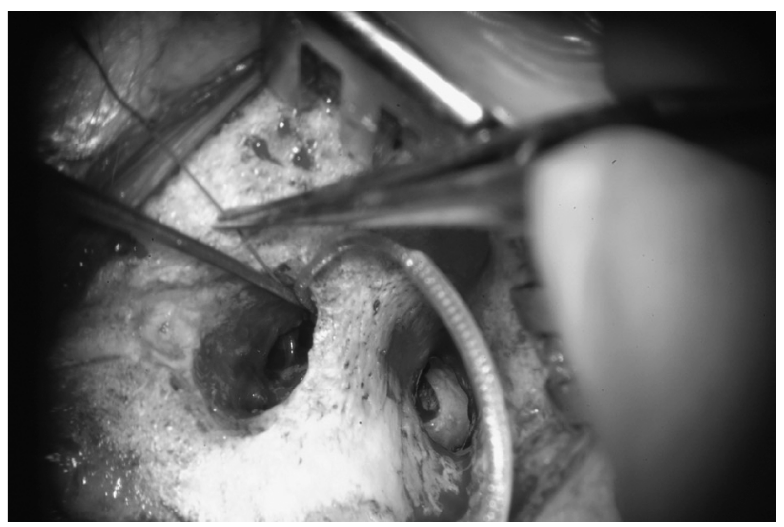

Figure 4.4 Photograph through the microscope of a right ear. The electrode array is placed through the SMA tunnel passing the middle ear into the cochleostomy. 
Surgical complications were divided into major and minor complications defined as follows: 1) complications that required revision surgery were considered to be major complications, and 2) complications that could resolve with conservative treatment were defined as minor complications. The duration of the surgery was measured for all cochlear implantation procedures. Duration of the surgical procedure was defined as the time between the first incision and the closing of the wound in three layers after cochlear implantation. The time taken for intra-operative recordings such as neural response telemetry and spread of excitation was excluded from the duration of surgery. Explantation procedures were excluded from data analysis with respect to the duration of surgery.

Three different types of cochlear implants were used for implantation; the Nucleus 24Countour, the Nucleus 24Countour Advance with Softip, and Advanced Bionics HiFocus Helix. Before cochlear implantation, a preoperative computed tomographic scan of the temporal bone was made to identify any middle or inner ear abnormalities and also to determine the position of the middle fossa dura to help guide the creation of the suprameatal tunnel.

From January 2005 onwards, in 71 of 104 patients (68.2\%), we used a mobile digital X-ray C-arm (Philips BV Pulsera, Best, Netherlands) with 3-dimensional (3D) functionality and modified for motorized movement to acquire per-operative 3D x-ray images. This procedure is described elsewhere, but the main purpose of perioperative imaging during cochlear implantation is to verify the position of the electrode array in the cochlea (11). The electrode array was scanned once before removal of the stylet in the case of the Nucleus 24Countour and the Nucleus 24Countour Advance with Softip. Scanning was repeated once after full insertion of the electrode to verify correct insertion of the electrode. This technique has been very helpful in identifying the lumen within the cochlea especially in diseases such as severe otosclerosis.

The overall major complication rate in this study was 3.7\% (4 of 107). All complications developed postoperatively. The major complications consisted of extrusion (explantation) of the implant due to wound infection $(n=2)$, incorrect routing of the electrode $(n=1)$, and device failure $(n=1)$. One other patient underwent explantation of the cochlear device as a consequence of severe painful sensations around the well. This event was not classified as a surgical complication because of the patient's psychiatric illness, which was the cause of the explantation.

In 2 cases where explantation of the cochlear implant was required, we tried to identify the reason for the wound infections. The first patient developed a hematoma immediately after surgery as a consequence of anticoagulant use for peripheral arterial disease and heart attack. There was a wound infection with a fistula 1 year later, which 
was promptly treated with antibiotics. Unfortunately, the wound infection persisted, and explantation of the cochlear device was required. The second patient experienced tenderness around the receiver-stimulator package. Examination of the skin showed a skin reaction induced by multiple subcutaneous sutures behind the ear and around the implant. Subsequent revision of the skin with removal of the sutures and adequate antibiotic therapy failed to stop the progression of the wound (device) infection. Eventually, the implant had to be removed. Both patients who underwent explantation of the device were reimplanted successfully later.

The other 2 major complications resulted from the incorrect routing of the electrode due to surgical failure and device failure months after the surgery. The first patient experienced severe postoperative vertigo after cochlear implantation. Intra-operative measurements showed reduced impedance and neural response telemetry reactions, suggesting that the implant was performing only moderately. Postoperatively, a computed tomographic scan was obtained that showed a misdirection of the electrode array in the cochlea. The tip of the implant was situated in the horizontal semicircular canal. A revision operation was performed 12 weeks postoperatively. There were no further complaints of vertigo, and implant function was normal. This patient resumed his high academic position with success and a good hearing result. Further information regarding this special case is described elsewhere. ${ }^{12}$

The patient who experienced device failure noticed her speech recognition was progressively deteriorating 1 year after implantation. Audiological investigations showed that 6 electrodes started to malfunction during the course of a few months. The implant was removed, and the device manufacturer confirmed the malfunctioning of the 6 electrodes. Further investigations failed to identify any damage to the electrodes or any other obvious reason for the device failure. This was in line with the striking fact that there was no immediate perioperative failure of the device.

\section{Minor complications}

In this study, the minor complication rate was $23.4 \%$ (25 of 107). These complications consisted of tinnitus (7.5\%), vertigo (5.6\%), eardrum perforation (2.8\%), hematoma (2.8\%), and miscellaneous (4.7\%). All minor complications are listed in Figure 4.5. Other cases involved the perception of pain around the receiver-stimulator package, lesion of the skin surrounding the implant, and otalgia. All minor complications were successfully man-aged with conservative therapy. Figure 4.6 shows the distribution of minor complications in relation to the cause of deafness. Surprisingly, 7 of 11 patients in whom the deafness resulted from maternal rubella infection experienced minor complications. To examine the correlation between cause and minor complications, a Fisher's exact test was performed, with a Bonferonni correction for multiple testing 
due to the small number of cases per sub-group. Only maternal rubella infection was found to be statistically significant.

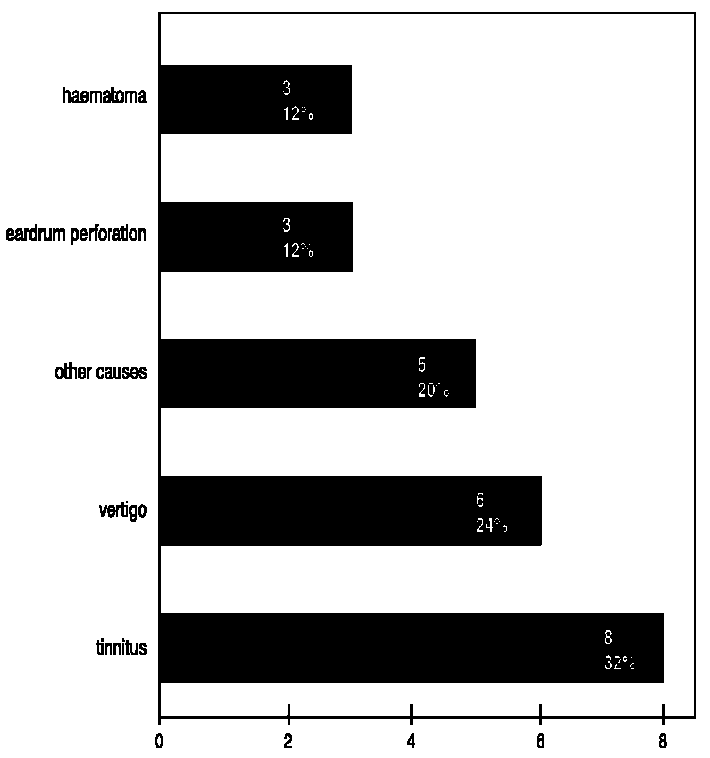

Figure 4.5 This figure shows the number of minor complications that were identified in this study.

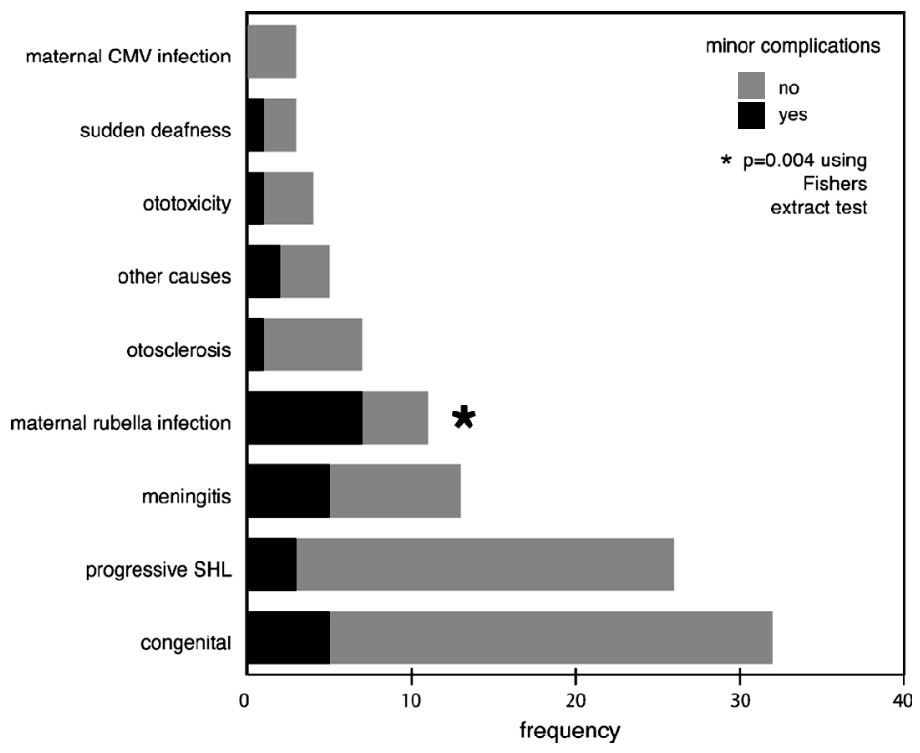

Figure 4.6 This figure shows the various causes of deafness related to postoperative minor complications. 


\section{Duration of surgery}

We recorded the duration of surgery for all cochlear implantations and reimplantations $(n=111)$. The mean duration for cochlear implantation was 111.7 minutes. The shortest procedure took 60.0 minutes, the longest 261.1 minutes. The latter was caused by difficulties inserting the electrode due to sclerosis of the cochlea. In $70.0 \%$ of cases, we performed intra-operative scanning to verify the position of the electrode array. Scanning the electrode array using the 3D rotational $\mathrm{x}$-ray added 15 minutes to the surgical procedure. The mean duration of surgery declined from 111.7 to 95.3 minutes if the intra-operative scanning was not included. Figure 4.7 is a high-low chart showing that there is no tendency for the mean duration of surgery to decline. Furthermore, the mean time of surgery is constant during the study period, which means there is no learning curve with respect to the duration of the procedure. Two causes of variation in the duration of surgery were identified in 2004 and 2006. In both procedures, the insertion of the electrode was extremely difficult due to sclerosis of the cochlea and a low-lying middle fossa dura. Figure 4.8 shows that the cause of deafness does not affect the mean time of surgery. Furthermore, it shows that the mean duration of surgery is longer in otosclerosis cases in comparison with other causes of deafness. However, a 1-way analysis of variance test showed that there were no significant differences in the mean surgery time correlated to the various causes of deafness.

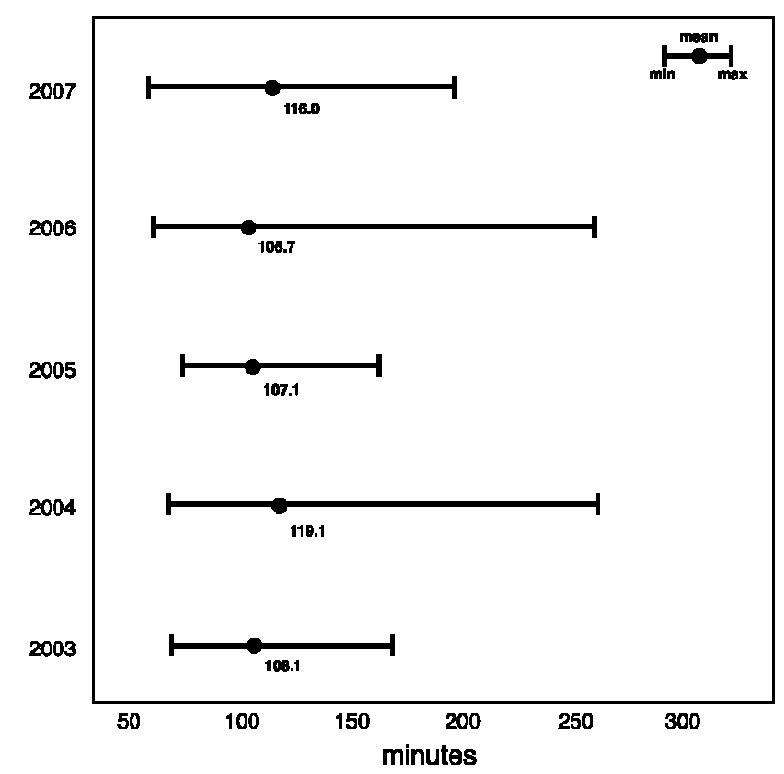

Figure 4.7 High-low chart of the operation time in relation to the study years. The mean time of surgery showed no declination during the study period. 


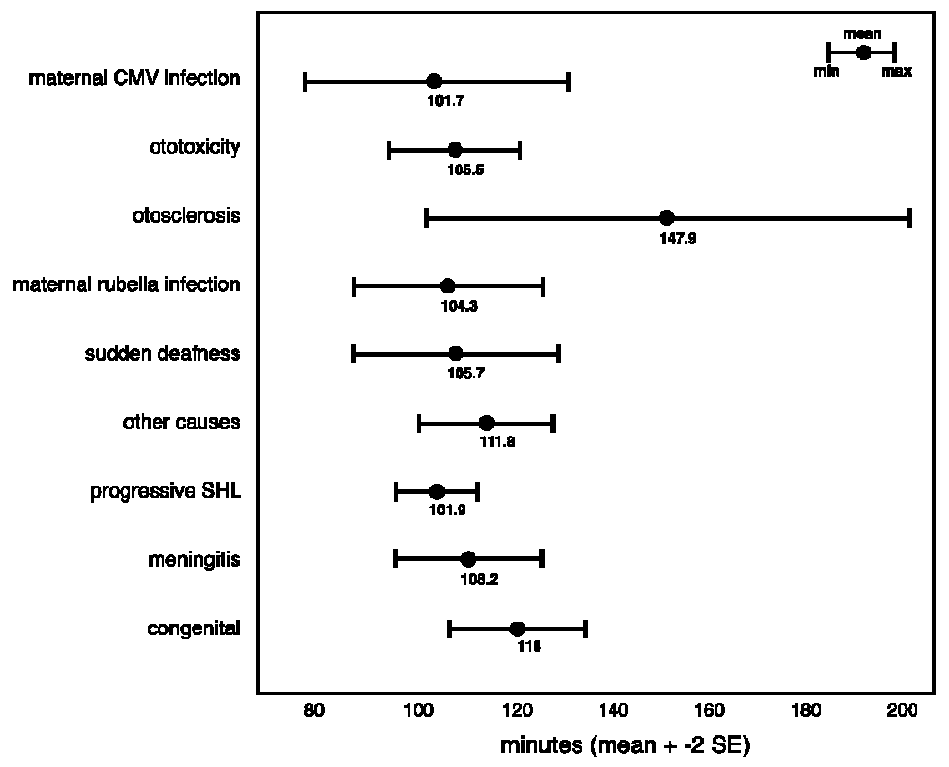

Figure 4.8 Median time of surgery with respect to the cause of deafness. No significance difference was found between the duration of surgery and cause of deafness.

\section{Discussion}

This study is the second largest evaluation of cochlear complications associated with the SMA technique developed in 1999 by Kronenberg et al.,, ${ }^{7,8}$ and it reaffirms the feasibility and safeness of this procedure for cochlear implantation. The technique is based on a retroauricular tympanotomy approach to enter the middle ear cavity. Subsequently, the electrode is introduced to the middle ear by drilling a suprameatal tunnel. In this study, major complications occurred in $3.7 \%$ of cases (4 of 107). When mechanical failures of the device are not included, the incidence of major complication declines to $2.8 \%$ (3 of 107). This low incidence of major complications compares favorably with previous studies of the classic technique, which report major complication rates of between 3.0 and $13.7 \% .{ }^{13-16}$ Furthermore, our results are in keeping with Kronenberg et al., ${ }^{7,8}$ who reported an incidence of major complications of $1.3 \%$ ( 2 of 151). The low incidence of major complications in both studies could be a confirmation that the SMA technique is as safe as the classic technique.

A notable observation was the contribution of wound infections requiring explantation of the device to the overall number of major complications. Although 2 of 4 major complications were identified as infection-related, this number is in keeping with the 
incidence of wound infection in other studies, which ranges between 1.7 and 3.3\%. ${ }^{17-19}$ All wound infections occurred 1 year or more after implantation, which concurs with Cunningham et al., ${ }^{19}$ who reported wound infections occurring at a mean time of 11.2 months after implantation. In this study, wound infections failed to improve despite culture-directed antibiotic therapy. Although clinical evidence is lacking, this striking observation may be linked to the presence of a biofilm. Antonelli et al. ${ }^{20}$ have stated that further conservative treatment of a biofilm-mediated infection may well prove futile, and explantation may be necessary if a standard course of systemic antibiotic therapy fails (e.g., 2 weeks of parenteral, culture-directed antibiotics).

The incidence of minor complications in this study (23.4\%) is in keeping with other studies using the MPTA technique. ${ }^{13,15}$ Reports of minor complications with the SMA technique are sparse. ${ }^{7,8}$ It is not therefore possible to make an accurate comparison between incidence rates from studies of the SMA procedure for cochlear implantation. The range of minor complications including: vertigo, tinnitus, and hematoma is in line with other studies using the MPTA technique. ${ }^{13-16}$ It is remarkable that 3 patients were identified with a tympanic membrane perforation postoperatively in this study. This is in line with Kronenberg et al.,", ${ }^{7,8}$ who reported 2 tympanic membrane perforations that were later repaired with tympanoplasty. In our study, the tympanic membrane perforations closed spontaneously.

To our knowledge, only 5 tertiary medical centers have published their experiences and results for the SMA technique. These are the studies from Kronenberg et al., Arnoldner et al., Yin et al., Hausler, and Keratzidis. ${ }^{7-10,21-23}$ The last 2 reported on their use of a mastoid-saving surgical approach, which was a modification of the existing SMA technique. On the basis of these findings, we think the SMA is an underused and underappreciated surgical technique compared with the classic technique. In the case of inexperienced surgeons trained in the standard retroauricular and mastoidectomy approaches, this is understandable because the surgeon must have the skills required to drill a grove into the ear canal and a tunnel in the calvarium of the skull. These are not techniques that are used in daily practice. Although neither technique seems difficult, thorough training is needed to prevent complications. Therefore, training for inexperienced surgeons will always favor the MPTA for cochlear implantation. Furthermore, in the first publication of Kronenberg et al., ${ }^{8}$ the SMA technique received both praise and substantial criticism from its 3 reviewers because this unique approach was very different from the past practice of otologists. Major comments were 1) it required skills not usually exercised by otologic surgeons, 2 ) it seemed to be a blind dissection, 3 ) it included the placement of electrodes and other devices in a grove in the ear canal, and 4) insertion of the electrode into the scala tympani took place without direct visualization along the axis of the basal turn, precluding observation of the status of the interior of the cochlea. 


\section{Drawbacks of SMA technique}

In our opinion, the SMA technique involves a few potential restrictions that we observed in this study.

1) Insertion of the electrode in the cochleostomy is accompanied by a stretching of the electrode array compared with the classic approach. When introducing the electrode array in the middle ear, the electrode array has to be bent over to enter the cochleostomy site (Figure 4.9). Furthermore, the SMA technique involves a difficult round window approach. This may become an issue when patients with ski slope audiograms are being given implants. These patients undergo experimental treatment with shorter and thinner electrode arrays (hybrid arrays), and hearing preservation is of the highest importance because of the low frequencies. Currently, hybrid shorterelectrode arrays are inserted into the round window through an incision. These investigational devices may become main-stream in the near future. In this study, we did not see any device failures as a consequence of possible kinking of the electrode during insertion.

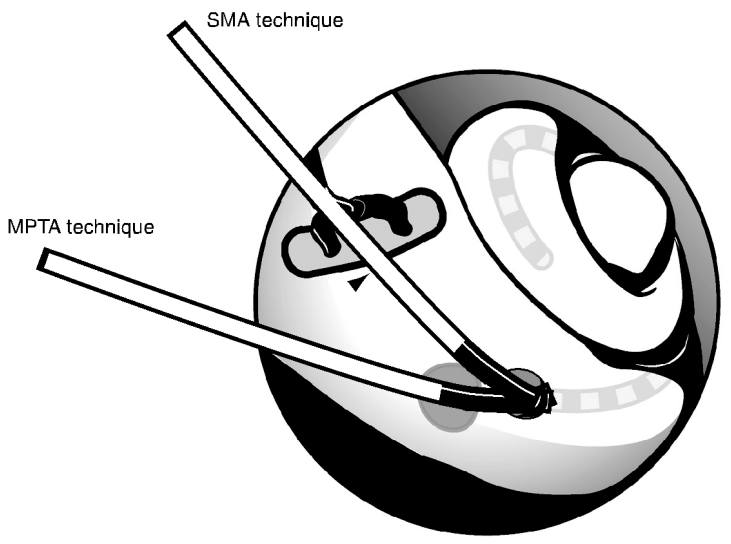

Figure 4.9 The different approaches of the cochleostomy site by means of the MPTA and SMA technique. Introducing the electrode in the scala tympani is accompanied with a stretching over of the electrode in contrast to the MPTA technique.

2) A low-lying dura is considered to be a relative contraindication for cochlear implantation because it presents an obstacle to the creation of the suprameatal tunnel. In this study, 1 patient was identified with a low-lying dura (dura virtually on top of the external auditory canal). After removal of the incus, we succeeded in maneuvering the electrode to the cochleostomy site. Kinking of the tip of the electrode and the malfunctioning of 6 electrodes led us to perform a posterior tympanotomy to create more exposure. Eventually, the electrode was inserted successfully. 


\section{Advantages of the SMA technique}

Several advantages inherent to the SMA technique have been discussed in comparison with the classic technique. First, the SMA technique results in gentler tissue handling due to the preservation of the mastoid and the safe distance between the facial nerve and the suprameatal tunnel. Not conducting a mastoidectomy prevents retroauricular bony defects and improves the aesthetic results. Furthermore, it prevents the development of granulation tissue, damage to the mucosa, and scar tissue in the mastoid cavity. The facial nerve is protected by the body of the incus during the atticoantrostomy, and so it is almost impossible to injure the facial nerve. The same applies to the chorda tympani; this structure is clearly visible and can be easily preserved after performing the endaural tympanotomy. In keeping with Kronenberg et al., we observed no facial paralysis or injury of the chorda tympani. ${ }^{7,8}$

Second, the SMA technique shortens the duration of surgery by 30 to 60 minutes compared with the classic technique. In this study, the mean duration of cochlear implantation was 111.7 minutes. Excluding the time involved in the intra-operative scanning of the electrode reduces the mean time for surgery to 95.3 minutes. During this study period, we did not identify a learning curve with respect to the duration of surgery. This could be explained by the fact that the manual skills of both senior surgeons are optimally developed.

Third, the SMA technique is associated with a wider exposure of the middle ear contents and the site for performing a cochleostomy. The wide exposure makes it easier to maneuver to the electrode into the cochleostomy. Furthermore, the wide exposure will enhance the ability to deal with a high jugular bulb or a perioperative gusher.

\section{Modifications to the original SMA technique}

Two modifications were made to the SMA technique introduced by Kronenberg et al. ${ }^{24}$ Instead of the large inverted J-shaped incision, we performed a small $(2 \mathrm{~cm})$ retroauricular skin incision, followed by a small temporo-partial $(3 \mathrm{~cm})$ skin incision rather than 1 large incision. Connection of the 2 incisions results in a subperiostal tunnel in which the electrode array is guided toward the suprameatal tunnel. In our opinion, this modification results in a smaller wound bed, which may improve wound healing and simultaneously reduce subsequent wound infections. Moreover, the intact overlying skin improves the fixation of the electrode array. Disappointingly, this modification did not result in the prevention of wound (device) infections in this study. Two patients underwent explantation of the device as a result of wound infections with fistula formation. The wound infection in 1 patient may have been the result of hematoma formation that occurred after cochlear implantation. In this case, the wound infection might be attributed to a clinical occult bacterial contamination of the 
receiver-stimulator. The other wound infection may have been induced by multiple subcutaneous sutures that were extruded spontaneously. Revision of the skin with removal of the sutures and adequate antibiotic therapy failed to halt the progression of the infection. In the case of wound infections, we think that if the receiverstimulator package or electrode is involved, a point of no return is reached so that the cochlear implant has to be removed.

Another modification was made with respect to the creation of the atticoantrostomy. Instead of opening the attic transmeatally, the attic was opened by drilling a groove lateral to the body of the incus through the suprameatal tunnel. We think that this results in gentler tissue handling for the skin of the external auditory canal. During the drilling of the suprameatal tunnel, packing is placed in the external auditory canal to prevent bone dust entering the middle ear.

This study confirms that SMA is a safe, simple, and quick technique that is feasible for cochlear implantation in most cases. Our results are in keeping with other tertiary medical centers that use the SMA technique. A potential restriction of the SMA technique might be the bending of the electrode array when it is inserted in the cochleostomy. 


\section{References}

1. House WF. Cochlear implants. Ann Otol Rhinol Laryngol 1976;85: 1 Y93.

2. Cohen NL, Hoffman RA. Complications of cochlear implant sur gery in adults and children. Ann Otol Rhinol Laryngol 1991;100: 708Y11.

3. Cohen NL. Medical or surgical complications related to the Nucleus multichannel cochlear implant. Ann Otol Rhinol Laryngol 1989; 98:754.

4. Webb RL, Lehnhardt E, Clark GM, Laszig R, Pyman BC, Franz BK. Surgical complications with the cochlear multiple-channel intra-cochlear implant: experience at Hannover and Melbourne. Ann Otol Rhinol Laryngol 1991;100:131-6.

5. Fayad JN, Wanna GB, Micheletto JN, Parisier SC. Facial nerve paralysis following cochlear implant surgery. Laryngoscope 2003; 113:1344-6.

6. Hehar SS, Nikolopulos TP, Gibbin KP, O'Donoqhue GM. Surgery and functional outcomes in deaf children receiving cochlear im-plants before age 2 years. Arch Otolaryngol Head Neck Surg 2002; 128:11-4.

7. Kronenberg J, Migirov L, Dagan T. Suprameatal approach: new surgical approach for cochlear implantation. J Laryngol Otol 2001; 115:283-5.

8. Kronenberg J, Migirov L, Baumgartner WD. The suprameatal approach in cochlear implant surgery: an alternative surgical approach to cochlear implantation, Otol Neurotol 2004;25:41-4.

9. Arnoldner C, Baumgartner WD, Gstoettner W, Hamzavi J. Surgical considerations in cochlear implantation in children and adults: review of 342 cases in Vienna. Acta Otolaryngol 2005;125: 228-34.

10. Migirov L, Yakirevitch A, Kronenberg J. Surgical and medical complications following cochlear implantation: comparison of two surgical approaches. J Otorhinolaryngol Relat Spec 2006;68: 213-9.

11. Carelsen B, Grolman W, Tange R, Streekstra GJ, van Kemenade P, Jansen RJ, Freling NJ, White M, Maat $B$, Fokkens WJ. Cochlear implant electrode array insertion monitoring with intra-operative 3D rotational x-ray. Clin Otolaryngol 2007;32:46-50.

12. Tange RA, Grolman W, Maat A. Intracochlear misdirection im-plantation of a cochlear implant. Acta Otolaryngol (Scand) 2006; 126:650-2.

13. Proops DW, Stoddart RL, Donaldson I. Medical, surgical and au-diological complications of the first 100 adult cochlear implant patients in Birmingham. J Laryngol Otol 1999;24:14-7.

14. Hoffman RA, Cohen NL. Complications of cochlear implant sur-gery. Ann Otol Rhinol Laryngol 1995;420-2.

15. Collins $\mathrm{MM}$, Hawthorne $\mathrm{MH}$, el Hmd K. Cochlear implantation in a district general hospital: problems and complications in the first five years. J Laryngol Otol 1997;111:325-32

16. Aschendorff A, Marangos N, Laszig RR. Complications and reim-plantation. Adv Otorhinolaryngol 1997;52:167-70.

17. Hoffman RA, Cohen NL. Complications of cochlear implant sur-gery. Ann Oto Rhinol Laryngol 1995;104:420-2.

18. Yu KCY, Hegarty JL, Gantz BJ, Lalwani AK. Conservative man-agement of infections in cochlear implant recipients. Otolaryngol Head Neck Surg 2001;125:66-70.

19. Cunningham CD, Slattery WH, Luxford WM. Postoperative infec-tion in cochlear implant patients. Otolaryngol Head Neck Surg 2004;131:109-14.

20. Antonelli PJ, Lee JC, Burne RA. Bacterial biofilms may contribute to persistent cochlear implant infection. Otol Neurotol 2004;25: 953-7.

21. Yin S, Chen Z, Wu Y, Wang L, Zhang J, Zhou W, Zhou W, Huang J, Shen Z, Qiu J. Suprameatal approach for cochlear implantation in 45 Chinese children. Int J Pediatric Otorhinolaryngol 2008;72:397-403.

22. Hausler R. Cochlear implantation without mastoidectomy: the peri-canal electrode insertion technique. Acta Otolaryngol 2002;122: 715-9.

23. Kiratzidis T. 'Veria operation': cochlear implantation without a mastoidectomy and a posterior tympanotomy. A new surgical tech-nique. Adv Otorhinolaryngol 2000;57:127-30.

24. Tange RA, Grolman W. Mastoid saving surgical approach (MASSA) and our experience with a new electrode with softip for cochlear implantation. J Ind Soc Otol 2004;2:29-32. 
(2) 69

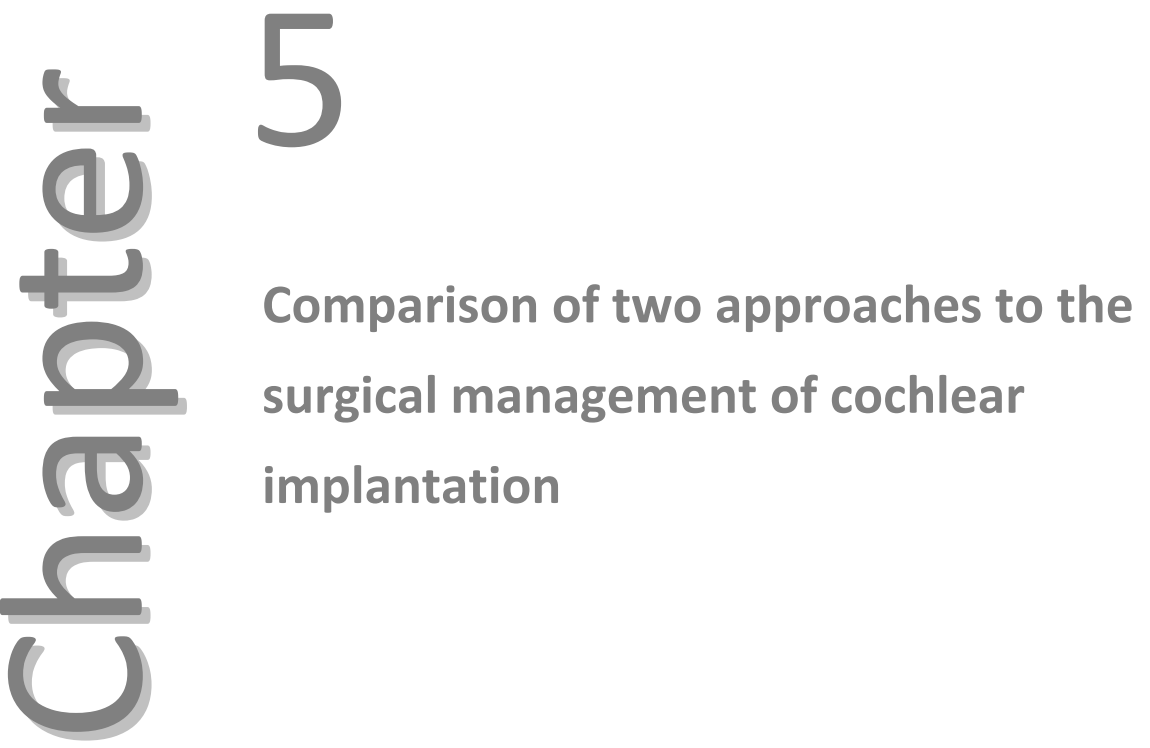

JTF Postelmans, W Grolman, RA Tange, RJ Stokroos

Laryngoscope 2009;119:151-158 


\section{Abstract}

\section{Objective}

Our study was designed to compare two surgical approaches that are currently employed in cochlear implantation.

\section{Material and method}

There were 315 patients who were divided into two groups according to the surgical technique used for implantation. The suprameatal approach (SMA) was followed for 104 patients (107 implantations) in Amsterdam while the mastoidectomy with posterior tympanotomy approach (MPTA) was adhered to for 211 (214 implantations) in Maastricht. The outcome variables of interest were duration of surgery and peri-or postoperative complications.

\section{Results}

In the SMA group the incidence of major and minor complications were $3.7 \%(4 / 107)$ and $23.4 \%$ (25/107), respectively while this was $6.5 \%(14 / 214)$ and $22.4 \%(48 / 214)$, respectively, in the MPTA group. A chi-square statistic of $1.096(p=0.295)$ and $0.021(p=0.884$,$) for minor and major$ complications, respectively, indicated no statistically significant differences between the two techniques. Mean duration of surgery was significantly shorter $(p<0.0005)$ in the SMA (111.7 minutes) than in the MPTA (132.2 minutes) groups.

\section{Conclusion}

The suprameatal approach is clearly a good alternative to the classical surgery technique for cochlear implantation. 


\section{Introduction}

Up till now, classical mastoidectomy with posterior tympanotomy (MPTA) has been the most widely used technique in cochlear implantation. The MPTA technique has proven to be efficient for the vast majority of cases. ${ }^{1-5}$ However, one main drawback of this technique is the possibility that the chorda tympani may be sacrificed and/or that the facial nerve may be injured. In the early days of cochlear implantation incidences of injury to the chorda tympani and facial nerve of 1.7 to $2.0 \%$ were not uncommon. ${ }^{6-8}$ Although there has been a decline in the incidence of injury to the chorda tympani and facial nerve in recent years, it still occurs on rare occasions. ${ }^{9,10}$ Since the introduction of the MPTA technique by House ${ }^{11}$ in 1961, several surgical strategies have been described in literature as alternatives to overcome the risk of facial nerve injury. ${ }^{12-19}$ Alternative techniques for cochlear implantation include: i) the endomeatal approach, ${ }^{12,13}$ ii) the middle fossa approach, ${ }^{14}$ iii) the mastoid tunnel technique, ${ }^{15}$ iv) the pericanal electrode insertion technique, ${ }^{16} \mathrm{v}$ ) and the suprameatal technique. ${ }^{17-19}$ Beside the reduced risk of facial injury, all these alternative techniques share the property that mastoidectomy is avoided. Individually, none of these studies have been shown to have a definite advantage relative to the widely used MPTA technique mainly because of their limited feasibility. However, this does not apply to the suprameatal technique (SMA), introduced by Kronenberg in 1999, which today seems to be gaining popularity among ear surgeons. ${ }^{17-19}$ As a result of a personal communication with Kronenberg, Yin et al. reported that so far more than 600 patients have received their cochlear implant by means of the SMA-technique. ${ }^{17,20}$ The SMA approach involves exposing the middle ear through the external auditory canal and inserting electrodes

into the cochlea through a suprameatal tunnel bypassing the mastoid cavity. ${ }^{17}$ Unlike other alternative techniques, this technique is suitable for both adults and children. Second, extrusion of the electrode through the skin of the external auditory canal is avoided by using the suprameatal tunnel.

There have been very few studies comparing the MPTA and the SMA approach with respect to complication rates and feasibility. ${ }^{21}$ The primary purpose of this study was to compare the SMA and the classical MPTA approaches to cochlear implantation with respect to surgical complications and duration of surgery.

\section{Material and methods}

\section{Patient selection}

After obtaining institutional review board approval, a retrospective chart review was conducted assessing postoperative surgical complications of all adult and pediatric patients who have undergone cochlear implantation at the Maastricht University Medical Center or the Amsterdam Medical Center. The patients were divided into two 
groups according to surgical technique. All patients who received their cochlear implant in Maastricht did so from the senior author (RJS) using the MPTA technique. Patients who underwent cochlear implantation by means of the SMA technique (Amsterdam) were treated by the other senior authors (RAT and WG). Both techniques were performed with devices from two major cochlear implant manufacturers; Cochlear (Syndney, Australia) and Advanced Bionics (Sylmar, USA). The postoperative surgical complications of 112 patients in the MPTA group have been described elsewhere. $^{1}$

The database included patients who had undergone cochlear implantation at one of the two university hospitals between January 2000 and January 2008. There were 211 patients who underwent cochlear implantation at the Maastricht University Medical Center (MPTA group) and 104 at the Amsterdam Medical Center (SMA group). The total number of procedures in the SMA group was 115 . Of these, 107 were for implantation (including 101 unilateral and 3 simultaneous bilateral procedures), 4 for explantation, and 4 for re-implantation. There were a total number of 227 procedures in the MPTA group. Of these, 214 were for implantation (including 208 unilateral and 3 simultaneous bilateral procedures), 1 for explantation without subsequent reimplantation, 9 for explantation with subsequent re-implantation and 3 explorations.

\section{Patients' demographics}

The SMA group was comprised of 85 adults and 19 children, with a mean age of 39.6 years. The MPTA group consisted of 166 adults and 45 children with a mean age of 45.3 years. In the SMA group, the mean follow up of patients 25.7 months (range 3.0-59.0 months) in contrast to 33.6 months (range 3.0-87.0 months) in the MPTA group. There was a significant difference in mean follow up and mean age at implantation ( $p=0.001, p=0.015)$, respectively. In the SMA group, the main aetiology was congenital hearing loss $(30.8 \%)$ and progressive sensorineural hearing loss e.c.i (25.0\%) followed by meningitis (12.5\%) and otosclerosis (6.7\%). In the MPTA group, both congenital hearing loss $(17.1 \%)$ and progressive sensorineural hearing loss e.c.i.(17.4\%) were the main causes of deafness. This was followed by other causes (9.3\%) and otosclerosis (8.4\%). Figure 5.1 depicts the aetiologies of deafness per group. Cause of deafness did not appear to differ significantly between the two groups.

Clinical criteria examined in each patient included age at time of implantation, cause of deafness, imaging results of the temporal bone, type of implant, time of surgery, surgical complications and follow up. Additionally, surgical complications were divided into major and minor complications as follows: 1) complications which required revision surgery or re-admission of patients to the hospital were considered as major complications and 2) those which could be resolved by conservative treatment were 
defined as minor complications. Duration of surgery was defined as the time from skin incision to closure of the wound in three layers. Consequently, time required for audiological measurement after cochlear implantation was not included in the real surgery time. There was a minimum follow up of 3 months for all patients who underwent cochlear implantation.

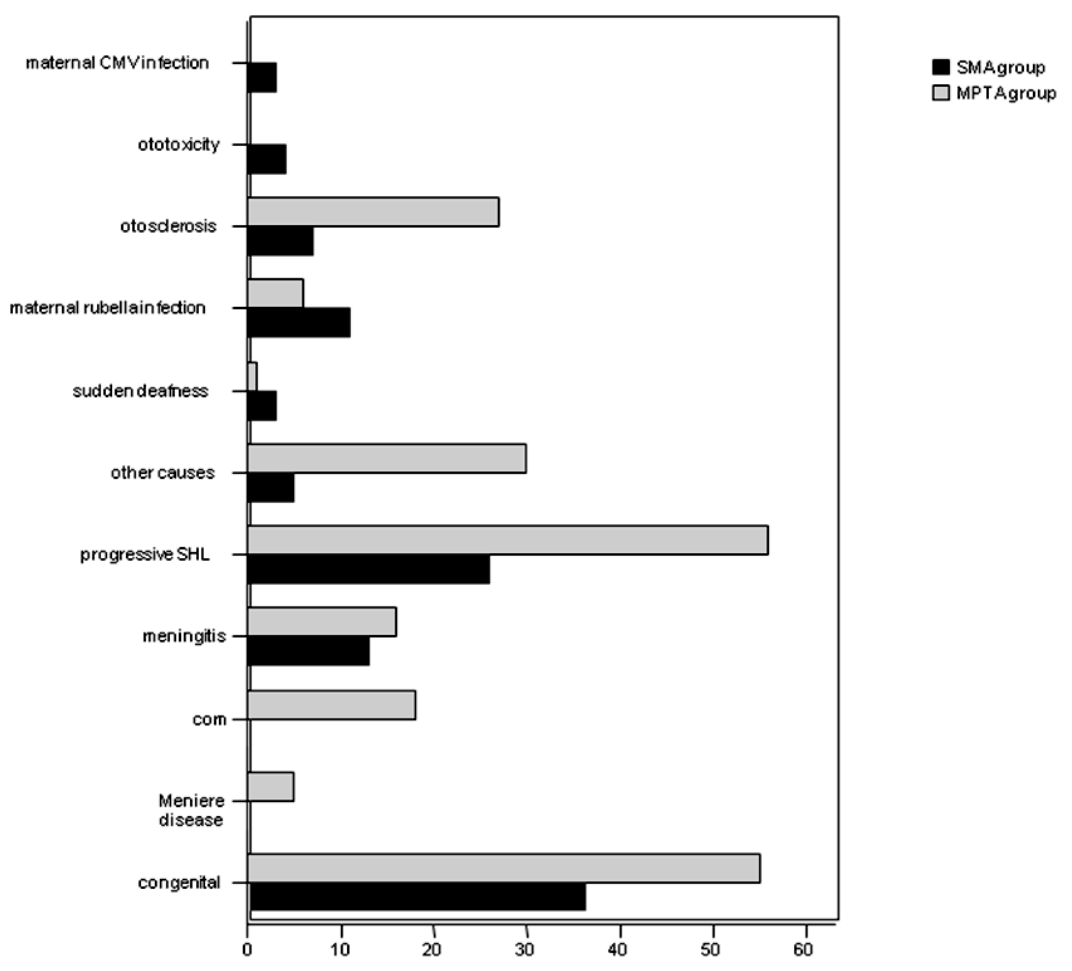

Figure 5.1 Distribution ( $\mathrm{n}$ ) of the etiology of deafness in the SMA and MPTA groups.

\section{Surgical techniques}

The MPTA technique for cochlear implantation was performed as described by Clark et al. in $1979 .^{22}$ The SMA technique used is a modification of the original procedure introduced by Kronenberg et al. ${ }^{7}$. It consists of the following steps:

(1) The middle ear cavity is entered via an endaural tympanotomy after performing a retroauricular incision of approximately 2 to 3 centimeters. This part of the approach is equivalent to a retroauricular tympanotomy approach. (Figure 5.2) 


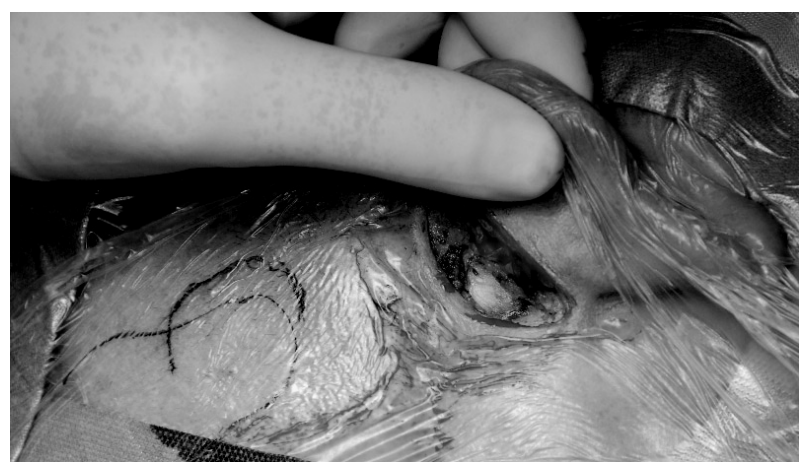

Figure 5.2 The middle ear cavity is entered via an endaural tympanotomy after performing a retroauricular incision of approximately 2-3 centimeters. This is equivalent to a retroauricular tympanotomy approach.

(2) A suprameatal tunnel is drilled superoposterior to the suprameatal spina towards the posterior part of the aditus ad antrum at 1 o'clock position for the left and the 11 o'clock right ear (Figure 5.3). Special attention is required for the middle fossa dura to avoid possible injury from drilling the suprameatal tunnel. The direction of the tunnel is in an oblique line, beneath the dura, from posterosuperior to anteroinferior. Surgical landmarks are the horizontal semi-circular canal and the body of the incus. Drilling is stopped when the body of the incus is visualized. Subsequently, a groove through the suprameatal tunnel is drilled lateral to the body of the incus to connect the antrum with the recessus epitympanicus.

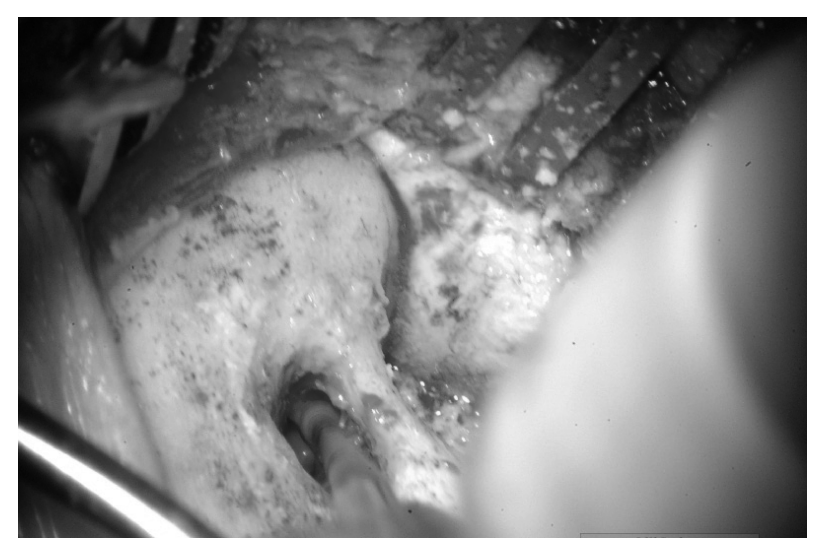

Figure 5.3 Photo through the microscope of a right ear while the SMA tunnel is being drilled. The inside of the tunnel the body of the incus has been visualized. 
(3) A second incision of 2 to $3 \mathrm{~cm}$ is made temporopartially, followed by drilling the well to accommodate the receiver-stimulator package. Creating a subperiostal connection between the two incisions gives rise to a subperiostal tunnel leaving the skin intact. The electrode array is introduced into the middle ear through the subperiostal and suprameatal tunnel, which both protect the electrode from injury (Figure 5.4)

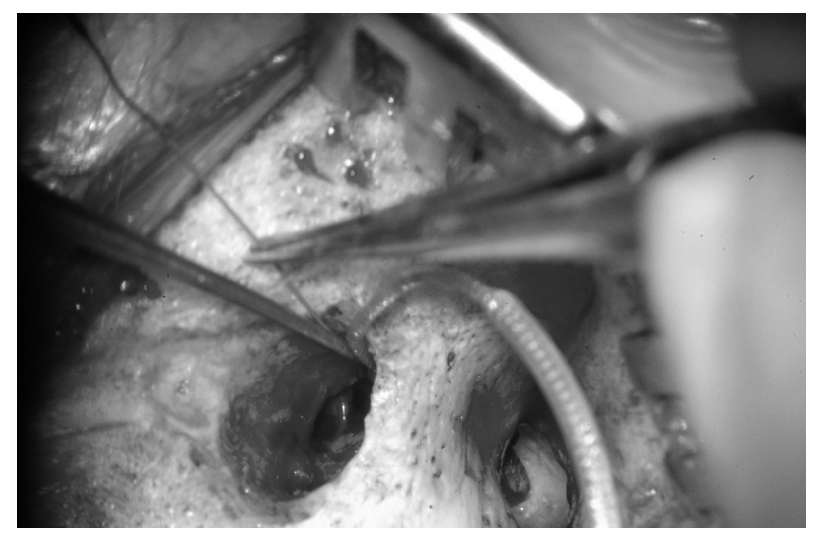

Figure 5.4 Photo through the microscope of a right ear. The electrode array is placed through the SMA tunnel passing the middle ear into the cochleostomy.

(4) The electrode is inserted into the cochleostomy, which is drilled anteroinferior to the oval window and gives access to the scala tympani (Figure 5.5). The cochleostomy is not sealed with temporal muscle or other material due to the minimal size of the cochleostomy hole. In children extra attention is placed on the positioning of the lead of the electrode to allow sufficient leeway for growth. The tympanomeatal flap is placed back and the external ear canal is packed with gauze. The two incisions are closed in 3 layers.

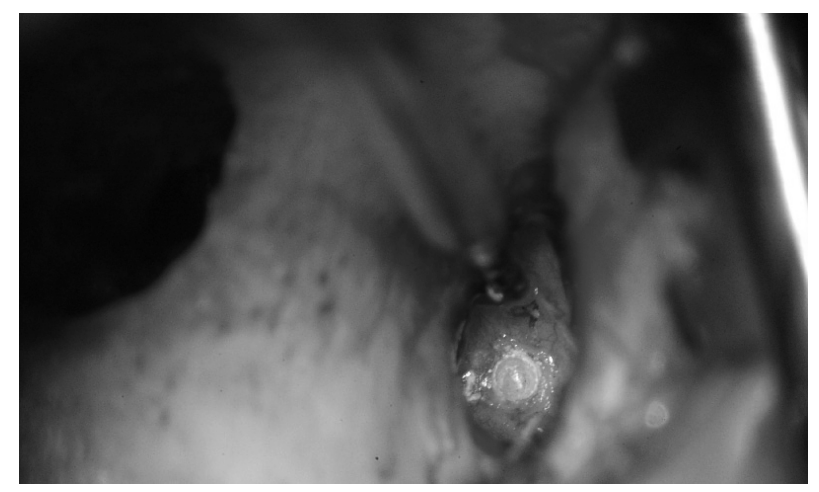

Figure 5.5 Photo through the microscope of a right ear. The cochleostomy is drilled through the external auditory canal. 
Modifications to the original procedure included making two small incisions rather than a large inverted J-shaped incision to improve wound healing. Second, the atticoantrostomy was made via the suprameatal tunnel instead of the external auditory canal to prevent injury to the external auditory skin.

\section{Intra-operative 3D X-ray images}

Among 71 patients (68.2\%) in the SMA group, a mobile digital X-ray C-arm (Philips BV Pulsera, Best, the Netherlands) was used to verify the position of the electrode in the cochlea, intra-operatively. This procedure is described elsewhere in detail. ${ }^{23}$ Scanning of the electrode array was carried out before and after removal of the stylet to confirm proper placement of the electrode.

\section{Statistical analysis}

The statistical package SPSS 11.5 was used for data analysis, with the statistical procedures: t-tests, chi-square tests and logistic regression conducted to compare the two groups.

\section{Results}

\section{Incidence of complications}

There were 4 (3.7\%) major complications in the SMA and 14 (6.5\%) in the MPTA group. This difference was not significant (Chi-square=1.096, $p=0.295)$. There were $25(23.4 \%)$ minor complications in the SMA and $48(22.4 \%)$ in the MPTA group. This difference was also not significant (Chi-square $=0.021, p=0.884$ ). After making adjustments for age, follow up, and cause of deafness through logistic regression modelling, there were no statistically significant differences in number of major nor minor complications between the two groups. However, age did appear to be associated with a higher rate of minor complications $(p=0.001)$. The older the patient the more likely that minor complications occurred in both groups.

Figure 5.6 and 5.7 depicts the number of major complication and minor complications, which occurred in both groups. Surprisingly, the number of device failures accounted for $38.9 \%$ of all major complications in the MPTA group. All minor complications were resolved within three month in both groups. Notable is the occurrence of two intermittent facial nerve paralyses in the MPTA group. Both facial nerve injuries occurred as a consequence of heat generated by the burr shaft during the posterior tympanotomy. In Figure 5.8 it can be seen that there is a decline in major complications in the MPTA group during the first two years after the onset of cochlear implantation. After these first two years the incidence of major complications stabilizes. In contrast to the MPTA group, all major complications in the SMA group 
occurred in the first two years. Because of the relative later onset time of the SMA procedures, it was not possible to observe a clear trend.

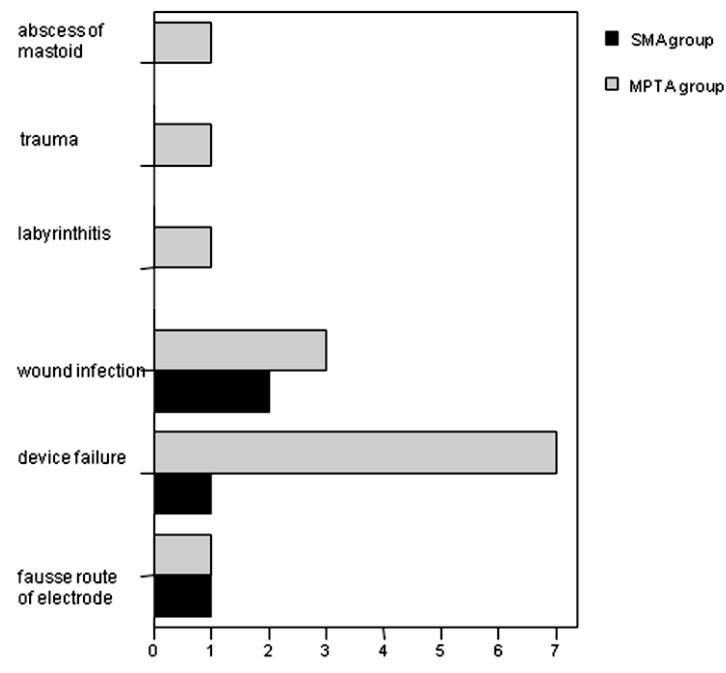

Figure $5.6 \quad$ Types of major complications for both groups.

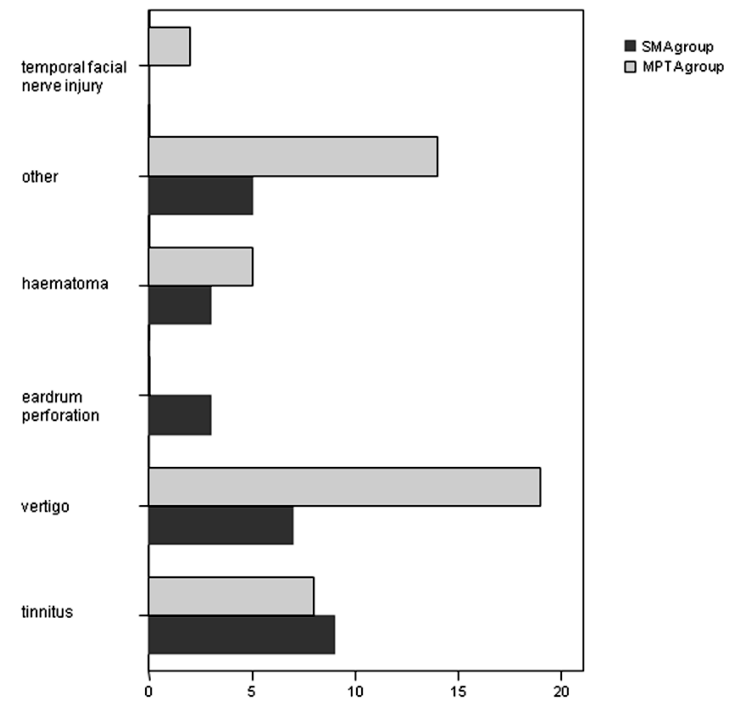

Figure 5.7 Minor complications in both groups. 


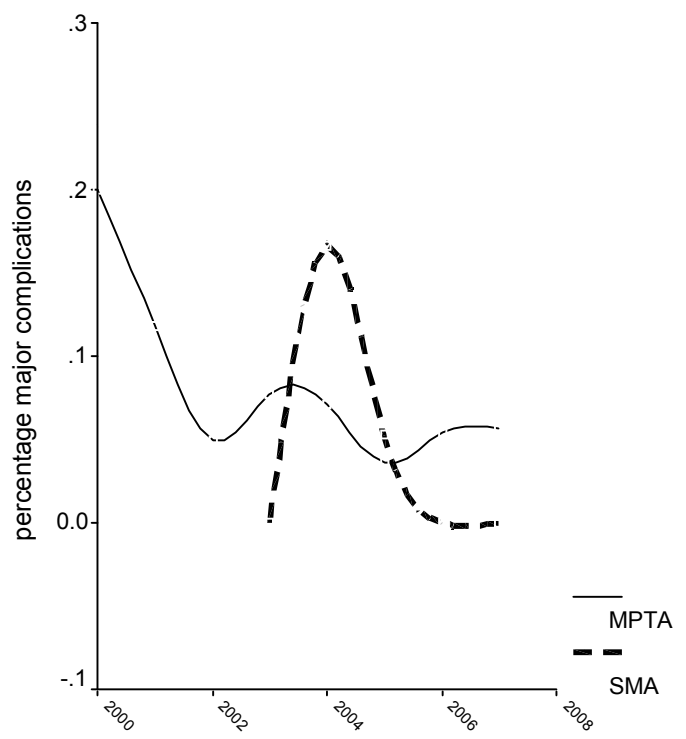

Figure 5.8 Percentage major complications relative to study period. A decline in incidence occurs in the first two years after onset of the cochlear implant programme in the MPTA group. There is no clear trend with respect to the SMA group.

\section{Major complications in the SMA group}

In two patients explantation of the device was required as a consequence of a wound infection surrounding the receiver-stimulator package. In one case a late wound infection with fistula formation developed one year after surgery. Despite antibiotic therapy, the wound infection persisted and explantation of the cochlear device was required. Cause of infection might be attributed to clinical occult contamination of the device by a haematoma, which developed immediately after surgery. In the second case a skin reaction attributed to multiple subcutaneous sutures evolved into a wound infection. Subsequent revision of the skin with removal of the sutures and adequate antibiotic therapy did not ward off progression of the infection. Eventually, the implant had to be removed. Both patients who underwent explanation of the device were reimplanted successfully at a later time. The two remaining major complications in the SMA group included a fausse route of the electrode and a device failure. The complication with a fausse route has been described in a previous report. ${ }^{24}$ In one patient, progressive deterioration of the patients' speech recognition indicated there was a device failure. Audiological tests one year after implantation showed that six electrodes were malfunctioning, while audiological tests performed directly after cochlear implantation had not indicated any dysfunction. The implant was removed and subsequent re-implantation was performed with satisfactory audiological outcomes. The complaints of this patient were confirmed by measurement of the 
device integrity by the manufacturer, which eventually showed malfunctioning of six electrodes.

\section{Major complications in the MPTA group}

In two patients, one child, one adult, subsequent surgical interventions were needed due to a traumatic luxation of the device magnet. ${ }^{25}$ In the case of the child, reposition of the device was sufficient to ward off possible extrusion of the implant. In the adult case, however, the implant had penetrated through the skin. During revision surgery it turned out that the well was filled with granulation tissue. For that reason a new well was drilled approximately 3 centimetres beneath the pre-existing one. Six months after this revision surgery, the implant again tended to extrude requiring re-exploration. The implant was rotated cranially and placed into the original well. Eventually the device was explanted as a consequence of persisting flap problems and six months later a successful re-implantation was performed.

With respect to wound infection related complications, three patients could be identified in the MPTA group. In one child an acute otitis media induced a mastoiditis with abscess formation, which was managed by evacuation of the abscess with preservation of the implant. Supplement treatment consisted of ear drains and antibiotic therapy. Another patient developed a wound infection which was induced by a flaring up of chronic otitis media. Efforts to save the cochlear implant by antibiotic therapy and rotating the device cranial under the temporal muscle were not successful. Explanation of the device was required and successful re-implantation was carried out by way of staged surgery one year later. Another patient developed a fistula as a consequence of wound infection four month after cochlear implantation. Antibiotic therapy could not ward off subsequent surgery. The implant was rotated and placed beneath the temporal muscle, which resulted in a satisfactory postoperative outcome.

With respect to device failures, 7 of the 214 patients (3.2\%) could be identified who all underwent explantation and subsequent successful re-implantation. In one patient a fausse route of the electrode accounted for postoperative vertigo and facial nerve stimulation. CT images of the temporal bone showed the tip of the electrode lying in the vestibulum. During re-exploration, the cochleostomy was enlarged and thereafter the electrode was re-inserted in the scala tympani. The correct position of the electrode was verified with a mobile X-ray intra-operatively.

\section{Time of surgery}

In this study, another point of interest was the difference in surgery time between the two groups. Unsurprisingly, the mean duration of surgery varied greatly according to the surgical technique applied. The mean surgery time was 111.7 minutes for the SMA and 132.2 minutes for the MPTA group, and this difference of 20.5 minutes was 
statistically significant $(p<0.0005)$. Logistic regression was applied to determine the effect of deafness on surgery time. The adjusted time difference was 18.7 minutes, with still a statistically significantly shorter surgery time for the SMA group. When surgery time is plotted against the study period for the MPTA group, a reduction in surgery time can be observed within the first four years (Figure 5.9). Mean surgery time was 300 minutes at the onset of the cochlear implantation programme and this levelled off to a plateau of 100 minutes. Apparently there is a learning curve with respect to duration of surgery which is maintained for four years after onset of the cochlear implant programme. Moreover, surgery time for the MPTA eventually corresponds to that of the SMA group, which arrives at a rather consistent value immediately. No decline in surgery time is then observed in the SMA group.

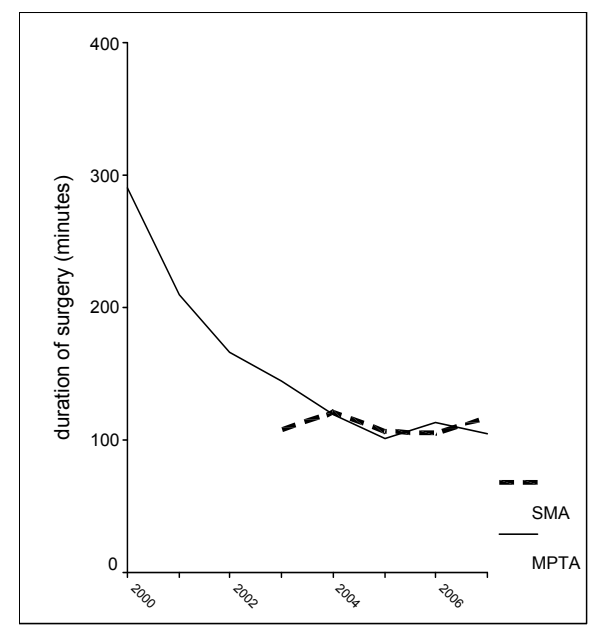

Figure 5.9 Duration of surgery of both groups is plotted against study period. A significant reduction in duration of surgery occurs for the MPTA procedure after initial onset.

\section{Discussion}

This study showed no difference in complication rates in cochlear implantations by means of the potentially more hazardous MPTA procedure than with the SMA procedure. These findings are in keeping with a previous study of Migirov et al. which showed that the SMA procedure is as safe as the classic MPTA procedure. ${ }^{21}$ There was however a significant difference in surgery time. The SMA procedure had a mean surgery time of 111.7 minutes compared to 130.1 minutes for the MPTA procedure. These time differences were only present during the first four years following the initial cochlear implantation in the MPTA group (Figure 5.9). 
Although this study shows that the incidence of complications using the SMA procedure is in keeping with the classic MPTA procedure; there are still some drawbacks and also advantages which deserve attention.

\section{Drawbacks}

To date, many surgeons attempt to reduce the risk of damage to the interior of the cochlea by means of soft surgery introduced by Lenhardt in $1993 .{ }^{26}$ The concept of "soft surgery" for cochlear implantation consists of a small, localized cochleostomy and gentle electrode insertion, the hope being that by limiting damage to the inner ear, conservation of the preoperative residual hearing thresholds may be maintained. However, in the SMA technique the possibility of observing the interior of the cochlea is compromised. In contrast to the MPTA technique visualization of the cochleostomy site is obtained transmeatally with a perpendicular view of the status of the interior of the cochlea. This deters ability to observe the course of the tip of the electrode array along the basal turn after insertion relative to the oblique view onto the cochlea via the facial recess approach. Therefore, we have chosen to verify the position of the electrode after removal of the stylet by means of a mobile digital X-ray C-arm (Philips BV Pulsera, Best, the Netherlands) per-operatively. Although the position of the electrode in the cochlea can be observed this technique does not rule out displacement of the electrode to another scala. Another study will be devoted to determining and evaluating the position of the electrode by means of multi-slice computer tomography.

Second, in contrast to the MPTA procedure the SMA technique includes an increased risk of electrode kinking as a consequence of the 30 degrees more superiorly insertion of the electrode. This potential drawback of bending over of the electrode to overcome the steep angle has been illustrated in Figure 5.10. Although this alternative insertion technique raises the risk of injuring the electrode array, neither published reports nor our results confirm this concern. Therefore, the absence of device failure in the SMA group as a consequence of electrode kinking is unique. Another point of concern regarding the SMA procedure is the relatively more steep insertion of the electrode which increases the risk of rotating the electrode in an upward direction as a consequence of touching the outer wall of the scala tympani when the electrode is being pushed forward for further electrode insertion. This ruptures the basal membrane and the integrity of the scala media which may result in a loss of all preexisting residual hearing.

Third, introduction or expansion of the pre-existing conductive hearing loss may occur as a consequence of perioperative damage or fixation of the incus. This is then an additional hazard toward the objective of maintaining the level of residual hearing. Particularly in patients with a low-lying dura it is difficult to create the suprameatal tunnel. For example, there was one patient for whom the incus had to be removed as a consequence of the low-lying dura. Because this patient had no residual hearing left it 
did not influence the patients' speech understanding. In patients with a profound sensorineural hearing loss iatrogenic dislocation of the incus will probably have a minimal effect on the remaining residual hearing. This does not account for the patients with a ski slope audiogram, for whom hearing preservation has the highest priority.

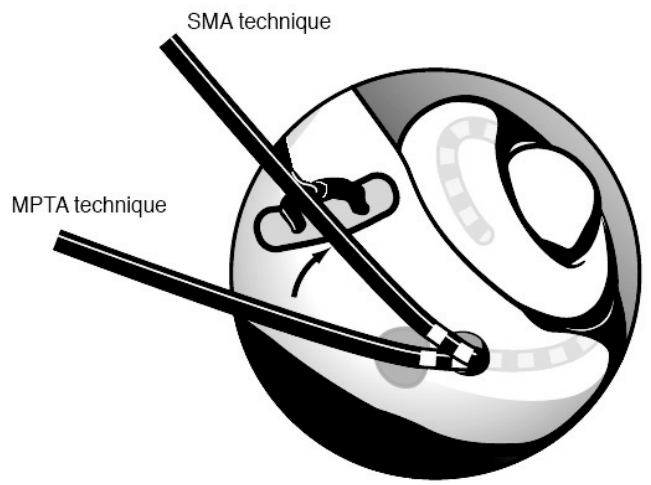

Figure 5.10 The difference in electrode directions for the two groups. Notable is that the electrode in the SMA group has to be bent over slightly for insertion in the cochleostomy site.

\section{Advantages}

First, the SMA procedure provides a better exposure of the electrode due to direct access of the middle ear contents compared to the classic MPTA technique. Incidentally, it is needed to remove bone from the posterior wall of the external ear canal in a posterosuperior direction to obtain a wider view of the middle ear contents which facilitates electrode maneuverability. Yin et al. described additional bone removal after elevation of the tympanomeatal flap in all forty-five Chinese pediatric cases because of differences due to race in the structure, shape, and dimension of the cranium. ${ }^{20}$ However, after removing some bone from the wall of the external auditory canal posterosuperior to the chorda tympani, the exposure was wide enough so that the cochlear promontory, oval window, and round window niche were completely visible.

Second, exclusion of the mastoidectomy and posterior tympanotomy account for a decline in surgery time when compared to inexperienced or moderately experienced ear surgeons performing cochlear implantations using the MPTA technique. Figure 5.9 shows a significant difference between surgery time after onset of the cochlear implant programme between the two groups. It is not surprising that there is a learning curve for the MPTA procedure as it is comprised of relatively more different 
surgical procedures. Thus, when only considering more experienced ear surgeons there is no difference in surgery time between the two procedures.

Third, in drilling the suprameatal tunnel, the body of the incus protects the facial nerve from injury. Introducing the electrode via the suprameatal tunnel into the middle ear spares the chorda tympani. In the SMA group no injury to the facial nerve and chorda tympani was observed. In contrast, in the MPTA group two cases were identified with temporary facial paralysis. With respect to the danger of sacrificing the chorda tympani, Lloyd et al. reported an alteration in subjective taste sensation in almost half of the study group who underwent cochlear implantation $(n=94){ }^{27}$ Eventually, 18 patients (19\%) experienced a permanently altered taste sensation after follow up (mean 51 months). Furthermore, Lloyd noticed a difference in resolution of the symptoms according to whether the chorda tympani was preserved or divided. ${ }^{27}$ Resolution of the symptoms was more likely when the chorda tympani was divided. In contrast to Lloyd et al., Mueller et al. observed a significant difference in objective taste scores after cochlear implantation while only one patient experienced subjective loss of taste. ${ }^{27,28}$ In general, the incidences of altered taste sensation in patients undergoing cochlear implantation by means of the MPTA procedure is in keeping with middle ear surgery for noninflammatory disease such as a stapedotomy. Although the chorda tympani is clearly exposed in the SMA procedure, it is nevertheless conceivable that micro traumata may occur during the procedure which as a consequence alters taste. Although no patients complained about taste differences in the SMA group, this study is lacking in that it has not included an objective measurement of taste pre- and postoperatively.

\section{Study limitations}

This multicenter retrospective study is characterized, with its design at two locations each with their own approaches, by an inherent selection bias. In other words the patients were not randomized to one of the two therapeutic approaches. The MPTA group was older and it appeared that age is associated with more minor complications although this did not result in a difference in rate of minor complications between the two groups. Another limitation is the relatively short follow-up duration of less than 3 years in the SMA group. The differences in the positioning of the electrode in the cochlea of both techniques will soon be addressed in a prospective study by comparing the position of the electrode by means of multislice computer tomography.

\section{Conclusions}

Although we could not demonstrate a reduction in postoperative complications using the SMA technique as compared to the MPTA approach, the SMA technique has been demonstrated to be a simple and safe technique. There are so few existing studies comparing the SMA and MPTA techniques that more studies are needed to substantiate our findings. 


\section{References}

1. Postelmans JT, Cleffken B, Stokroos RJ. Post-operative complications of cochlear implantation in adults and children: five years' experience in Maastricht. J Laryngol Otol. 2007;121:318-23.

2. Rama-Lopez J, Cervera-Paz FJ, Manrique M. Cochlear implantation of patients with far-advanced otosclerosis. Otol Neurotol. 2006;27:153-8.

3. Proops DW, Stoddart RL, Donaldson I. Medical, surgical and audiological complications of the first 100 adult cochlear implant patients in Birmingham. J Laryngol Otol Suppl 1999;24:14-7.

4. Hoffman RA, Cohen NL. Complications of cochlear implant surgery. Ann Otol Rhinol Laryngol Suppl 1995;166:420-2.

5. Collins MM, Hawthorne $\mathrm{MH}$, el-Hmd K. Cochlear implantation in a district general hospital: problems and complications in the first five years. J Laryngol Otol 1997;111: 325-32.

6. Cohen NL, Hoffman RA. Complications of cochlear implant surgery in adults and children, Ann. Otol. Rhinol. Laryngol. 1991;100:708-11.

7. Cohen NL. Medical or surgical complications related to the Nucleus Multichannel Cochlear Implant, Ann. Otol. Rhinol. Laryngol. 1989;98:754.

8. Webb RL, Lehnhardt E, Clark GM, Laszig R, Pyman BC, Franz BK. Surgical complications with the cochlear multiple-channel intracochlear implant: experience at Hannover and Melbourne, Ann. Otol. Rhinol. Laryngol. 1991;100:131-6.

9. Fayad JN, Wanna GB, Micheletto JN, Parisier SC. Facial nerve paralysis following cochlear implant surgery, Laryngoscope 2003;113:1344-6.

10. Hehar SS, Nikolopoulos TP, Gibbin KP, O'Donoghue GM. Surgery and functional outcomes in deaf children receiving cochlear implants before age 2 years, Arch. Otolaryngol. Head Neck Surg. 2002;128:11-4.

11. House WF. Cochlear implants, Ann. Otol. Rhinol. Laryngol. 1976;85:1-93.

12. Banfai P, Kubik S, Hortmann G. Our extra-scalar operating method of cochlear implantation. Experience with 46 cases, Acta Otolaryngol. Suppl. 1984;41:9-12.

13. Chouard $\mathrm{CH}$, MacLeod P. Implantation of multiple intracochlear electrodes for rehabilitation of total deafness: preliminary report, Laryngoscope 1976;86:1743-51.

14. Colletti V, Fiorino FG, Carner M, Pacini L. Basal turn cochleostomy via the middle fossa route for cochlear implant insertion, Am. J. Otol. 1998;19:778-84.

15. Kiratzidis T. 'Veria operation': cochlear implantation without a mastoidectomy and a posterior tympanotomy. A new surgical technique, Adv. Otorhinolaryngol. 2000;57:127-30.

16. Hausler R. Cochlear implantation without mastoidectomy: the pericanal electrode insertion technique, Acta Otolaryngol. 2002;122:715-9.

17. Kronenberg J, Migirov L, Dagan T. Suprameatal approach: new surgical approach for cochlear implantation, J. Laryngol. Otol. 2001;115:283-5.

18. Kronenberg J, Migirov L, Baumgartner WD. The suprameatal approach in cochlear implant surgery: our experience with 80 patients, ORL J. Otorhinolaryngol. Relat. Spec. 2002;64: 403-5.

19. Kronenberg J, Baumgartner WD, Migirov L, Dagan T, Hildesheimer M. The suprameatal approach: an alternative surgical approach to cochlear implantation, Otol. Neurotol. 2004;25:41-5.

20. Yin S, Chen Z, Wu Y, Wang L, Zhang J, Zhou W, Zhou W, Huang J, Shen Z, Qiu J. Suprameatal approach for cochlear implantation in 45 Chinese children, Int J Pediatric Otorhinolaryngol 2008;72:397-403.

21. Migirov L, Yakirevitch A, Kronenberg J. Surgical and medical complications following cochlear implantation: comparison of two surgical approaches. ORL J Otorhinolaryngol Relat Spec. 2006;68: 213-9.

22. Clark GM, Patrick JF, Bailey Q. A cochlear implant round window electrode array. J Laryngol Otol. 1979;93:107-9.

23. Carelsen B, Grolman W, Tange R, Streekstra GJ, van Kemenade P, Jansen RJ, Freling NJ, White M, Maat B, Fokkens WJ. Cochlear implant electrode array insertion monitoring with intra-operative 3D rotational X-ray. Clin Otolaryngol. 2007;32:46-50.

24. Tange RA, Grolman W, Maat A. Intracochlear misdirection implantation of a cochlear implant. Acta Otolaryngol 2006;126:650-2 
25. Stokroos RJ, van Dijk P. Migration of cochlear implant magnets after head trauma in an adult and a child. Ear Nose Throat J. 2007;86:612-3.

26. Lehnhardt E. Intracochlear placement of cochlear implant electrodes in soft surgery technique HNO. 1993;41:356-9.

27. Lloyd S, Meerton L, Di Cuffa R, Lavy J, Graham J. Taste change following cochlear implantation. Cochlear Implants Int. 2007;8:203-10.

28. Mueller CA, Khatib S, Temmel AF, Baumgartner WD, Hummel T. Effects of cochlear implantation on gustatory function. Ann Otol Rhinol Laryngol. 2007;116:498-501. 

(2) 87

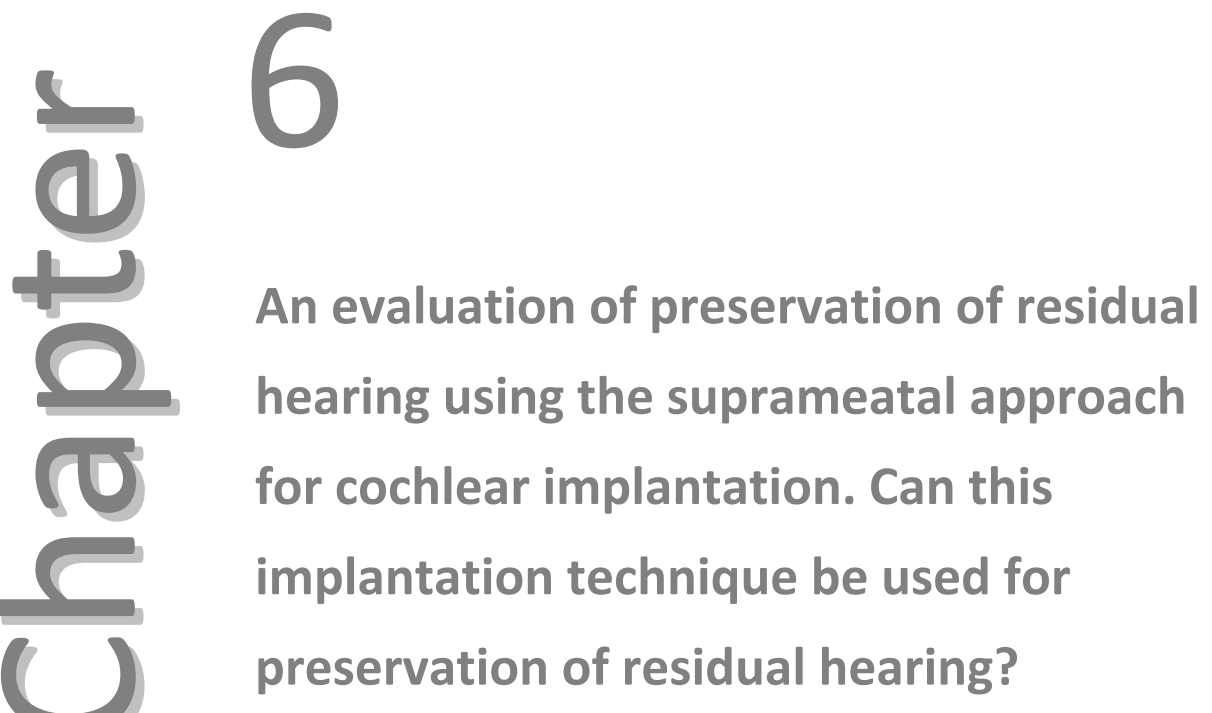

JTF Postelmans, E van Spronsen, W Grolman, RJ Stokroos, RA Tange, MJ Maré, WA Dreschler Laryngoscope 2011;121:1794-1799 


\section{Abstract}

\section{Objective}

This study was designed to test the hypothesis that preservation of residual hearing after cochlear implantation by means of the suprameatal approach (SMA) for cochlear implantation is possible using standard electrode arrays with full-length insertions.

\section{Material and methods}

In 109 severely to profoundly hearing impaired patients pre- and postoperative pure tone thresholds were analyzed by three independent analyses to observe the degree of hearing preservation.

\section{Results}

Single-subjects results showed a complete conservation of residual hearing ( $\triangle P T A \leq 10 \mathrm{~dB}$ ) in 27 out of 109 patients $(25.2 \%)$. Partial conservation of residual hearing ( $\triangle$ PTA $>10 \mathrm{~dB}$ ) was observed in 77 patients (72.0\%). However, these percentages have been affected severely by ceiling effects. Furthermore, group-subjects results demonstrated that the median postoperative PTA was $11.7 \mathrm{~dB}$ worse than the pre-operative PTA. For individual frequencies the median deteriorations were $15,20,10$, and $5 \mathrm{~dB}$ at $250 \mathrm{~Hz}, 500 \mathrm{~Hz}, 1000 \mathrm{~Hz}, 2000 \mathrm{~Hz}$, respectively. Stratification for absence of postoperative hearing thresholds showed a conservation of measurable postoperative hearing levels in $17.4 \%(19 / 109)$ of all study patients.

\section{Conclusion}

The results of this study demonstrate that complete preservation of residual hearing is possible in a limited number of patients using the SMA technique for cochlear implantation. 


\section{Introduction}

Since the introduction of the mastoidectomy with posterior tympanotomy approach (MPTA) technique by House in 1961, this technique has proven to be efficient and safe in the majority of cases. ${ }^{1-4}$ Nevertheless, several surgical strategies have been described in literature as alternative cochlear implantation techniques to overcome the potential facial paralysis and injury to the chorda tympani. ${ }^{5-9}$ Among the several alternative surgical approaches, the suprameatal approach (SMA) is the most frequently used implantation technique in literature and is still gaining popularity among ear surgeons. ${ }^{8,9}$ The SMA technique was introduced by Kronenberg in 1999, in which the electrode of the cochlear implant is introduced into the middle ear via a suprameatal route. ${ }^{8,9}$ This technique is characterized by several advantages compared to the MPTA technique, such as 1) the exclusion of a mastoidectomy and posterior tympanotomy which improves the aesthetic results with no retroauricular bony defect and 2) reduction of time of surgery. Furthermore, 3 ) the facial nerve is a safe distance from the suprameatal tunnel and is protected by the body of the incus. Nevertheless, this technique received both criticism and praise since its introduction in 1999, because this technique was very different from the past practice of ear surgeons. ${ }^{8,9}$ In general, there were multiple comments on this technique. ${ }^{8,9}$ First, it was believed that the SMA technique required skills not usually exercised by otologic surgeons. Second, it seemed to be a blinded dissection. Third, it included the placement of electrodes and other devices in a groove in the ear canal. Fourth, the SMA technique is characterized by a $30^{\circ}$ more superior insertion of the electrode compared to the MPTA technique. The more superior insertion might increase the risk of rotating the electrode in an upward direction as a consequence of touching the outer wall of the scala tympani when the electrode is being pushed forward for further electrode insertion. This might rupture the basal membrane and the integrity of the scala media, which may result in a loss of all pre-existing residual hearing. ${ }^{10,11}$ The first three critical comments have been contradicted by the results described in several studies in which the SMA technique has proven to be safe and efficient surgical technique for cochlear implantation. ${ }^{8-12}$ With respect to the latter comment, the question whether the SMA technique is appropriate for preserving residual hearing has never been addressed. It is important to investigate whether preservation of residual hearing after cochlear implantation using the SMA technique is possible as cochlear implant surgeons now wish to preserve residual hearing. Residual hearing in implantees has been shown to increase hearing performance in difficult or noisy listening environments, improve music perception and appreciation, and gives sound and voices a more natural quality. ${ }^{14-16}$ Therefore, the aim of this study is to evaluate the preservation of residual hearing after cochlear implantation with the SMA technique. The results could give an indication whether the SMA technique can play a role in the preservation of residual hearing or not. 
In accordance to other studies which investigated the preservation of residual hearing after cochlear implantation, alteration of pre-and postoperative thresholds in this study are assessed in patients with a severe to profound hearing loss near the capacity of the audiometer. In order to overcome this ceiling effect several calculation methods have been used in literature. ${ }^{16-25}$ These calculation methods may induce an overestimation of the degree of conservation of hearing in particular studies. Therefore, a second goal of this study was to introduce an alternative analysis besides the calculation methods that are usually applied in order to document the conservation of hearing after cochlear implantation more accurately.

\section{Methods and materials}

\section{Patients' selection criteria}

A retrospective chart review was conducted to retrieve pre- and postoperative hearing levels from every consecutive patient who underwent unilateral cochlear implantation at the department of Otolaryngology- Head and Neck Surgery, Academic Medical Centre during an 5-year period from January 2003 to January 2008. During this period, 113 cochlear implant operations were performed by the third author. Inclusion criteria for this study were: 1) Dutch as a primary language, 2) no revision surgery, 3) compliance with follow-up examinations and 4) some measurable hearing preoperatively. This latter was defined as measurable hearing thresholds at least at 1 audiometric frequency. Of the total amount of patients, we had to exclude 4 cases from analysis because major complications occurred postoperatively. Both 4 patients had to undergo revision surgery as a consequence of explantation of the device due to wound infection $(n=2)$, fausse route of the electrode $(n=1)$ and device failure $(n=1)$. The remaining 109 cases were considered for analysis.

Three different types of cochlear implants were used for implantation; the Nucleus 24 Countour (Cochlear Corp, Lane Cove, Australia), the Nucleus 24 Countour Advance with Softip (Cochlear Corp, Lane Cove, Australia), and Advanced Bionics HiFocus Helix (Advanced Bionics, Valencia, CA).

\section{Audiometric evaluation}

All pre-implantation and post-implantation audiometric testing was performed using an Interacoustics AC40 with TDH-39 headphones, calibrated to ISO-389 with adequate masking (if necessary) and in a sound-proof booth. In this study, we concentrated on audiometric thresholds at octave frequencies from $250 \mathrm{~Hz}$ to $2000 \mathrm{~Hz}$. For the determination of residual hearing loss, it is relevant to note that the maximum output levels of the audiometers allowed thresholds to be measured up to $110 \mathrm{~dB} \mathrm{HL}$ at 
$250 \mathrm{~Hz}$ and up to $120 \mathrm{~dB}$ for frequencies 500 to $2,000 \mathrm{~Hz}$. Baseline audiograms were obtained at the time of the patients' initial pre-implant evaluation. Any response reported as vibrotactile or questionably vibrotactile was considered as no response. Furthermore, postoperative audiograms were performed in identical test conditions at least 6 months after surgery and they were measured without the use of the external processor of the implant.

\section{Surgical technique}

In this study, the SMA technique was used for all cochlear implantations. The surgical technique used in this study was a modification to the original procedure introduced by Kronenberg et al. in 1999., ${ }^{8,9}$ For a more detailed description of this technique and additional photographs we refer to previous published studies of the first author. ${ }^{10,11}$ The elected surgical technique in our series was the conventional one, which includes minimal cochleostomy (anteroinferior to the round window membrane) and perilymph preservation only.

\section{Statistical analysis}

Postoperative audiograms obtained six months after implantation were evaluated to determine the difference between pre- and postoperative thresholds. All data were entered into a computer database and analyzed with a spreadsheet program. As a consequence of the severe or profound preoperative hearing losses, a large number of postoperative thresholds could not be measured because they exceeded the maximum output of the audiometer. It is important to consider these limitations due to the capacity of the audiometer, because data of preoperatively or postoperatively unmeasurable hearing thresholds could wrongly be excluded from analysis. This means that severe loss of residual hearing would then not be taken into account. In order to document the audiometric effects as accurately as possible and avoid selection bias, we applied not only analysis techniques as used earlier by Kiefer and James et al., ${ }^{17,18}$ but we also developed a third method ourselves.

I) According to Kiefer et al., pure- tone averages (PTAs) were calculated for the frequencies 250,500 and $1.000 \mathrm{~Hz} .{ }^{17}$ Nominal value of the maximum output of the audiometer $\left(f_{\max }\right)$ plus $5 \mathrm{~dB}$ was assigned if there was no response up to the limit of the maximum output of the audiometer at a given frequency. The pre- and postoperative PTA differences were categorized according to Balkany et al.: complete hearing conservation (0-10d B), partial hearing conservation ( $>11 \mathrm{~dB}$ or more), and a group in which no change could be assessed, because the audiometric thresholds were above $f_{\max }$, both for pre- and post-operative audiometry. ${ }^{21}$ With respect to complete hearing conservation, the $10-\mathrm{dB}$ variation was accepted as within normal audiological fluctuations as it is frequently seen in subjects undergoing repeated audiometric testing under identical situations. 
II) According to James et al., we recorded the thresholds beyond the $f_{\max }$ as "not measurable" (NM) to encounter the potential overestimation of conservation in case of using an artificial value by means of the $f_{\max }$ plus $5 \mathrm{~dB}$ as described above. ${ }^{18}$ Rather than calculating average values, they analyzed the shifts of the population medians by means of median values obtained for each test frequency. NM values were considered as "very large" levels so that they are always found at high end of the distribution of data points for each frequency, either for the post-operative levels or for the corresponding differences of pre- to postoperative thresholds. The non-numeric value of NM is encountered by using the median instead of the mean which enables the possibility to use all differences of pre- and postoperative thresholds to offer a valid measure of central tendency of the degree of preservation of hearing as long as less than $50 \%$ has the value NM.

III) The third analysis was obtained by subdividing the patients in 4 groups according to the presence or absence of PTA pre-and postoperative hearing levels. PTA hearing levels were considered as measurable when pre- and postoperative thresholds did not exceed the $f_{\max }$ at frequency 250,500 , and $1000 \mathrm{~Hz}$ and could be recorded by the audiologist. Moreover, pre- or postoperative hearing thresholds were assigned as non measurable (NM) when the postoperative were beyond the $f_{\max }$ of the audiometer. Group 1 consisted of all patients in whom a pre- and postoperative threshold could be recorded. Patients with measurable preoperative thresholds but NM thresholds postoperatively were included in group 2. Group 3 consisted of patients with a measurable postoperative hearing level, but with the absence of recorded preoperative hearing levels. The remaining patients were included in group 4 which consisted of all patients with NM thresholds pre- and postoperatively. Complete reservation of residual hearing was considered if pre- and post hearing levels showed a change of $\leq 10 \mathrm{dBHL}$ or less. Partial conservation was defined as a deterioration of $\geq 10 \mathrm{dBHL}$ post-operatively, but still with measurable hearing.

\section{Results}

In this study, 109 patients were included who underwent cochlear implantation using the SMA technique without the occurrence of major postoperative complications. The calculation of the degree of preservation of residual hearing was evaluated applying the three different analyses which are described above.

\section{Single-Subject Results according to Kiefer et al. ${ }^{17}$}

Complete conservation of residual hearing $(\triangle \mathrm{PTA} \leq 10 \mathrm{~dB})$ for the average audiometric thresholds at 250, 500, and $1000 \mathrm{~Hz}$ occurred in 27 patients (24.7\% 27/109). Furthermore, partial conservation of residual hearing $(\triangle P T A>10 \mathrm{~dB}$ ) was present in 
77 patients (70.6 \% 77/109). In 5 patients the level of conservation of residual hearing could not be assessed (Table 6.1). The mean PTA was $97.1 \mathrm{dBHL}$ (SD $\pm 15.5 \mathrm{dBHL}$ ) and $115.6 \mathrm{dBHL}$ ( $\mathrm{SD} \pm 8.1 \mathrm{dBHL}$ ) pre- and postoperative, respectively. Thus, at the time of post-implant testing, mean PTA for the entire group of 109 patients decreased at least by $18.5 \mathrm{dBHL}$. Figure 6.1 shows a scatterplot of the relationship between individual pre -and postoperative PTA thresholds after cochlear implantation. All dots between the black diagonal straight lines represent patients in whom the residual hearing did not change significantly $( \pm 10 \mathrm{~dB})$.

Table 6.1 Percentage hearing conservation and mean changes in pure-tone average pre-implant and post-implant according to Kiefer et al.

\begin{tabular}{|c|c|c|c|c|c|}
\hline $\begin{array}{c}\text { Preop PTA }{ }^{1} \\
(\mathrm{dbHL})\end{array}$ & $\begin{array}{c}\text { Postop PTA }{ }^{1} \\
(\mathrm{dbHL})\end{array}$ & $\triangle$ PTA $(\mathrm{dB})$ & $\begin{array}{c}\text { Complete hearing } \\
\text { conservation }^{2}\end{array}$ & $\begin{array}{l}\text { Partial hearing } \\
\text { conservation }^{2}\end{array}$ & $\begin{array}{l}\text { Loss of residual } \\
\text { hearing }\end{array}$ \\
\hline $\begin{array}{l}97.1 \mathrm{dBHL} \\
(\mathrm{SD} \pm 15.5)\end{array}$ & $\begin{array}{c}115.6 \mathrm{dBHL} \\
(\mathrm{SD} \pm 8.1)\end{array}$ & $18.5 \mathrm{~dB} \mathrm{HL}$ & $25.2 \%(27 / 109)$ & $72.0 \%(77 / 109)$ & $4.8 \%(5 / 109)$ \\
\hline
\end{tabular}

${ }^{1}$ PTA was calculated as an average of thresholds at 250,500 and $1000 \mathrm{~Hz}$. In case of exceeding the maximum output of the audiometer fmax +5 was assigned. ${ }^{2}$ Complete hearing reservation refers to postoperative loss of hearing of 0 to $10 \mathrm{~dB}$. Partial hearing conservation is considered as a postoperative hearing loss of more with some residual hearing. Loss of residual hearing refers to the absence of pre-and postoperative thresholds.

\section{Group data results according to James et al. ${ }^{18}$}

The median changes in pre- and postoperative thresholds could not be calculated exactly for the individual frequencies, because more than $50 \%$ of the subjects showed thresholds above the maximum output of the audiometer at 250,500, 1000, and $2000 \mathrm{~Hz}$. But the differences between the maximum audiometer output levels and the pre-operative median thresholds showed that the threshold deteriorations were at least $20 \mathrm{~dB}, 25 \mathrm{~dB}$, and $15 \mathrm{~dB}$ at 250,500 , and $1000 \mathrm{~Hz}$, respectively. These results show estimations of the minimum degree of hearing deterioration at a given frequency, that is present, but may be underestimated due to ceiling effects are based on the assigning of a very large artificial value (999) in case of unmeasurable thresholds.

Please note that the trend in these data cannot be interpreted as less deterioration at higher frequencies, because the ceiling effect may be expected to be stronger for frequencies where the pre-operative residual thresholds are closer to the maximum levels provided by the audiometer.

If we apply the medians on the selection of subjects that had measurable hearing thresholds (as was done in the original approach by James ${ }^{18}$ ) we found the results of Table 6.2. These median thresholds and median thresholds changes were obtained by assigning a large value in case of unmeasurable thresholds at a given frequency. After applying this analysis, the median PTA at 250,500, and $1000 \mathrm{~Hz}$ deteriorates from 93.3 to $105 \mathrm{~dB}$ (11.7 dB; $n=19)$. Likewise the deteriorations at 250, 500, and $1000 \mathrm{~Hz}$ are $15 d B(n=41), 20 d B(n=50)$, and $10 d B(n=37)$, respectively. 


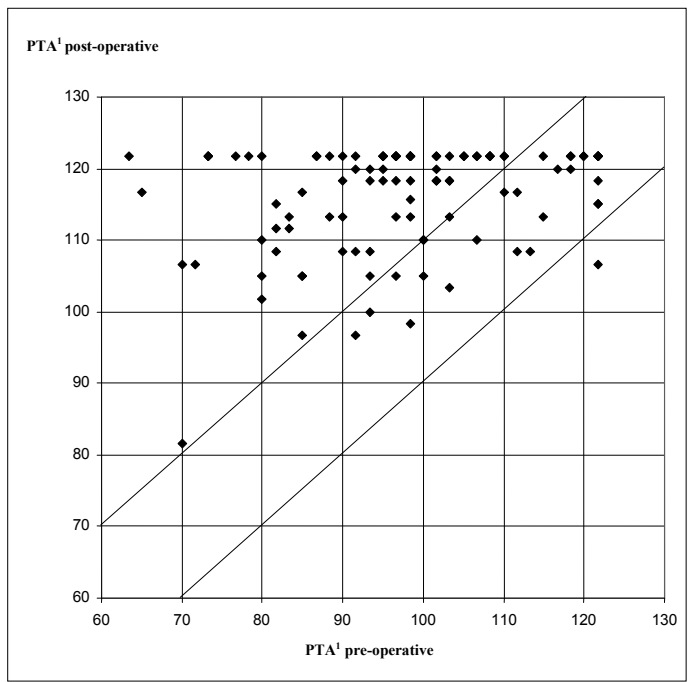

Figure 6.1 Shows a scatter plot of the relationship between individual pre -and postoperative PTA thresholds after cochlear implantation. All dots between the black diagonal straight lines represent patients in whom the residual hearing did not change significantly ( $\pm 10 \mathrm{~dB}$ ).

${ }^{1}$ PTA was calculated as an average of thresholds at 250,500 and $1000 \mathrm{~Hz}$. In case of exceeding the maximum output of the audiometer $\mathrm{fmax}+5$ was assigned.

Table 6.2 Summarizes the median thresholds and median alterations in this study.

$\begin{array}{lccrcc} & \text { PTA }^{1} & 250 \mathrm{~Hz}^{2} & 500 \mathrm{~Hz} & 1000 \mathrm{~Hz} & 2000 \mathrm{~Hz} \\ \begin{array}{l}\text { Number of } \\ \text { patients }\end{array} & 19 & 41 & 50 & 37 & 33 \\ \text { Preoperative } & 93.3 \mathrm{~dB} & 85.0 \mathrm{~dB} & 95.0 \mathrm{~dB} & 105.0 \mathrm{~dB} & 120.0 \mathrm{~dB} \\ \text { Postoperative } & 105.0 \mathrm{~dB} & 100.0 \mathrm{~dB} & 115.0 \mathrm{~dB} & 115.0 \mathrm{~dB} & 115.0 \mathrm{~dB} \\ \text { Change } & 11.7 \mathrm{~dB} & 15.0 \mathrm{~dB} & 20.0 \mathrm{~dB} & 10.0 \mathrm{~dB} & 5.0 \mathrm{~dB}\end{array}$

${ }^{1}$ PTA was calculated as the median of the average thresholds at 250,500 and $1000 \mathrm{~Hz}$ (a very large value of 999 was assigned in case of unmeasurable thresholds). ${ }^{2}$ Median thresholds and median alteration were calculated by assigning a very large value of 999 in case of unmeasurable thresholds

\section{Alternative analysis}

After subdividing the patients into groups according to the presence or absence of preand/or postoperative measurable PTA hearing levels, it is clear that a preservation of hearing can only be measured in patients with a measurable audiogram postoperatively (groups 1 and 3) (Table 6.3). For the average thresholds at 250, 500, and $1000 \mathrm{~Hz}$ this regarded 19 patients (18 in group 1 and 1 in group 3). Of these 19 patients, 9 patients could be identified with a complete conservation of hearing. The remaining 10 patients had a deterioration of more than $10 \mathrm{dBHL}$ after implantation. The mean preoperative PTA for all 19 patients was $90.1 \mathrm{~dB}( \pm 14.7)$ and 
declined to $104.6 \mathrm{~dB}( \pm 7.6)$ after cochlear implantation. This accounts for a change of PTA hearing threshold of $14.5 \mathrm{~dB}$ after cochlear implantation. In Figure 6.2 the change of hearing thresholds is displayed in a scatter plot. Hearing thresholds of patients in group $2(n=63)$ and $4(n=27)$ were not taken into account for further analysis as consequence of unmeasurable post-operative hearing thresholds. For the individual frequencies groups the subjects with post-operative measurable hearing (groups 1 and 3) consisted of 33 to 50 subjects and could be analyzed. For these subgroups, the results according to the criteria of Balkany in terms of complete and partial conservation of hearing are presented in Table 6.4. ${ }^{21}$

Table 6.3 Applying the alternative analysis in order to calculate the degree of preservation of hearing in terms of the PTA at 250, 500, and $1000 \mathrm{~Hz}$, the patients are categorized according the presence or absence of pre-and postoperative thresholds.

$\begin{array}{lll}\text { Group } & \text { Preoperative thresholds } & \text { Postoperative thresholds } \\ 1(n=18) & \text { measurable } & \text { measurable } \\ 2(n=63) & \text { measurable } & \text { unmeasurable } \\ 3(n=1) & \text { unmeasurable } & \text { measurable } \\ 4(n=27) & \text { unmeasurable } & \text { unmeasurable }\end{array}$

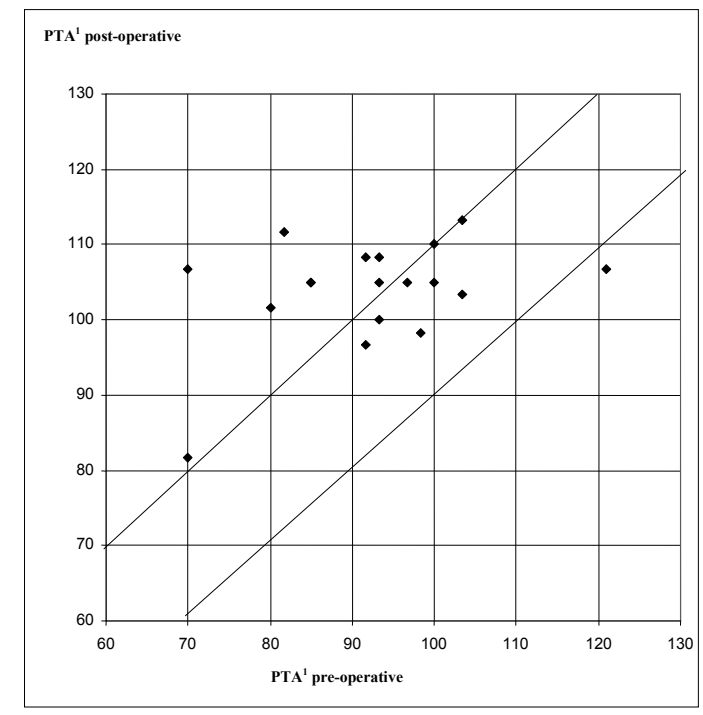

Figure 6.2 Shows a scatter plot of the relationship between individual pre -and postoperative PTA thresholds after cochlear implantation in group I and III. All dots between the black diagonal straight lines represent patients in whom the residual hearing was preserved completely $( \pm 10 \mathrm{~dB})$. 
Table 6.4 Shows the results of calculation the degree of residual hearing using the alternative analysis. Complete and partial conservation median conservation after cochlear implant surgery at frequencies 250,500, 1000 and $2000 \mathrm{~Hz}$ is displayed for the subjects in whom we could measure post-operative thresholds.

\begin{tabular}{|c|c|c|c|c|c|}
\hline & PTA & $250 \mathrm{~Hz}$ & $500 \mathrm{~Hz}$ & $1000 \mathrm{~Hz}$ & $2000 \mathrm{~Hz}$ \\
\hline $\mathrm{N}$ of subjects & 19 & 41 & 50 & 37 & 33 \\
\hline $\begin{array}{l}\text { Complete hearing } \\
\text { conservation }\end{array}$ & $47.4 \%$ & $53.7 \%$ & $38.0 \%$ & $67.6 \%$ & $87.9 \%$ \\
\hline $\begin{array}{l}\text { Partial hearing } \\
\text { conservation }\end{array}$ & $52.6 \%$ & $46.3 \%$ & $62.0 \%$ & $32.4 \%$ & $12.1 \%$ \\
\hline
\end{tabular}

\section{Discussion}

This study clearly demonstrates that preservation of hearing can be obtained using the SMA technique for cochlear implantation. Although several patients could be identified with a complete preservation of residual hearing, deterioration of preoperative hearing levels occurred in a large number of patients. In accordance to other studies, a significant number of postoperative thresholds at frequencies of interest were beyond the maximum capacity of the audiometer which severely complicated the interpretation of results in this study in terms of the true conservation of hearing. ${ }^{17-21}$ As in our study, this ceiling effect has plagued previous studies of hearing conservation involving implantation of profoundly hearing-impaired patients and must be taken into account to attain an accurate assessment of residual hearing. ${ }^{21-25}$ As was stated in previous studies, there is no golden standard how to assess the hearing loss or preservation accurately in studies that investigate the preservation of residual hearing in patients with severe to profound hearing loss. ${ }^{21-25}$ However, the lack of uniform calculation methods to determine and present the various degrees of preserved hearing obscures the precise degree of conservation of hearing and hence affect the potential for comparisons across different studies.

Therefore, the outcome of preservation of residual hearing in this study, can only be compared with other studies which used identical calculation methods. In general, calculation methods according to Kiefer and James are the most frequently used in literature. ${ }^{17,18}$ Therefore, we used both calculation methods to facilitate comparison of our results with other studies with respect to the conservation of hearing after cochlear implantation. Nonetheless it remains difficult to directly compare results across the different studies due to variations in subject selection, different clinical management schemes, and different targets (for example, electroacoustic versus electrical stimulation alone). Notable fact is that the results of preservation of hearing of other similar studies (which are described below) are all obtained using the MPTA technique. 
1) In the calculation method according to Kiefer et al., we observed a reduction of the mean PTA of $18.5 \mathrm{dBHL}$ (from $97.1 \mathrm{dBHL}$ to $115.6 \mathrm{dBHL}$ ). ${ }^{17}$ Furthermore, complete and partial conservation of residual hearing was calculated in 27 subjects (24.7\% 27/109) and 77 subjects (70.6\% 77/109), respectively. This is well in agreement with the incidences of conservation of residual hearing found in other studies which used this analysis, but the numbers of patients are limited. Moreover, Balkany ${ }^{21}$ observed in $32.1 \%(9 / 28)$ of subjects a complete conservation of hearing, while in $53.6 \%$ (15/28) of subject a partial conservation was observed. Hodges et al. observed a complete conservation of residual hearing in 21 of 40 (52.5\%). ${ }^{6}$ Similar percentages of preservation of residual hearing were reported by Berrettini et al. ${ }^{23}$ who showed complete hearing conservation in 6 of 11 patients (54.5\%). In only 2 of 11 patients complete loss of residual hearing was observed. Table 6.5 summarizes the difference of outcome between the above mentioned studies with respect to the mean alteration of mean PTA levels. In all these studies identical perimodiolar electrode arrays were used. Unfortunately, the outcome of degree of conservation may have been overestimated in these studies due to the fact that thresholds above the maximum of the audiometer range were assigned an artificial values $(f m a x+5)$. Therefore, applying this analysis accounts for an abundance of postoperative hearing levels at the ceiling limit, which may be closer to the pre-operative hearing levels than the true postoperative hearing levels. In our opinion, this calculation method is not the most appropriate one in order to assess the conservation of hearing in patients with a severe or profound hearing loss.

Table 6.5 Summarizes the difference of outcome between several studies with respect to the mean alteration of pre-and postoperative PTA levels.

\begin{tabular}{|c|c|c|c|c|c|}
\hline Study group & $\begin{array}{l}\text { Study } \\
\text { patients } \\
\text { (n) }\end{array}$ & $\begin{array}{l}\text { Preoperative } \\
\text { PTA } \\
\text { (db HL) }\end{array}$ & $\begin{array}{l}\text { Postoperative } \\
\text { PTA } \\
\text { (dB HL) }\end{array}$ & $\begin{array}{l}\triangle \mathrm{PTA} \\
(\mathrm{dB})\end{array}$ & $\begin{array}{l}\text { Complete } \\
\text { preservation } \\
(\%)\end{array}$ \\
\hline Postelmans et al. & 109 & 97.1 & 115.6 & 18.5 & 24.7 \\
\hline Balkany et al. $^{21}$ & 28 & 92.8 & 109.7 & 16.9 & 32.1 \\
\hline Hodges et al. ${ }^{19}$ & 40 & 107.4 & 119.4 & 12.0 & 52.5 \\
\hline Berrettini et al. ${ }^{23}$ & 11 & 98.0 & 113.3 & 12.6 & 54.5 \\
\hline
\end{tabular}

2) According to the analysis of James et al. we observed a deterioration of $11.7 \mathrm{~dB}$ for the median PTA in this study group ( $n=19$, from $93.3 \mathrm{~dB}$ to $105 \mathrm{~dB}$ ). ${ }^{18}$ Likewise, we found that the deteriorations at 250,500 , and $1000 \mathrm{~Hz}$ were $15 \mathrm{~dB}(\mathrm{n}=41), 20$ $d B(n=50)$, and $10 d B(n=37)$, respectively. These alterations per frequency are well in agreement with the results of Garcia-lbanez et al. who reported an median change of $15 \mathrm{~dB}, 15 \mathrm{~dB}$ and $25 \mathrm{~dB}$ at 250,500 and $1000 \mathrm{~Hz}$, respectively $(n=18){ }^{25}$ James et al. showed deteriorations of threshold levels of 23,27 , and $33 \mathrm{~dB}$ for the frequencies 125,250 and $500 \mathrm{~Hz}$, respectively $(n=12) .{ }^{18}$ More favourable results were reported by Balkany and Dinardo et al. who also calculated the median changes beside the mean changes. ${ }^{21,22}$ Table 6.6 summarizes the difference of 
outcome between the above mentioned studies with respect to the median alteration of pre-and postoperative hearing levels. In contrast to the first analysis the outcome of this analysis is more accurate as it reflects the central tendency of the true threshold shifts for the group, permitting inclusion of non-measurable threshold responses postoperatively. Although this analysis gives a more accurate outcome of conservation of hearing, unfortunately it does not address the individual subject outcome.

Table 6.6 Summary of median deterioration of threshold levels after cochlear implantation at a given frequency for several similar studies.

$\begin{array}{lcccc}\text { Study group } & 125 \mathrm{~Hz} & 250 \mathrm{~Hz} & 500 \mathrm{~Hz} & 1000 \mathrm{~Hz} \\ \text { Postelmans et al. }^{26} & \mathrm{~nm} & 15 \mathrm{~dB} & 20 \mathrm{~dB} & 10 \mathrm{~dB} \\ \text { James et al. }^{26} & 23 \mathrm{~dB} & 27 \mathrm{~dB} & 33 \mathrm{~dB} & \mathrm{~nm} \\ \text { Garcia-lbanez et al. }^{33} & \mathrm{~nm} & 15 \mathrm{~dB} & 15 \mathrm{~dB} & 25 \mathrm{~dB} \\ \text { Balkany et al. }^{29} & \mathrm{~nm} & 15 \mathrm{~dB} & 15 \mathrm{~dB} & 5 \mathrm{~dB} \\ \text { Dinardo et al. }^{30} & \mathrm{~nm} & 10 \mathrm{~dB} & 10 \mathrm{~dB} & 5 \mathrm{~dB}\end{array}$

In order to overcome the restrictions of above mentioned calculation methods, we introduced an alternative analysis in which we categorized the patients according to the absence or presence of pre-and postoperative thresholds. This analysis is stricter and shows that conservation of measurable PTA's can only be proven in $17.4 \%(19 / 109)$ of all patients. Complete or partial conservation of residual hearing could only be established in $8.3 \%(9 / 109)$ and $9.2 \%(10 / 109)$ of all study patients, respectively. Calculation of hearing preservation is only possible in patients with measurable postoperative hearing levels at a given frequency of interest. Consequently, the ceiling effect does not play a role in this subgroup, and the assessment of the preservation of hearing can be performed more accurately. The main advantage of this technique is that it eliminates the ceiling effect from the targeted outcome measure while allowing analysis of its frequency and degree. Therefore, this analysis is more suitable for the calculation of preservation of residual hearing in large numbers of study patients characterized by pre-and postoperative hearing thresholds near the capacity of the audiometer. However, a selection bias is encountered as a consequence of eliminating those patients that had no responses at the $f_{\max }$. A major drawback of this analysis is that important data shall be lost for further analysis. Subsequently, the absolute hearing loss is underestimated relatively due to elimination of the patients with the worst results. So, this analysis is far off to be a golden standard but can still contribute to an accurate calculation of the conservation of hearing.

\section{Conclusions}

Applying the above three described calculation methods, this study illustrates that in a limited number of patients a complete conservation of hearing can be proven using 
the SMA technique. Assessment of true alterations of pre-and postoperative thresholds were obscured due to the fact that a large number of thresholds in this study were beyond the maximum output of the diameter. To overcome this ceiling effect different calculation method were used in order to determine and present the accurate degrees of hearing preservation. All three calculation methods showed a different preservation of hearing. Therefore, we recommend that the ceiling effect must be taken into account by using more than one calculation method in future studies, to estimate the accurate preservation of residual hearing. 


\section{References}

1. Postelmans JT, Cleffken B, Stokroos RJ. Post-operative complications of cochlear implantation in adults and children: five years' experience in Maastricht. J Laryngol Otol 2007;121:318-23.

2. Proops DW, Stoddart RL, Donaldson I. Medical, surgical and audiological complications of the first 100 adult cochlear implant patients in Birmingham. J Laryngol Otol Suppl 1999;24:14-7.

3. Collins MM, Hawthorne MH, el-Hmd K. Cochlear implantation in a district general hospital: problems and complications in the first five years. J Laryngol Otol 1997;111:325-32.

4. House WF. Cochlear implants. Ann Otol Rhinol Laryngol 1976;85:1Y93.

5. Colletti V, Fiorino FG, Carner M, Pacini L. Basal turn cochleostomy via the middle fossa route for cochlear implant insertion. Am J Otol 1998;19:778-84.

6. Kiratzidis T. 'Veria operation': cochlear implantation without a mastoidectomy and a posterior tympanotomy. A new surgical technique. Adv Otorhinolaryngol 2000;57:127-30.

7. Hausler R. Cochlear implantation without mastoidectomy: the pericanal electrode insertion technique. Acta Otolaryngol 2002;122:715-9.

8. Kronenberg J, Migirov L, Dagan T. Suprameatal approach: new surgical approach for cochlear implantation. J Laryngol Otol 2001;115:283-5.

9. Kronenberg J, Baumgartner WD, Migirov L, Dagan T, Hildesheimer M. The suprameatal approach: an alternative surgical approach to cochlear implantation. Otol Neurotol 2004;25:41-5.

10. Postelmans JT, Grolman W, Tange RA, Stokroos RJ. Comparison of two approaches to the surgical management of cochlear implantation. Laryngoscope. 2009 ;119:1571-8.

11. Postelmans JT, Tange RA, Stokroos RJ, Grolman W. The suprameatal approach: a safe alternative surgical technique for cochlear implantation. Otol Neurotol. $2010 ; 31: 196-203$.

12. Yin S, Chen Z, Wu Y, Wang L, Zhang J, Zhou W, Zhou W, Huang J, Shen Z, Qiu J. Suprameatal approach for cochlear implantation in 45 Chinese children. Int J Pediatric Otorhinolaryngol 2008;72:397-403.

13. Gantz BJ, Turner CW. Combining acoustic and electoral hearing. Laryngoscope 2005;115:1726-30

14. Gantz BJ, Turner C. Combining acoustic and electal speech processing: lowa/Nucleus hybrid implant. Acta Otolaryngol 2004;124:344-7.

15. Gstoettner W, Kiefer J, Baumgartner WD, Pok S, Peters S, Adunka O. Hearing preservation in cochlear implantation for electric acoustic stimulation. Acta Otolaryngol 2004;124:348-52.

16. Fraysse B, Macías AR, Sterkers O, Burdo S, Ramsden R, Deguine O, Klenzner T, Lenarz T, Rodriguez $\mathrm{MM}$, Von Wallenberg $\mathrm{E}$, James $\mathrm{C}$. Residual hearing conservation and electroacoustic stimulation with the nucleus 24 contour advance cochlear implant. Otol Neurotol 2006;27:624-33.

17. Kiefer J, Gstoettner W, Baumgartner W, Pok SM, Tillein J, Ye Q, von Ilberg C. Conservation of lowfrequency hearing in cochlear implantation. Acta Otolaryngol 2004;123:272-80.

18. James C, Albegger K, Battmer R, Burdo S, Deggouj N, Deguine O, Dillier N, Gersdorff M, Laszig R, Lenarz $T$, Rodriguez MM, Mondain M, Offeciers E, Macías AR, Ramsden R, Sterkers O, Von Wallenberg E, Weber B, Fraysse B. Preservation of residual hearing with cochlear implantation: how and why. Acta Otolaryngol 2005;125:481-91.

19. Hodges AV, Schloffman J, Balkany T. Conservation of residual hearing with cochlear implantation. Am J Otol 1997;18:179-83.

20. Kiefer J, von Ilberg C, Reimer B, Knecht R, Gall V, Diller G, Stürzebecher E, Pfennigdorff T, Spelsberg A. Results of cochlear implantation in patients with severe to profound hearing loss- implications for the indications. Audiology 1998; 37:382-95.

21. Balkany TJ, Connell SS, Hodges AV, Payne SL, Telischi FF, Eshraghi AA, Angeli SI, Germani R, Messiah S, Arheart KL. Conservation of residual acoustic hearing after cochlear implantation. Oto Neurotol 2006;27:1083-8.

22. Di Nardo W, Cantore I, Melillo P, Cianfrone F, Scorpecci A, Paludetti G. Residual hearing in cochlear implant patients. Eur Arch Otorhinolaryngol 2007;264:855-60.

23. Berrettini S, Forli F, Passetti S. Preservation of residual hearing following cochlear implantation: comparison between three surgical techniques. Journal of Laryngol Otol 2008;122:246-52.

24. Soda-Merhy A, Gonzalez-Valenzuela, Tirado-Gutierrez. Residual hearing after cochlear implantation: comparison between straight and perimodiolar implants. Otolaryngology-Head and Neck surgery 2008;139:399-404. 
25. Garcia-lbanez L, Macias AR, Morera C, Rodriguez MM, Szyfter W, Skarszynski H, Emamdjomeh H, Baumgartner WD. An evaluation of the preservation of residual hearing with the Nucleus ${ }^{\circledR}$ Contour AdvanceTM electrode. Acta Oto-Laryngol. 2009;129:651-64. 

(2) 103
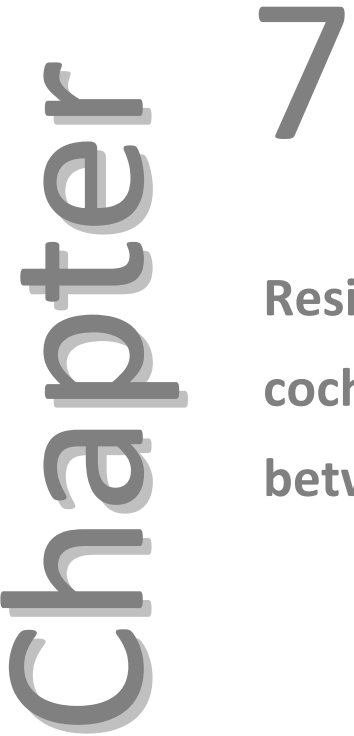

Residual hearing preservation after cochlear implantation: comparison between two surgical techniques

JTF Postelmans, RJ Stokroos, E van Spronsen, W Grolman, RA Tange, MJ Maré, WA Dreschler 


\section{Abstract}

\section{Introduction}

The goal of this work was to review the pre-and postsurgical auditory thresholds of two surgical implantation techniques, namely the mastoidectomy with posterior tympanotomy approach (MPTA) and suprameatal approach (SMA), to determine whether there is a difference in the degree of preservation of residual hearing.

\section{Methods}

In a series of 430 consecutive implanted patients 227 patients had measurable pre-operative hearing thresholds at $250 \mathrm{~Hz}, 500 \mathrm{~Hz}$, and $1000 \mathrm{~Hz}$. These patients were divided into two groups according to the surgical technique that was used for implantation. The SMA approach was followed for 84 patients in Amsterdam, whereas the MPTA technique was adhered to 143 patients in Maastricht. The outcome variables of interest were alteration of pre-and postoperative auditory thresholds after cochlear implantation.

\section{Results}

Complete or partial preservation of residual hearing was obtained in $21.4 \%$ and $21.7 \%$ in the SMA and MPTA group, respectively. No statistical differences could be found between the SMA and MPTA group.

\section{Conclusion}

The SMA technique is correlated with a similar degree of hearing loss after cochlear implantation compared to the MPTA technique. However, both techniques were not able to conserve a measurable amount of hearing in patients with a substantial degree of residual hearing. Therefore, both surgical techniques need to be refined for patients in which residual acoustical hearing is pursued. 


\section{Introduction}

Since the onset of cochlear implantation in the 1960s, cochlear implantation surgeons have been concerned with the extent to which insertion of an electrode into the cochlea produces endocochlear damage and causes injury to neural structures. Initially, it was assumed that the insertion of an electrode would destroy any natural hearing ability by disrupting the cochlea's delicate fluid-filled infrastructure. ${ }^{1}$ Nevertheless, due to the development of less traumatic surgical techniques and improved electrode designs there has been a improvement in the preservation of residual hearing after cochlear implantation. Several studies have reported hearing conservation rates of more than $80 \%$ using both straight and curved electrode designs. $^{2-8}$ In these study subjects, conservation of residual hearing is correlated with 1) a better outcome in hearing performance in difficult or noisy listening environments, 2) improvement in perception and appreciation of music, and 3 ) increased quality and naturalness of sounds and voices. ${ }^{9-15}$ Although there may be some biasing factors playing a role here, these results have provided surgeons with the additional challenge of conserving preoperative residual hearing thresholds after cochlear implantation.

Even though conservation of residual hearing is a realistic goal in most patients, there are still a significant number of patients who lose their residual hearing after cochlear implant surgery, in spite of all efforts. A number of factors have been identified as possible causes of residual hearing loss after cochlear implantation including i) acoustic trauma caused while drilling near the cochlea, ii) mechanical damage of the neural epithelium due to electrode insertion, iii) alteration of cochlear fluid homeostasis, iv) bacterial infection and cochlear fibrosis due to a foreign body reaction to the electrode components, and v) sequela of the probable initial inflammatory reaction. ${ }^{15}$ Although it is thought that some of these effects may be related to characteristics of the electrode array (its diameter, stiffness and length) and the placement of the cochleostomy, the actual cause of hearing loss in these patients remains elusive and open for debate. ${ }^{16}$

It is remarkable that almost all studies which have aimed to evaluate the preservation of residual hearing after cochlear implant surgery have used the classic mastoidectomy with posterior tympanotomy approach (MPTA), in spite of the existence of several alternative implantation techniques. ${ }^{13-16,}$ 18-22 Although the MPTA technique for cochlear implant surgery, as described by House, has still been the most commonly used surgical technique worldwide, several alternative techniques have been introduced to overcome the risk of injury to the facial nerve and chorda tympani. ${ }^{17-22}$ The suprameatal approach (SMA) is the most frequently used of these alternative implantation techniques. ${ }^{18-22}$ This particular technique is performed by drilling a suprameatal tunnel whereby the electrode of the cochlear implant is introduced into the middle ear, so bypassing a mastoidectomy. ${ }^{22-24}$ This alternative surgical technique continues to gain popularity among otologists. ${ }^{22-24}$ 
In previous studies, we demonstrated the SMA technique is as safe and efficient as the MPTA technique. Furthermore, this technique is associated with a low incidence of postoperative complications. ${ }^{23,24}$ However; studies which investigated the role of the SMA technique on the preservation of residual hearing are sparse. It is essential to determine whether an equivalent degree of preservation of residual hearing can be maintained with the SMA technique as with the MPTA technique in view of the increased clinical importance of residual hearing preservation. Particular surgical aspects of the SMA technique differ substantially from the MPTA technique, such as 1 ) the placement of the cochleostomy on the promontory and 2) the course of the electrode in the middle ear towards the cochleostomy. These differences might influence the outcome of hearing preservation. ${ }^{23,24}$

Recently we showed that complete preservation of residual hearing can be achieved using the SMA technique. ${ }^{25}$ Yet, direct comparison of our results to other studies using the MPTA technique was difficult due to variation in subject selection, clinical management schemes, and targets (for example, electroacoustic versus electrical stimulation alone). Up to now, no studies have been published regarding the differences in preservation of residual hearing between the SMA and MPTA techniques. The primary purpose of this study is therefore to compare the preservation of residual hearing after cochlear implantation between the MPTA and SMA technique to address the question which surgical approach is most appropriate to preserve residual hearing. Furthermore, this study will focus on the use of a standardlength array with full insertion.

\section{Methods and materials}

\section{Patient selection criteria}

A retrospective chart review was conducted to retrieve pre- and postoperative hearing levels from each patient who had undergone unilateral cochlear implantation at the department of Otolaryngology- Head and Neck Surgery of the Maastricht University Medical Centre or the Amsterdam Medical Centre. The patients were divided into two groups according to the surgical technique applied. All patients who received their cochlear implant in Maastricht did so from the senior author (RJS) using the MPTA technique. Patients who underwent cochlear implantation by means of the SMA technique (Amsterdam) were treated by the other senior author (WG). Both surgeons have performed more than 250 cochlear implantations each. Cochlear implantation was performed with devices from three major cochlear implant manufactures, namely Cochlear (Sydney, Australia), Advanced Bionics (Sylmar, CA) and MED-EL (Innsbruck, Austria). 
Inclusion criteria for this study were: 1) Dutch as a primary language, 2) compliance with follow-up examinations 3) full insertion of the electrode into the cochlea, and 4) measurable preoperative hearing levels at 250, 500 and $1000 \mathrm{~Hz}$.

\section{Audiometric evaluation}

For all included participants the pre-implantation and post-implantation audiometric testing was performed using an Interacoustics AC40 with TDH-39 headphones, calibrated to ISO-389 with adequate masking (if necessary) and in a sound-proof booth. In this study, we concentrated on audiometric thresholds at octave frequencies from $250 \mathrm{~Hz}$ to $1000 \mathrm{~Hz}$. For the determination of residual hearing loss, it is relevant to note that the maximum output levels of the audiometers allowed thresholds to be measured up to $110 \mathrm{~dB} \mathrm{HL}$ at $250 \mathrm{~Hz}$ and up to $120 \mathrm{~dB}$ for frequencies 500 and $1000 \mathrm{~Hz}$. Baseline audiograms were obtained at the time of the patients' initial preimplant evaluation. Any response reported as vibrotactile or questionably vibrotactile was considered as no response. Furthermore, postoperative audiograms were performed in identical test conditions at 6 months after surgery and they were measured without the use of the external processor of the implant.

\section{Surgical technique of the SMA technique}

The SMA technique used in this study is a modification of the original procedure introduced by Kronenberg et al. in $1999 .^{22}$ A more detailed description supplemented with photographs can be found in previously published studies by the first author. ${ }^{23,24}$

Briefly, the following steps can be identified.

First, the middle ear cavity is entered via an endaural tympanotomy after performing a retroauricular incision of approximately 2 to $3 \mathrm{~cm}$.

Second, a suprameatal tunnel is drilled superoposterior to the suprameatal spina towards the posterior part of the aditus ad antrum. Drilling is stopped when the body of the incus is visualized. Subsequently, a groove through the suprameatal tunnel is drilled lateral to the body of the incus to connect the antrum with the recessus epitympanicus.

Third, a second small semicircular temporopartial incision of $2.5 \mathrm{~cm}$ is made to visualize the myoperiosteal layer. This second incision is made in the myoperiosteal layer to drill a well in the temporopartial calvaria to fixate the receiver-stimulator of the implant and to cover the receiver-stimulator package.

Last, a cochleostomy is performed through the external ear canal and before insertion of the electrode hyaluronic acid is injected into the cochlea. After completing the insertion of the electrode, the cochleostomy is not sealed with temporal muscle or other material because of the minimal size of the cochleostomy hole. 
Important to note is that the elected surgical technique in our series was the conventional one, which includes minimal cochleostomy (anteroinferior to the round window membrane), slow insertion of the electrode into the cochleostomy and perilymph preservation only.

\section{Surgical technique of the MPTA technique}

For the MPTA technique, a standard approach via a retroauricular incision involving partial mastoidectomy and posterior tympanotomy was used. With respect to the positioning and drilling of the cochleostomy site surgical techniques were identical to the SMA technique.

Our surgical protocol was modified in 2007 to achieve an atraumatic insertion of the electrode by slightly modifying the position of the cochleostomy on the promotorium. More specifically, the bony niche overhang and the ridge of bone immediately inferior to the round window membrane (crista fenestra, hook region) are removed using slow-rotating diamond drills and skeeters (from stapes surgery). After visualization of the annulus of the round window, the lateral anterior portion of the membrane is incised with a sharp needle. The electrode is slowly inserted in an inferior-anterior direction so that it is in a line with the longitudinal axis of the lower basal turn of the scala tympani. In all cases in which the MPTA technique was used, the cochleostomy was sealed with temporal fascia and fibrin glue.

\section{Statistical analysis}

Audiological hearing thresholds for each subject at 250, 500 and $1000 \mathrm{~Hz}$ were assessed for clinically significant changes to preoperative baseline thresholds for the implanted ear at six months post-implant through calculation of a threshold difference value.

All data were entered into a computer database and analyzed with a spreadsheet program. Hearing preservation was considered complete when average low frequency (250, 500 and $1000 \mathrm{~Hz}$ ) was $\leq 10 \mathrm{~dB} \mathrm{HL}$ compared to preoperative pure-tone thresholds. Hearing preservation was considered partial in case of low-frequency hearing loss of more than $10 \mathrm{~dB} \mathrm{HL}$ relative to preoperative pure-tone thresholds. As such, hearing preservation to within $10 \mathrm{~dB}$ of the preoperative hearing thresholds reflects the gold standard for hearing preservation. The effects for the average lowfrequency hearing loss threshold difference values for each subject were also calculated for each of the frequencies by subtracting the preoperative baseline threshold from the six months post-implanted threshold.

The statistical package SPSS 11.5 (SPSS, Inc., Chicago, IL) was used for data analysis, with the statistical procedures: t-tests and chi-square tests conducted to compare the groups with respect to preservation of hearing. 


\section{Results}

\section{SMA group}

A total of 430 patients who underwent cochlear implantation between 2001 and 2010 at the Maastricht University Medical Centre (MPTA) or Amsterdam Medical Centre (SMA) were considered for this study. With respect to the SMA group, in 25 of 109 (22.9\%) preoperative thresholds at frequencies of interest were not measurable at 250, 500 and $1000 \mathrm{~Hz}$ and were therefore excluded from further analysis. In these patients the alteration of pre-and postoperative thresholds after cochlear implantation could not be established (Figure 7.1). There were then 84 of these 109 (71.1\%) patients selected for further analysis. Complete (change in $\triangle$ PTA $\leq 10 \mathrm{~dB}$ ) and partial (change in $\triangle$ PTA $>10 \mathrm{~dB}$ ) conservation of residual hearing was observed in $9.5 \%(8 / 84)$ and $11.9 \%$ (10/84), respectively. In 66 of 84 patients (78.6\%) the postoperative thresholds exceeded the maximum output of the audiometer at the frequencies of interest (figure II). In these patients, it was not possible to assess the exact degree of preservation of hearing due to a ceiling effect of the audiometer.

\section{MPTA group}

For the MPTA group, preoperative thresholds could be not be measured in 178 of 321 (55.5\%) patients at 250, 500 and $1000 \mathrm{~Hz}$. In these patients the pre- and postoperative thresholds could not be established and these patients were excluded for further analysis (Figure 7.1). In total, 143 of $321(45.5 \%)$ patients remained for further analysis. In 31 subjects of the 143 remaining patients (21.7\%), pre- and postoperative hearing levels could be obtained. Complete (change in $\triangle$ PTA $\leq 10 \mathrm{~dB}$ ) and partial (change in $\triangle$ PTA $>10 \mathrm{~dB}$ ) conservation of residual hearing in this group was $13.3 \%$ and $8.4 \%$, respectively. In 112 of $143(78.3 \%)$ patients the postoperative thresholds were beyond the maximum output of the audiometer (Figure 7.2).

Thus, the percentages of partial and complete preservation of residual hearing were $21.4 \%$ and $21.7 \%$ in the SMA and MPTA groups, respectively. This difference was not statistically significant.

For a more thorough comparison of the two groups, we stratified for the presence of measurable postoperative thresholds at frequencies of interest. This sub-analysis showed a complete conservation of residual hearing (change in $\triangle$ PTA $\leq 10 \mathrm{~dB}$ ) in $44.4 \%$ ( 8 of 18 ) and $61.3 \%$ (19 of 31 ) of patients in the SMA group and MPTA group, respectively. Partial conservation of residual hearing (change in $\triangle$ PTA $>10 \mathrm{~dB}$ ) was thus accomplished in $55.6 \%$ (10 of 18 ) and $38.7 \%$ (12 of 31 ) in the SMA and MPTA cases, respectively (see Table 7.1). The distribution between complete and partial conservation of hearing differed significantly between the two subgroups with both measurable pre- and post-operative audiograms. Nevertheless, conservation of hearing was not influenced by the implemented modification in 2007 of the MPTA surgical technique. 


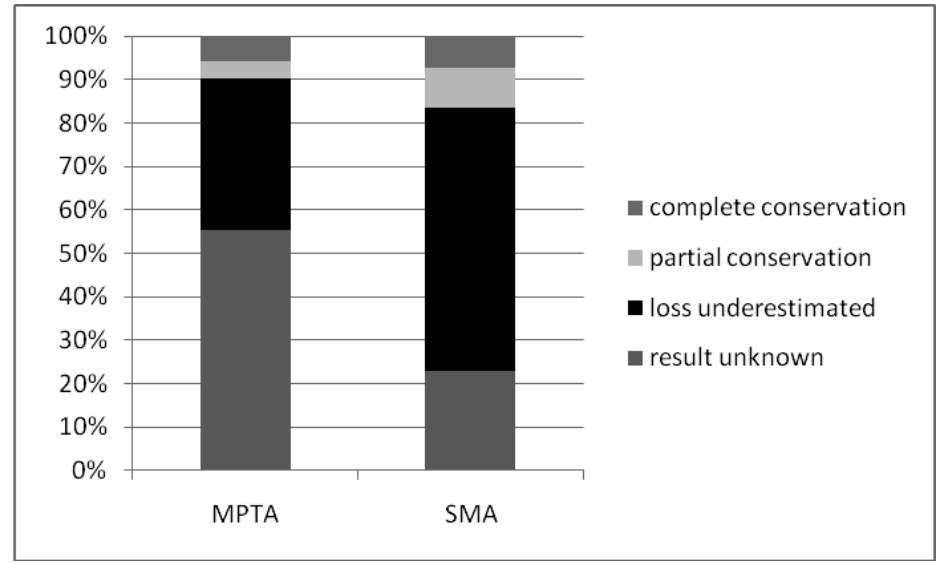

Figure 7.1 Distribution of measurable pre-and postoperative hearing levels. In the majority of patients hearing loss could not be calculated accurately as a consequence of unmeasurable pre- or postoperative hearing levels (loss underestimated or results unknown)

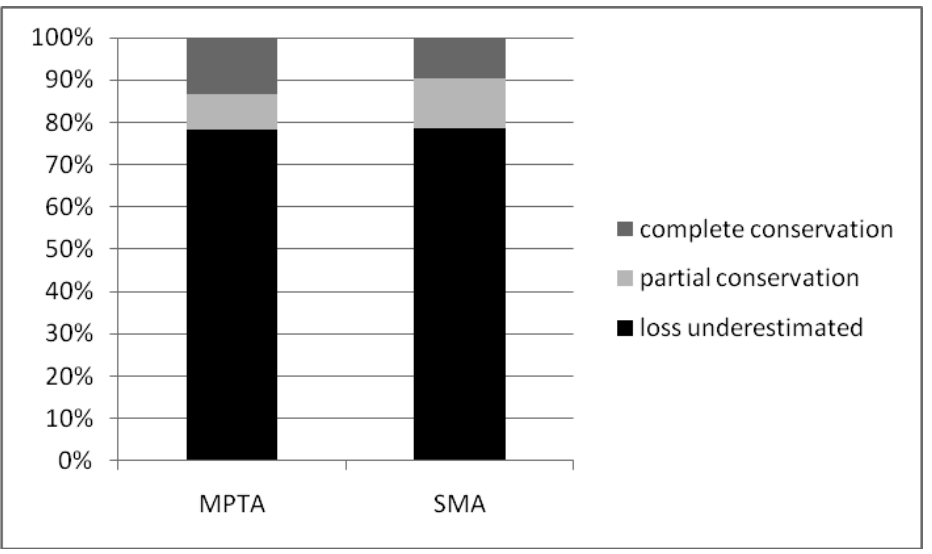

Figure 7.2 Percentage of patients for whom calculations could be obtained of either partial or complete conservation of residual hearing after cochlear implantation according to the inclusion criteria of this study.

\section{Mean preservation of hearing using the sub-analysis}

Further analysis within this subgroup showed that the mean PTA across all study patients in the SMA group was $88.4 \mathrm{~dB} H \mathrm{HL}(\mathrm{SD} \pm 13.1 \mathrm{~dB} \mathrm{HL})$ pre-operatively and $104.5 \mathrm{~dB} H \mathrm{HL}(\mathrm{SD} \pm 7.6 \mathrm{db} \mathrm{HL}$ ) postoperatively. Thus, at the time of post-implant testing, mean PTA for the SMA group had decreased on average by $16.1 \mathrm{~dB} \mathrm{HL}$. In the MPTA group, the mean PTA across the MPTA group declined on average by $8.9 \mathrm{~dB} \mathrm{HL}$ after 
cochlear implantation (preoperative mean $92.3 \mathrm{~dB} \mathrm{HL}$ (SD $\pm 9.1 \mathrm{~dB} \mathrm{HL}$ ) and postoperative mean $101.2 \mathrm{dBHL}(\mathrm{SD} \pm 7.3 \mathrm{~dB} \mathrm{HL})$ ) (Table 7.1). The difference of $7.2 \mathrm{dbHL}$ between the two groups with respect to preservation was also statistically significantly different. Figures 7.3 and 7.4 present scatter plots of the relationship between individual pre-and postoperative mean PTA thresholds after cochlear implantation. Figure 7.3 and 7.4 show that complete conservation of hearing is not possible in patients for whom pre-operative PTA hearing levels are $\leq 90 \mathrm{~dB}$. Although this notable fact applies to both groups, Figure 7.5 shows that more patients with these hearing losses are more predominant in the SMA group, suggesting that part of the difference between the two groups can be attributed to this.

Mean change between pre- and postoperative thresholds at 250,500 , and $1,000 \mathrm{~Hz}$ ranged from 18.2, 21.4, and $8.6 \mathrm{~dB} \mathrm{HL}$, respectively in the SMA group. For the MPTA group, mean changes between pre- and postoperative thresholds at 250, 500 and $1000 \mathrm{~Hz}$ were 8.1, 11.1 and 7.6, respectively.

Table 7.1 Mean improvement in pure-tone average for the SMA and MPTA groups.

\begin{tabular}{|c|c|c|c|c|c|}
\hline $\begin{array}{l}\text { Study } \\
\text { group }\end{array}$ & & $\begin{array}{l}\text { PTA }^{1} \\
(\mathrm{db} \mathrm{HL})\end{array}$ & $\begin{array}{l}250 \mathrm{~Hz} \\
\text { (db HL) }\end{array}$ & $\begin{array}{l}500 \mathrm{~Hz} \\
\text { (db HL) }\end{array}$ & $\begin{array}{l}1000 \mathrm{~Hz} \\
(\mathrm{db} \mathrm{HL})\end{array}$ \\
\hline \multirow[t]{4}{*}{ SMA } & Preoperative & $88.4 \mathrm{~dB} \mathrm{HL}$ & $76.1 \mathrm{~dB} \mathrm{HL}$ & $85.0 \mathrm{~dB} \mathrm{HL}$ & $104.2 \mathrm{~dB} \mathrm{HL}$ \\
\hline & Postoperative & $104.5 \mathrm{~dB} \mathrm{HL}$ & $94.4 \mathrm{~dB} H \mathrm{HL}$ & $106.4 \mathrm{~dB} \mathrm{HL}$ & $112.8 \mathrm{~dB} \mathrm{HL}$ \\
\hline & Change & $16.1 \mathrm{~dB} \mathrm{HL}$ & $18.3 \mathrm{db} \mathrm{HL}$ & $21.4 \mathrm{db} \mathrm{HL}$ & $8.6 \mathrm{~dB} \mathrm{HL}$ \\
\hline & $\begin{array}{l}\text { Complete } \\
\text { conservation }\end{array}$ & $\begin{array}{l}44.4 \% \\
(8 / 18)\end{array}$ & $\begin{array}{l}\text { Partial } \\
\text { conservation }\end{array}$ & $55.6 \%(10 / 18)$ & \\
\hline $\begin{array}{l}\text { Study } \\
\text { group }\end{array}$ & & $\begin{array}{l}\text { PTA }^{1} \\
(\mathrm{db} \mathrm{HL})\end{array}$ & $\begin{array}{l}250 \mathrm{~Hz} \\
(\mathrm{db} \mathrm{HL})\end{array}$ & $\begin{array}{l}500 \mathrm{~Hz} \\
(\mathrm{db} \mathrm{HL})\end{array}$ & $\begin{array}{l}1000 \mathrm{~Hz} \\
(\mathrm{db} \mathrm{HL})\end{array}$ \\
\hline \multirow[t]{4}{*}{ MPTA } & Preoperative & $92.3 \mathrm{~dB} \mathrm{HL}$ & $82.9 \mathrm{~dB} \mathrm{HL}$ & $91.3 \mathrm{~dB} \mathrm{HL}$ & $102.6 \mathrm{~dB} \mathrm{HL}$ \\
\hline & Postoperative & $101.2 \mathrm{~dB} \mathrm{HL}$ & $91.0 \mathrm{~dB} \mathrm{HL}$ & $102.4 \mathrm{~dB} \mathrm{HL}$ & $110.2 \mathrm{~dB} \mathrm{HL}$ \\
\hline & Change & $8.9 \mathrm{~dB} \mathrm{HL}$ & $8.1 \mathrm{~dB} \mathrm{HL}$ & $11.1 \mathrm{db} \mathrm{HL}$ & $7.6 \mathrm{~dB} \mathrm{HL}$ \\
\hline & $\begin{array}{l}{ }^{2} \text { Complete } \\
\text { conservation }\end{array}$ & $\begin{array}{l}61.3 \% \\
(19 / 31)\end{array}$ & $\begin{array}{l}{ }^{2} \text { Partial } \\
\text { conservation }\end{array}$ & $\begin{array}{l}38.7 \% \\
(12 / 31)\end{array}$ & \\
\hline
\end{tabular}

${ }^{1}$ PTA was calculated as mean values of thresholds at 250,500 and $1000 \mathrm{~Hz}$. ${ }^{2}$ Complete hearing reservation refers to postoperative loss of hearing of $\leq 10 \mathrm{~dB}$. Partial hearing conservation is considered as a postoperative loss of hearing of $>10 \mathrm{~dB}$. 


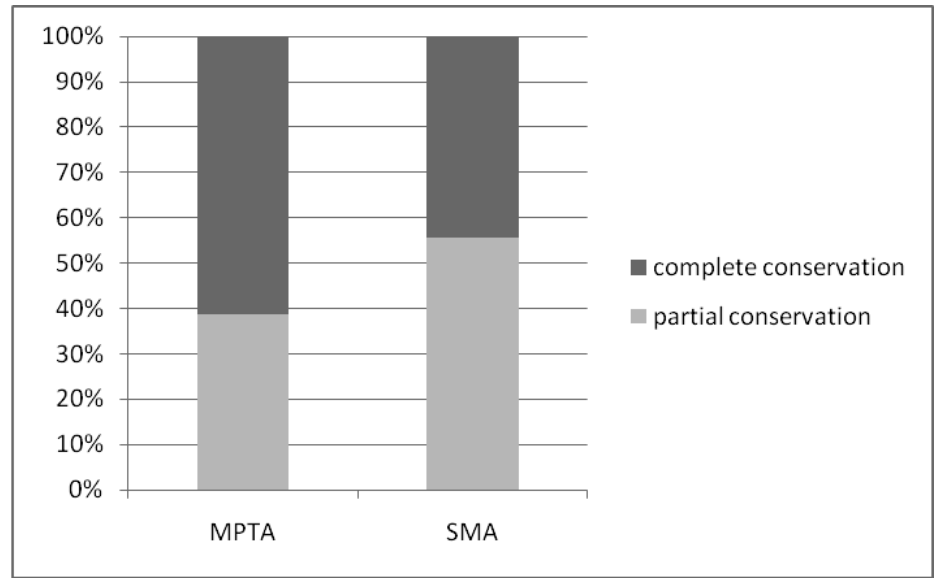

Figure 7.3 Distribution of complete and partial conservation of residual hearing relative to surgical technique after performing the subanalysis.

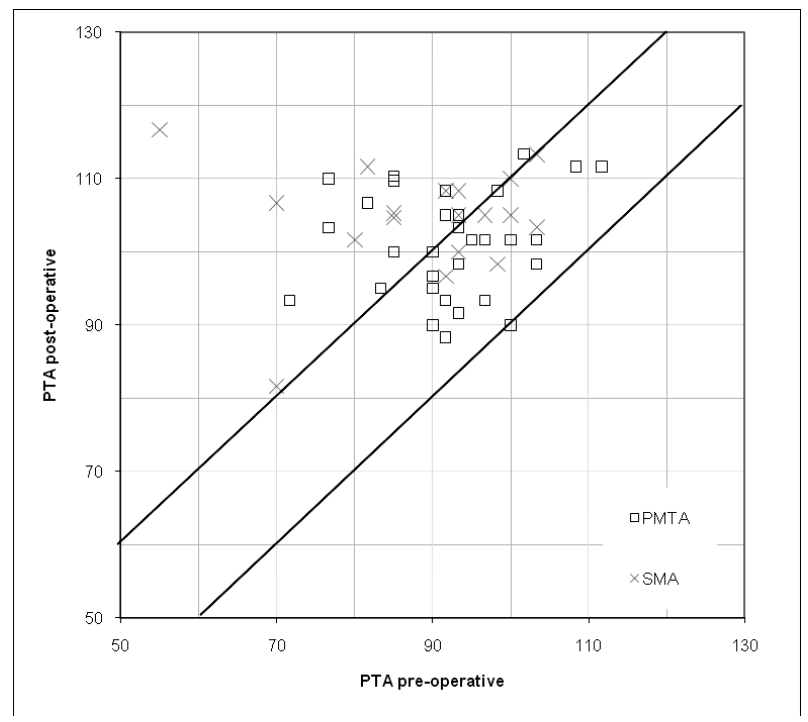

Figure 7.4 Scatter plot of post-surgery versus pre-surgery PTA hearing levels relative to the either the SMA and MPTA procedure after performing a subanalysis. 


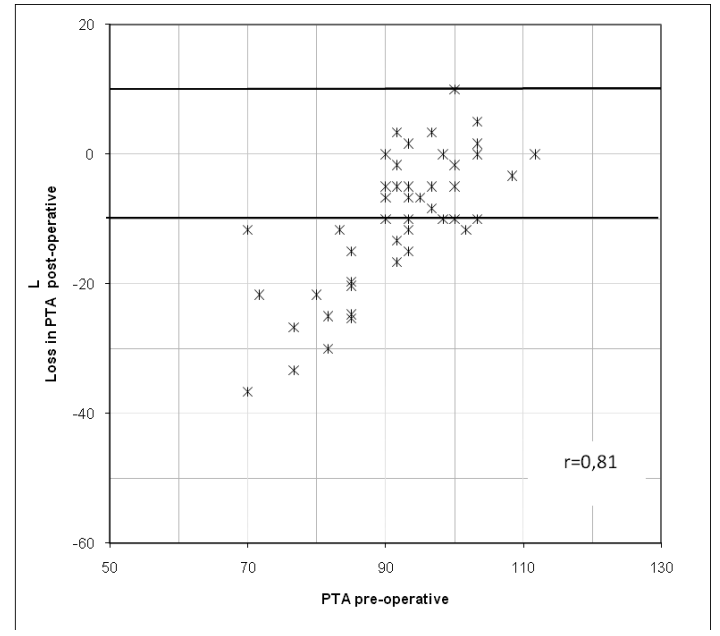

Figure 7.5 Scatter plot of mean reduction in PTA hearing levels after performing the sub analysis. Noteworthy is the fact is that relatively more hearing can be preserved for PTA levels $>90 \mathrm{~dB}$.

\section{Median preservation of hearing using the sub analysis}

The median PTA for the SMA group preoperatively was $92.5 \mathrm{~dB} \mathrm{HL}$. The median postoperative PTA was $105.0 \mathrm{~dB} \mathrm{HL}$ with a change of $12.5 \mathrm{~dB}$. With respect to the MPTA group, median PTA was preoperatively 91.7 and postoperatively 101.7, which accounts for a decline in median PTA of $10.0 \mathrm{db} \mathrm{HL}$ after cochlear implantation. This outcome is in good agreement with the values obtained from calculating mean values and allowing us to conclude that the differences are not influenced by extremes values. The change in median hearing thresholds for 250,500 , and $1,000 \mathrm{~Hz}$ was 12.5 , 20.0, 10.0 dB HL for the SMA group and 5.0, 10.0, 5.0, for the MPTA group (Table 7.2).

Table 7.2 Median improvement in pure-tone average for three frequency levels pre-implant and postimplant for the SMA and MPTA group.

\begin{tabular}{|c|c|c|c|c|c|}
\hline $\begin{array}{l}\text { Study } \\
\text { group }\end{array}$ & & $\begin{array}{l}\text { PTA }^{1} \\
\text { (db HL) }\end{array}$ & $\begin{array}{l}250 \mathrm{~Hz} \\
(\mathrm{db} \mathrm{HL})\end{array}$ & $\begin{array}{l}500 \mathrm{~Hz} \\
(\mathrm{db} \mathrm{HL})\end{array}$ & $\begin{array}{l}1000 \mathrm{~Hz} \\
(\mathrm{db} \mathrm{HL})\end{array}$ \\
\hline SMA & $\begin{array}{l}\text { Preoperative } \\
\text { Postoperative } \\
\text { Change }\end{array}$ & $\begin{array}{l}92.5 \mathrm{~dB} H \mathrm{HL} \\
105.0 \mathrm{~dB} \mathrm{HL} \\
12.5 \mathrm{~dB} \mathrm{HL}\end{array}$ & $\begin{array}{l}82.5 \mathrm{~dB} \mathrm{HL} \\
95.0 \mathrm{~dB} \mathrm{HL} \\
12.5 \mathrm{db} \mathrm{HL}\end{array}$ & $\begin{array}{l}87.5 \mathrm{~dB} H \mathrm{HL} \\
107.5 \mathrm{~dB} \mathrm{HL} \\
20.0 \mathrm{db} \mathrm{HL}\end{array}$ & $\begin{array}{l}105.0 \mathrm{~dB} \mathrm{HL} \\
115.0 \mathrm{~dB} \mathrm{HL} \\
10.0 \mathrm{~dB} \mathrm{HL}\end{array}$ \\
\hline $\begin{array}{l}\text { Study } \\
\text { group }\end{array}$ & & $\begin{array}{l}\text { PTA }^{1} \\
(\mathrm{db} H \mathrm{HL})\end{array}$ & $\begin{array}{l}250 \mathrm{~Hz} \\
(\mathrm{db} \mathrm{HL})\end{array}$ & $\begin{array}{l}500 \mathrm{~Hz} \\
(\mathrm{db} \mathrm{HL})\end{array}$ & $\begin{array}{l}1000 \mathrm{~Hz} \\
(\mathrm{db} \mathrm{HL})\end{array}$ \\
\hline MPTA & $\begin{array}{l}\text { Preoperative } \\
\text { Postoperative } \\
\text { Change }\end{array}$ & $\begin{array}{l}\text { 91.7 dB HL } \\
101.7 \mathrm{~dB} \mathrm{HL} \\
10.0 \mathrm{~dB} \mathrm{HL}\end{array}$ & $\begin{array}{l}85.0 \mathrm{~dB} \mathrm{HL} \\
90.0 \mathrm{~dB} \mathrm{HL} \\
5.0 \mathrm{db} \mathrm{HL}\end{array}$ & $\begin{array}{l}90.0 \mathrm{~dB} H \mathrm{HL} \\
100.0 \mathrm{~dB} \mathrm{HL} \\
10.0 \mathrm{db} \mathrm{HL}\end{array}$ & $\begin{array}{l}105.0 \mathrm{~dB} \mathrm{HL} \\
110.0 \mathrm{~dB} \mathrm{HL} \\
5.0 \mathrm{~dB} \mathrm{HL}\end{array}$ \\
\hline
\end{tabular}

${ }^{1}$ PTA was calculated as median values of thresholds at 250,500 and $1000 \mathrm{~Hz}$. 


\section{Discussion}

This study shows that there is no difference between the SMA and MPTA techniques in preservation of residual hearing after cochlear implantation. To our knowledge, no studies thus far have compared the hearing preservation between these two surgical approaches. In this study, the complete preservation of residual hearing was $9.5 \%$ and $13.3 \%$ in the SMA and MPTA group, respectively. With respect to partial preservation of hearing, $11.9 \%$ and $8.4 \%$ were found in the SMA and MPTA groups, respectively. With respect to complete and partial hearing conservation, no statistical differences could be found between the SMA and MPTA groups.

A notable fact is that the overall partial and complete hearing preservation in both groups are distinctly lower than other studies and may be explained by the following. ${ }^{10,13,26-28}$

1) First, a reason for the poor results of hearing preservation in both groups might be explained by the high number of patients that were included in this study. To our knowledge, this study is the first one which analysed the preservation of residual hearing for the whole cohort of patients who had undergone cochlear implantation in two centres, thereby excluding a selection bias of the best cases.

2) Second, we only included patients with measurable hearing thresholds at 250, 500 and $1000 \mathrm{~Hz}$ to avoid inclusion bias. In contrast, several studies are available in literature which included patients for further analysis who had only measurable thresholds at a particular frequency of interest. ${ }^{10,13,26-28}$ This is a consequence of the enrolment of typical cochlear implant recipients in a study, who are characterized by severe to profound hearing loss. In these studies, the absence of preoperative hearing thresholds at other frequencies has been overcome by using artificial data points in order to avoid losing data. This can be done by using the maximum output of the audiometer at a given frequency plus $5 \mathrm{~dB}(\mathrm{fmax}+5 \mathrm{~dB})$ or applying very large levels to calculate the mean or median conservation of residual hearing, respectively. However, these calculation methods may account for an overestimation of residual hearing and generate a selection bias.

3) Last, the surgical technique in both groups was not optimally tuned to preserve residual hearing as is done in soft surgery. In both groups we only fulfilled the main criteria of soft surgery by drilling a minimal cochleostomy and perilymphe preservation. Important additional components of the soft surgery protocol including the use of steroids during and following surgery and a slow insertion of the electrode into the cochlea have not been followed. Therefore, the percentages of hearing preservation may improve after applying these additional steps for both groups.

In order to substantiate the preservation of hearing more accurately for both surgical techniques, we performed an additional analysis on a subgroup in which we included the patients who were characterized by measurable pre- and post-operative hearing levels at 250, 500 and $1000 \mathrm{~Hz}$. The advantage of this sub-analysis is that a ceiling 
effect is eliminated. The results of this additional analysis demonstrate that the distribution between complete and partial preservation of hearing is significantly different in the MPTA group. In the MPTA and SMA group the complete conservation of residual hearing was $61.3 \%$ (19 of 31 ) and $44.4 \%$ (8 of 18), respectively. Further analysis showed that it was not possible to conserve complete hearing in patients in whom PTA levels were $<90 \mathrm{~dB}$, irrespective of the surgical technique that was used. As seen in figure III and IV, relatively more patients in the SMA group were identified with a PTA $<90 \mathrm{~dB}$. This imbalance may have been partly responsible for the differing outcomes of hearing conservation for the two groups.

Nevertheless, these differences cannot fully explain the difference in outcome with respect to conservation of hearing between the two groups. Some particular features of the SMA may contribute to the difference in hearing preservation and have already been hypothesized in literature including: 1) the placement of the cochleostomy and 2) possible fixation of the incus by the electrode, ${ }^{18,19}$

Hypothetically, the site of the cochleostomy on the promontory using the SMA technique could attribute to the deterioration of residual hearing. In case of the SMA technique, the cochleostoma is positioned slightly more anterior as compared to the MPTA technique. Recent studies have demonstrated the importance of the position of the cochleostomy as a contributing factor for potential damage to the spiral ligament, basilar membrane and osseous spiral lamina. ${ }^{29-31}$ If the cochleostomy is placed more anteriorly, rather than inferiorly, to the round window membrane, there is the distinct possibility of significant trauma to the adjacent basal turn structures accounting for loss of preexisting residual hearing. Briggs et al. showed that creation of an inferiorly placed cochleostomy to the round window membrane, measuring approximately $1 \mathrm{~mm}$ in diameter, can allow entry to the scala tympani. ${ }^{30,31}$ This can be done without injury to the spiral ligament or basilar membrane and hence allow preservation of the adjacent scala media and organ of Corti. One could argue that in the case of the SMA technique a more anterior cochleostomy is used and thereby results in potentially more damage to the spiral ligament, basilar membrane or osseous spiral lamina. ${ }^{18,19}$

A second hypothetical factor which might contribute to the loss of hearing in the SMA group is the risk of drilling on the incus and the influence of the electrode on the mechanical effects of incus vibration, since, after creation of the suprameatal tunnel, a small groove is drilled lateral to the body of the incus to complete the atticoantrostomy. Via this groove the electrode is led caudally to enter the middle ear. This would inevitably make the electrode array pass and possibly fixate the body and long crus of the incus. Especially in case of a thicker electrode this could impair the vibration of the incus with subsequent conductive hearing loss. This approach would make it more difficult to comply with existing standards of soft surgery which are more easily met by the MPTA approach as a potential drilling of the incus is more likely with the SMA technique 


\section{Study limitations}

This study is characterized by limitations due to selection bias which may have influenced the outcome, i.e., the preservation of residual hearing.

The first bias is due to the multicenter character of this study. An additional selection bias may arise simply because each location has its own approach introducing differences in outcomes and thus any subsequent interpretation and conclusion. Yet, if the approach would appear to be the most contributing factor to differences in residual hearing this bias would be irrelevant as results would show great differences. The second bias is introduced by the retrospective nature of this study. The samples were obtained on the basis of available hearing thresholds, and thus clearly the patients have not been randomized into one of the two therapeutic options. Furthermore, the patients represent only a certain percentage of the entire group at each of the two university hospitals. Performing a subgroup analysis whereby patients who had no postoperative response were eliminated to overcome this ceiling effect has perhaps generated an extra selection bias. Although the subgroup analysis showed a significant difference between the two groups, we cannot conclude that the MPTA technique can preserve more residual hearing.

\section{Future studies}

Additional information must be acquired in order to investigate the role of the SMA technique with respect to conservation of hearing. Second, the hypothesis that possible loss of hearing due to the alternative course of the electrode using the SMA technique needs to be substantiated. Therefore, we intend to present on short notice results of the differences in the positioning of the electrode in the cochlea between the SMA and MPTA technique. These findings might either confirm or reject some of the described hypothetical causes of loss of hearing associated with the SMA technique and this could lead to modifications of the surgical technique in order to minimize loss of any residual hearing.

\section{Conclusion}

This study demonstrates that conservation of residual hearing after using the SMA technique for cochlear implantation is similar to that obtained with the MPTA technique. To date there has not been a study which conducted specifically compares these two techniques regarding the preservation of residual hearing. Although the MPTA technique shows a significantly better preservation of residual hearing after stratification for measurable postoperative thresholds, we cannot conclude that the MPTA technique is more appropriate because of selection bias. Nevertheless, the observed hearing losses in patients with a substantial degree of residual hearing levels provide motivation for further refinement of both surgical techniques. 


\section{References}

1. Copeland BJ, Pillsbury HC 3rd. Cochlear implantation for the treatment of deafness. Annu Rev Med 2004;55:157-67.

2. Fraysse B, Dillier N, Klenzner T, Laszig R, Manrique M, Morera Perez C, Morgon AH, Müller-Deile J, Ramos Macias A. Cochlear implants for adults obtaining marginal benefit from acoustic amplification: a European study. Am J Otol 1998; 19:591-7.

3. Fraysse B, Macías AR, Sterkers O, Burdo S, Ramsden R, Deguine O, Klenzner T, Lenarz T, Rodriguez MM, Von Wallenberg E, James C. Combined electro-acoustic stimulation in conventional candidates for cochlear implantation. Otol Neurotol 2006;27:624-33.

4. James C, Albegger K, Battmer R, Burdo S, Deggouj N, Deguine O, Dillier N, Gersdorff M, Laszig R, Lenarz $T$, Rodriguez MM, Mondain M, Offeciers E, Macías AR, Ramsden R, Sterkers O, Von Wallenberg E, Weber B, Fraysse B. Preservation of residual hearing with cochlear implantation: how and why. Acta Otolaryngol 2005;125:481-91.

5. Gstoettner W, Kiefer J, Baumgartner WD, Pok S, Peters S, Adunka O. Hearing preservation in cochlear implantation for electric acoustic stimulation. Acta Otolaryngol 2004;124:348-52

6. Skarzyński H, Lorens A, D'Haese P, Walkowiak A, Piotrowska A, Sliwa L, Anderson I. Preservation of residual hearing in children and post-lingually deafened adults after cochlear implantation: an initial study. ORL J Otorhinolaryngol Relat Spec 2002;64:247-53.

7. Gantz B, Turner C, Gfeller K, Lowder M. Preservation of hearing in cochlear implant surgery: advantages of combined electrical and acoustical speech processing. Laryngoscope 2005;115:796-802.

8. Gantz BJ, Turner CW. Combining acoustic and electoral hearing. Laryngoscope 2005;115:1726-30

9. Kiefer J, Gstoettner W, Baumgartner W, Pok SM, Tillein J, Ye Q, von Ilberg C. Conservation of low frequency hearing in cochlear implantation. Acta Otolaryngol 124:272-80.

10. Balkany TJ, Connell SS, Hodges AV, Payne SL, Telischi FF, Eshraghi AA, Angeli SI, Germani R, Messiah S, Arheart KL. Conservation of residual acoustic hearing after cochlear implantation. Oto Neurotol 2006;27:1083-8.

11. Gtoettner W, Adunka O, Hamzavi J, Lautischer M, Baumgartner W. Speech discrimination scores of post-lingually deaf cochlear-implant patients. Wien Klin Wochenschr 2000; 112: 487-91. (in German)

12. Helms J, Müller J, Schön F, Moser L, Arnold W, Janssen T, Ramsden R, von Ilberg C, Kiefer J, Pfennigdorf T, Gstöttner W, Baumgartner W, Ehrenberger K, Skarzynski H, Ribari O, Thumfart W, Stephan K, Mann W, Heinemann M, Zorowka P, Lippert KL, Zenner HP, Bohndord M, Hüttenbrink K, Hochmair-Desoyer I, et al. Evaluation of performance with the COMBI 40 cochlear implant in adults: a multicentric study. ORL J Otorhinolaryngol Rel Spec 1997; 59:23-35.

13. Hodges AV, Schloffman J, Balkany T. Conservation of residual hearing with cochlear implantation. Am J Otol 1997;18:179-83.

14. Kiefer J, von Ilberg C, Reimer B, Knecht R, Gall V, Diller G, Stürzebecher E, Pfennigdorff T, Spelsberg A. Results of cochlear implantation in patients with severe to profound hearing loss- implications for the indications. Audiology 1998; 37:382-95.

15. van Dijk JE, von Olphen AF,Langereis M, Mens L, Broks J, Smoorenburg G. Predictors of cochlear implant performance. Audiology 1999; 38:109-16.

16. Berrettini S, Forli F, Passetti S. Preservation of residual hearing following cochlear implantation: comparison between three surgical techniques. Journal of Laryngol Otol 2008;122:246-52.

17. House WF. Cochlear implants. Ann Otol Rhinol Laryngol 1976;85:1-93.

18. Colletti V, Fiorino FG, Carner M, Sacchetto L, Giarbini N. New approach for cochlear implantation: Cochleostomy through the middle fossa. Otolaryngol Head Neck Surg 2000;123:467-74.

19. Kiratzidis T, Arnold W, lliades T: Veria operation updated. I. The trans-canal wall cochlear implantation. ORL J Otorhinolaryngol Relat Spec 2002; 64:406-12.

20. Kiratzidis T, Iliades T, Veria Operation AW II: Surgical results from 101 cases. ORL J Otorhinolaryngol Relat Spec 2002;64:413-6.

21. Hausler R: Cochlear implantation without mastoidectomy: The pericanal electrode insertion technique. Acta Otolaryngol 2002;122:715-9.

22. Kronenberg J, Baumgartner W, Migirov L, Dagan T, Hildesheimer M. The suprameatal approach: an alternative approach to cochlear implantation. Otol Neurotol 2004;25:41-5. 
23. Postelmans JT, Grolman W, Tange RA, Stokroos RJ. Comparison of two approaches to the surgical management of cochlear implantation. Laryngoscope. 2009 ;119:1571-8.

24. Postelmans JT, Tange RA, Stokroos RJ, Grolman W. The suprameatal approach: a safe alternative surgical technique for cochlear implantation. Otol Neurotol. $2010 ; 31: 196-203$.

25. Postelmans JT, van Spronsen E, Grolman W, Stokroos RJ, Tange RA, Maré MJ, Dreschler WA. An evaluation of preservation of resdiual hearing using the suprameatal approach for cochlear implantation. Can this implantation technique be used for the preservation of hearing? Laryngoscope 2011;121:1794-9.

26. Di Nardo W, Cantore I, Melillo P, Cianfrone F, Scorpecci A, Paludetti G. Residual hearing in cochlear implant patients. Eur Arch Otorhinolaryngol 2007;264:855-60.

27. Berrettini S, Forli F, Passetti S. Preservation of residual hearing following cochlear implantation: comparison between three surgical techniques. Journal of Laryngol Otol 2008;122:246-52.

28. Soda-Merhy A, Gonzalez-Valenzuela, Tirado-Gutierrez. Residual hearing after cochlear implantation: comparison between straight and perimodiolar implants. Otolaryngology-Head and Neck surgery 2008;139:399-404.

29. Dahm MC, Xu J, Tykocinski M, Shepherd RK, Clark GM. Post mortem study of intracochlear position of the Nucleus Standard 22 electrode array. Proc 5th European Symposium on Peadiatric Cochlear implantation, Antwerp, Belgium, June 4-7, 2000.

30. Briggs RJ, Tykocinski M, Saunders E, Hellier W, Dahm M, Pyman B, Clark GM. Surgical implications of perimodiolar electrode design: avoiding intracochlear damage and scala vestibuli insertion. Cochlear Implant Int 2001;2:135-49.

31. Briggs R, Tykocinski M, Stidha K, Roberson J. Cochleostomy site: implications for electrode placement and hearing preservation. Acta Oto-Laryngol. 2005;125:870-6. 
(2) 119

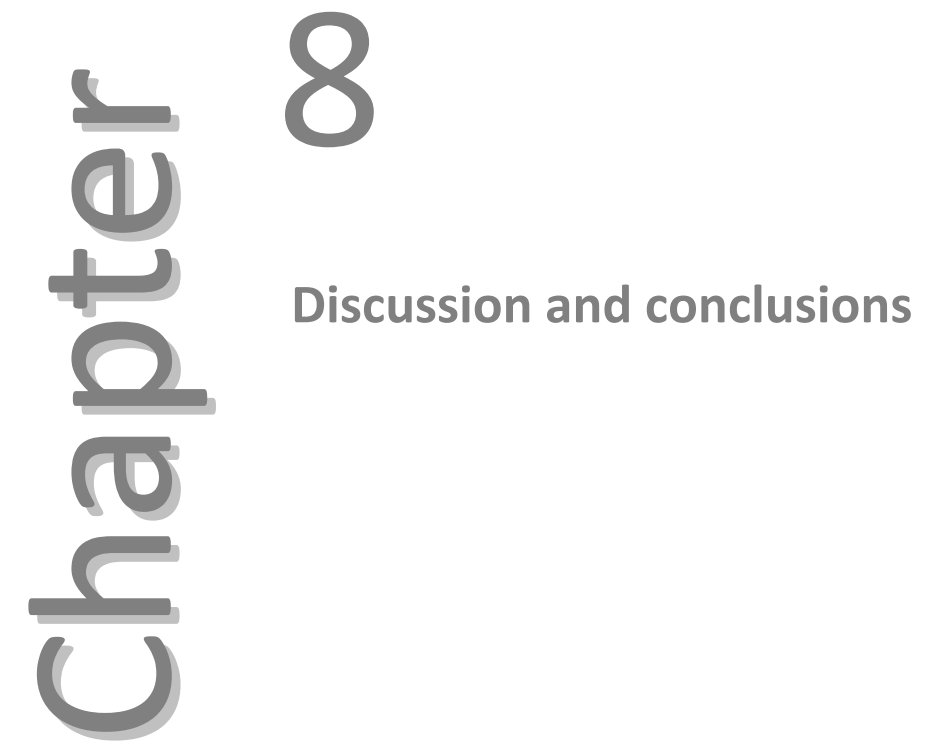


120 (3) Chapter 8 
This thesis addresses several aspects of the surgical management of cochlear implantation and preservation of residual hearing in profoundly hearing-impaired adults and children. In the following an overview is presented of the conclusions drawn in the separate chapters. Thereafter, based on these findings, general questions are posed with in particular a focus on whether the SMA technique should be viewed as a valuable surgical tool for the management and preservation of residual hearing in cochlear implant surgery.

Chapter 1 gives a general introduction with a short review of postoperative complications and different surgical techniques which can be used for cochlear implant surgery. At the end of this chapter, the objectives and outline of the study are delineated.

Chapter 2 focused on the postoperative complications occurring in the first five years after the onset of the adult and pediatric cochlear implant program at the department of Otorhinolaryngology-Head and Neck surgery of the Maastricht University Medical Centre. The surgical complication rate after cochlear implant surgery was low and was in keeping with rates reported in other studies. ${ }^{1-3}$ The incidence of major complications in our study was not only comparable to results reported in other studies, but was even at the lower end of the range, as seen in Table 8.1 which was published by Ovesen et al. ${ }^{1-16}$ As already noted by Ovesen et al., it should be kept in mind that other reports cited may not be comparable with respect to study sample, surgical methods and implant devices used, criteria for inclusion of complications, and treatment of complications. ${ }^{16}$

Table 8.1 Incidences of total complications and major complications after cochlear implantation of other studies. In this table, only studies assessing a minimum of 100 surgical procedures are included. $\mathrm{C}=$ children, $\mathrm{A}=$ adults. This table has been published by Ovesen et al. $^{16}$

\begin{tabular}{|c|c|c|c|c|c|}
\hline Study & Year & Children or adults & Operations (n) & $\begin{array}{c}\text { Complication (\%) } \\
\text { Total }\end{array}$ & Major \\
\hline Black et al. ${ }^{6}$ & 2007 & C & 221 & 26.7 & 5.9 \\
\hline Dodson et al. ${ }^{8}$ & 2007 & $C+A$ & 345 & 9.3 & \\
\hline Arnolder et al. ${ }^{2}$ & 2005 & $C+A$ & 342 & 12.2 & 5.0 \\
\hline Dutt et al..$^{9}$ & 2005 & $A$ & 111 & 18 & 3.2 \\
\hline Kandogan et al. ${ }^{11}$ & 2005 & $\mathrm{C}$ & 227 & 18.9 & 12.3 \\
\hline Lassig et al. ${ }^{14}$ & 2005 & $C+A$ & 875 & & 5.1 \\
\hline Bathia et al. $^{5}$ & 2004 & $\mathrm{C}$ & 300 & 18.3 & 2.3 \\
\hline Cunningham et al. ${ }^{4}$ & 2004 & $C+A$ & 733 & & 3.0 \\
\hline Green et al. ${ }^{1}$ & 2004 & $A$ & 240 & 25.4 & 6.3 \\
\hline Gysin et al. ${ }^{10}$ & 2000 & C & 112 & 9 & 4 \\
\hline Proops et al. ${ }^{3}$ & 1999 & $A$ & 100 & 39 & 3 \\
\hline Kempf et al. ${ }^{12}$ & $1997 / 9$ & C & 366 & & 7.2 \\
\hline Cohen et al. ${ }^{7}$ & 1988 & $A$ & 459 & 12 & 4.8 \\
\hline Postelmans et al. ${ }^{15}$ & 2007 & $C+A$ & 112 & 36 & 3.6 \\
\hline
\end{tabular}


Additionally, investigation of the origin of complications revealed that their occurrence had been mediated by device failure and wound infection as a consequence of flareups of pre-existent middle ear pathology. In all four subjects, the cochlear implant had to be explanted and subsequently re-implantation was performed. Awareness of such complications is crucial as they are a major concern to patients and their families, and to the healthcare staff involved. We learned our lessons regarding the reduction of postoperative complications in cochlear implantation especially in otitis media-prone children and patients with COM.

We observed that the incidence of post-operative complications in children with otitis media declined when cochlear implantation was preceded by the placement of ventilation tubes and a subsequent adenotomy. Based on these findings, we therefore recommended an adenotomy and placement of ventilation tubes in case of a pending cochlear implantation in otitis media prone children to minimize postoperative complications, and this has been agreed on by most authors. ${ }^{17-20}$ To reduce complications in patients with COM, a surgical algorithm was developed based on our own 5 years experience and reports described in literature.

Among the challenges faced in COM are increased risks of infection from the receiver stimulator package or the electrode cable and the associated risk of labyrinthitis or intracranial infection. ${ }^{21-23}$ Additional potential complications are extrusion of the receiver stimulator package or electrode, secondary to flap break down within the mastoid cavity or postauricular region. ${ }^{21-23}$ Intractable device infection and device removal and/or replacement are associated with substantial patient suffering and morbidity. ${ }^{21-23}$ Under conditions of cochlear implant infection in COM, the goal is elimination of infection and creation of a closed environment so the risk of infection associated with placement of a foreign material is reduced.

In chapter 3 our surgical algorithm was evaluated to determine whether it could be valuable as a tool to overcome susceptibility to complications after cochlear implantation in a setting of COM (Figure 8.1). This study clearly demonstrated that application of this surgical algorithm resulted in less cochlear implant-associated infections. Moreover, the incidence of major complications at $7.7 \%$ was in keeping with other studies, allowing us to conclude that our surgical algorithm can be applied in the management of COM, unconditionally. ${ }^{24-31}$

Numerous surgical techniques have been described in literature to overcome potential complications after cochlear implantation in patients with COM. Other surgical techniques which can be used, besides our surgical technique, are summarized in Table $8.2 \mathrm{a}$ and $8.2 \mathrm{~b} .{ }^{24-26,28,31-32}$. The advantages and drawbacks of each individual technique are also presented. Most surgical techniques included soft tissue coverage to prevent an exposed electrode array and subsequent device failure. Obliteration or, at least, soft tissue coverage of the implant electrode is an effective technique to prevent infection at the round window, implant extrusion, and implant failure. ${ }^{24-32}$ 


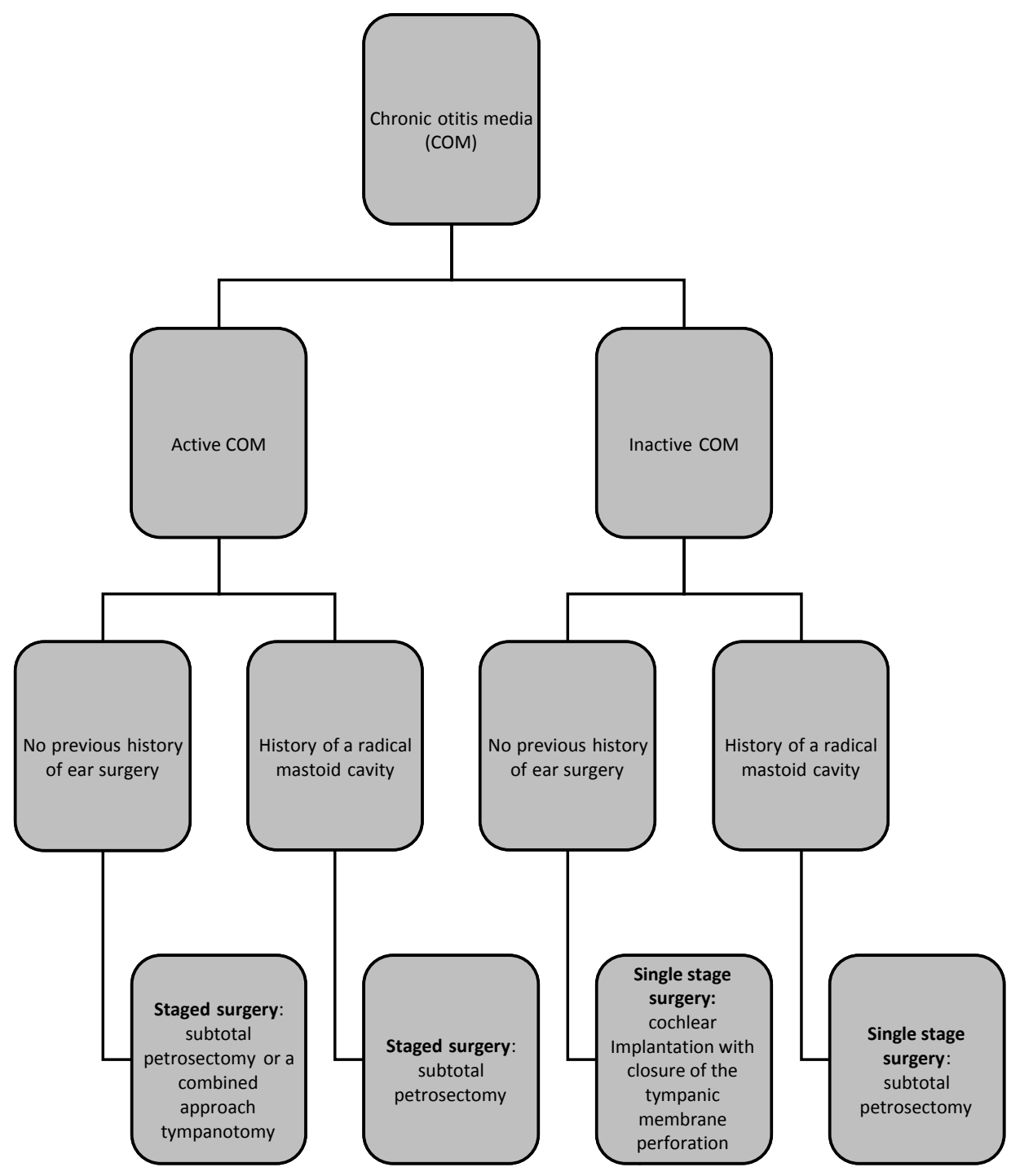

Figure 8.1 Surgical algorithm used in chapter 6 to successfully manage cochlear implantation in a setting of COM. 
Table 8.2a Summarizes the advantages and drawbacks of the various surgical technique for cochlear implantation in a setting of COM.

\begin{tabular}{|c|c|c|}
\hline Surgical technique & Advantages & Drawbacks \\
\hline \multirow{2}{*}{$\begin{array}{l}\text { Subtotal petrosectomy with obliteration } \\
\text { of the tympanomastoid cavity with } \\
\text { abdominal fat }\end{array}$} & $\begin{array}{l}\text { no life-long care of } \\
\text { particular ear }\end{array}$ & $\begin{array}{l}\text { risk of residue of } \\
\text { epithelial cells }\end{array}$ \\
\hline & $\begin{array}{l}\text { creation of a sterile and } \\
\text { isolated environment }\end{array}$ & $\begin{array}{l}\text { risk of occurrence of } \\
\text { mucocele }\end{array}$ \\
\hline \multirow[t]{2}{*}{$\begin{array}{l}\text { Revision mastoidectomy with subsequent } \\
\text { obliteration of the mastoid bowl with } \\
\text { reconstruction of the bony posterior wall }\end{array}$} & $\begin{array}{l}\text { electrode is protected } \\
\text { from cavity problems }\end{array}$ & $\begin{array}{l}\text { risk of epithelial cells and } \\
\text { necrosis of the cutaneous } \\
\text { layer or obliteration material }\end{array}$ \\
\hline & $\begin{array}{l}\text { reconstruction of a new } \\
\text { tympanic cavity- and } \\
\text { membrane avoids } \\
\text { exposure of the electrode } \\
\text { into the mastoid and } \\
\text { tympanic cavity }\end{array}$ & $\begin{array}{l}\text { electrode migration in the } \\
\text { cavity can develop }\end{array}$ \\
\hline
\end{tabular}

Table 8.2b Summarizes the advantages and drawbacks of the various surgical technique for cochlear implantation in a setting of COM.

$\begin{array}{lll}\begin{array}{l}\text { Surgical technique } \\ \begin{array}{l}\text { Revision mastoidectomy with creation of } a \\ \text { periosteal flap to cover the electrode }\end{array}\end{array} & \begin{array}{l}\text { Advantages } \\ \text { open technique }\end{array} & \text { electrode migration } \\ & \begin{array}{l}\text { covering of the electrode } \\ \text { array }\end{array} & \\ \text { Middle fossa approach } & \begin{array}{l}\text { bypassing possible } \\ \text { infected conventional } \\ \text { route }\end{array} & \begin{array}{l}\text { increasing insertion depths of } \\ \text { the electrode }\end{array} \\ & & \text { craniotomy }\end{array}$

In this study, a subtotal petrosectomy was applied which consists of the complete exenteration of all accessible air-cell tracts of the temporal bone, sealing the Eustachian tube orifice and closure of the external meatus. This was followed by obliteration of the tympanomastoid cleft with abdominal fat to cover the electrode array. An advantage of this technique is that life-long care of the particular ear is not required and swimming is allowed. Drawbacks of this procedure include: 1) a residue of epithelial cells in the tympanomastoid cavity which can cause a recurrence of cholesteatoma inducing an asymptomatic destruction of the temporal bone with consecutive device failure; 2 ) if not all mucosa is removed a mucocele may develop, necessitating re-exploration; 3 ) there is difficulty in facilitating radiological imaging and 
a further viewing to detect recurrent cholesteatoma by using diffusion weighted MRI. Nevertheless, studies which report on subtotal petrosectomy are encouraging, being accompanied by low incidences of complications. ${ }^{33-35}$ Lack of statistical power has contributed to the fact that no single technique can be shown to be clearly superior. Therefore, the surgeons' choice for a particular surgical technique is often customized to his own clinical expertise and preferences.

While chapter 2 and chapter 3 of this thesis identified obstacles in the surgical management of cochlear implantation by using the MPTA technique, the remaining four chapters dealt with surgical and audiological outcomes of alternative cochlear implantation techniques. Chapter 4 studied the incidence of surgical complications after cochlear implantation using the SMA technique. This implantation technique was originally developed by Kronenberg in 1999 and is based on a blind atticotomy approach, similar to what was once considered an acceptable approach to cholesteatoma. ${ }^{36-38}$ Studies that substantiated the feasibility of this surgical technique were promising and showed no postoperative complications with respect to facial nerves and mastoids. ${ }^{36-38}$ In light of these favourable preliminary results, the department of Otorhinolaryngology-Head and Neck surgery of the Amsterdam Medical Center adopted the SMA technique as the first choice for cochlear implantation in adults and children. This study clearly demonstrated that the SMA technique is accompanied by a low incidence of postoperative complications. Just like Kronenberg, we could not identify postoperative complications with respect to the facial nerve and mastoid. ${ }^{36-38}$ Furthermore, the incidence of complications were in keeping with other studies which applied the MPTA technique., ${ }^{2,9,15,16}$ Based on these findings we hypothesized in chapter 5 that the SMA techniques is as safe and feasible for cochlear implantation as the MPTA technique. This chapter showed that no difference in major and minor complication rates between the SMA and MPTA could be found. Another finding was that the SMA technique resulted in a reduction in surgery time, which is in accordance with what Kronenberg had reported. ${ }^{36-38}$ A notable fact is that time differences between these techniques were only present in the first four years following the initial cochlear implantation in the MPTA group. Thus, when considering only experienced surgeons the SMA technique provided no advantage regarding surgery time.

In addition to the reduction in surgery time, we discovered more advantages of the SMA technique meriting reporting. In our opinion, the SMA provides better exposure of the middle ear contents as these become more visible through the external auditory canal. Second, by drilling the suprameatal tunnel the body of the incus protects the facial nerve from injury. This is further supported by the fact that two subjects with temporary facial paralysis in the MPTA group could be identified. There were no cases of facial nerve injury in the SMA group. There were, however, some drawbacks experienced using the SMA technique. These drawbacks are mainly related to the preservation of residual hearing as a consequence of particular aspects related to the SMA technique. 
Because of the increased clinical importance of preservation of hearing in literature and the potential adverse effect of the SMA technique on residual hearing preservation, chapter 6 addresses whether the SMA technique can play a role in the conservation of residual hearing. Up till writing this report, it is surprising that no studies had been published regarding this. Outcome of our study showed it was possible to conserve of residual hearing in just a limited number of study subjects. Unfortunately, comparisons pre-and postoperative values were obscured because a large number of the subjects had pre-and postoperative thresholds beyond the maximum output of the audiometer. It is important to consider these limitations posed by the capacity of the audiometer as it resulted in the exclusion of cases with severe loss of residual hearing

To overcome this ceiling problem, we used three independent approaches: 1) The first approach was already described by Kiefer et al., who calculated individual data by substituting fmax $+5 \mathrm{~dB}$ as a data point for frequencies of interest with no registered values at fmax. ${ }^{39}$ This reduces underestimation of the preservation of hearing loss but is an artificial data point. 2) The second approach was introduced by James et al, who calculated the median loss for each frequency at interest, and simply reported the number of subjects with some residual hearing. ${ }^{40}$ Application of this calculation method provides insight into central tendencies of the group, but at a loss of information about individual cases 3 ) We developed the third approach whereby all subjects without measurable pre-and postoperative thresholds are excluded, which neutralizes the ceiling effect. Unfortunately, important data is lost, and in particular the worst cases are not included. Each calculation method has its own limitations and this supports our standpoint that preservation of hearing must be assessed by using more than one calculation method in order to obtain adequate data to evaluate hearing preservation.

In chapter 7 we showed that there was no difference in the preservation of hearing after cochlear implantation between the SMA and MPTA techniques. Due to the ceiling effect it was not possible to calculate the exact preservation of hearing. Without excluding the ceiling effect the percentages of partial and complete preservation of residual hearing were $21.4 \%$ and $21.7 \%$ in the SMA and MPTA groups, respectively. Applying a sub analysis in which the ceiling effect problem was met by a stratification of measurable postoperative thresholds indicated that there was a significant difference in favour of the MPTA technique. Further investigation showed that it was not possible to conserve complete hearing in patients with PTA levels $<90 \mathrm{~dB}$, irrespective of the surgical technique and that there were relatively more patients in the SMA group with a PTA $<90 \mathrm{~dB}$. This imbalance may be in part responsible for the difference found between the two techniques. Nevertheless, this cannot fully explain the difference with respect to hearing conservation. Some particular features of the SMA which may contribute to difference in hearing preservation have already been 
hypothesized in literature and include: 1 ) the placement of the cochleostomy and 2) possible fixation of the incus by the electrode, ${ }^{18,19}$

Cochlear implant technology and surgical implantation techniques have been characterized by a rapid and continuous evolution during the past two decades. ${ }^{41}$ Both have been shown to be safe, successful and efficient in improving the quality of life in a great number of patients who suffer severe to profound hearing loss. ${ }^{1-16} \mathrm{Up}$ till the previous century, the focus has long been to offer these patients an opportunity to (re)establish their hearing and re-introduce them into the hearing world by means of cochlear implantation. As speech perception outcomes have improved, primarily due to improvements in both speech processor software and hardware, patient selection criteria continue to be relaxed resulting in a rapid growth of cochlear implantation in patients with a substantial degree of residual hearing. ${ }^{42-44}$ This development has resulted in further improvement in outcomes because patients whose preoperative residual hearing is conserved may perform relatively better afterwards. ${ }^{44-49}$ Therefore, hearing conservation has obtained a new level of clinical importance and today's surgeons must strive to minimize surgical trauma while inserting the electrode array. The results of chapter 6 and 7 gave rise to several hypotheses with respect to the origin of the loss of residual hearing when applying the SMA surgical technique.

We claim that the SMA technique has certain characteristics which result in relative disadvantages regarding the preservation of residual hearing. These characteristics include: 1) a more superior direction of the electrode tip, 2) the placement of the cochleostomy, and 3) possible fixation of the incus by the electrode.

1) The insertion of the electrode in the cochleostomy site might be the key element which is responsible for significant hearing loss after cochlear implantation when using the SMA technique. In case of the MPTA technique, the tip of the electrode array is held parallel to the course of the lower basal turn and is slowly inserted in the cochleostomy in line with the longitudinal axis of the lower basal turn of the scala tympani, placing it as far away as possible from the modiolus and osseous spiral lamina. The course of the electrode array for the SMA technique differs notably from the MPTA technique. As a consequence of introducing the electrode into the attic, it has to be lead inferiorly to reach the region of the round window and stapes. Subsequently, the electrode array has to bend over to overcome the steep angle to come in line with the longitudinal axis of the lower basal turn of the scala tympani. As already described by Kronenberg et al, bending the electrode leads automatically to a 30 degree more upward direction of the electrodes tip during insertion. ${ }^{36-38}$ Thus, insertion of the electrode might apply force on the lateral wall of the basal turn which may then in turn lead to rotation of the tip being pushed forward for further electrode insertion. Consequently, this might account for displacement of the electrode in the scala tympani to scala vestibuli due to rupture of the basal membrane with subsequent loss of residual hearing. 
2) Deterioration of residual hearing might also be explained by the placement of the cochleostomy on the promotorium when using the SMA technique. Recent studies have demonstrated the potential for damage to the spiral ligament, basilar membrane and osseous spiral lamina occurring with the creation of the cochleostomy..$^{50-52}$ If the cochleostomy is placed more anteriorly, rather than inferiorly, to the round window membrane, there is the distinct possibility of significant trauma to the adjacent basal turn structures which accounts for a deterioration of residual hearing. Briggs et al. showed that creation of an inferiorly placed cochleostomy to the round window membrane, measuring approximately 1 $\mathrm{mm}$ in diameter, can allow entry to the scala tympani. ${ }^{51,52}$ This can be done without injury to the spiral ligament or basilar membrane and hence allow preservation of the adjacent scala media and organ of Corti. However, in case of the SMA technique, the course of the electrode has to overcome a steep angle to come in line with the longitudinal axis of the basal turn of the scala tympani when the electrode is inserted in an inferior placed cochleostomy or via the round window approach. However, based on our clinical observations, insertion of the electrode into the round window or into a more inferior place is not possible due to the steep angle which has to be overcome by the electrode. On the other hand, the angle declines when the cochleostomy is placed more anteriorly to the round window on the promotorium. This means that the surgeons are then forced to place the cochleostomy slightly more anteriorly to the round window than is the case with the MPTA technique which facilitates an easier electrode insertion.

3) The final hypothetical factor which might contribute to the loss of hearing in the SMA group is the risk of drilling the incus and the influence of the electrode on the mechanical effects on incus vibration. Furthermore, after creation of the suprameatal tunnel a small groove is drilled lateral to the body of the incus to complete the atticoantrostomy. Via this groove the electrode is led caudally to enter the middle ear. Finally, the electrode array will come to lie against the body and long crus of the incus, especially in case of a more thicker electrode, which may impair the vibration of the incus with subsequent hearing loss. It is easy to imagine that it is more difficult to comply to the standards of soft surgery when using the SMA approach as drilling the incus occurs relatively more readily than with the MPTA technique.

Unfortunately, these arguments are based on assumptions based on our own experience with the SMA technique. In chapters 5, 6 and 7 study limitations are given regarding the lack of randomizing consecutive patients to one of the therapeutic approaches in these multicenter retrospective studies. These limitations could be overcome in future studies by comparing outcomes of postoperative complications and preservation of hearing in a more randomized controlled setting. Furthermore, the actual source of the hearing loss by using the SMA technique could be investigated by 
comparing the position of the electrodes of both techniques by means of imaging techniques such as computed tomography (CT) or cone beam computed tomography (CBCT). Applying these imaging techniques has already answered some important questions with respect to the cause of hearing loss after cochlear implantation using the MPTA technique. Besides imaging studies, human temporal bone studies also be mandatory to contribute to the determining the mechanisms related to the differences in the hearing loss between the two techniques. Conducting such future studies will certainly provide more insight as to whether the above described hypotheses might be true or should be withdrawn. 


\section{References}

1. Green KM, Bhatt YM, Saeed SR, Ramsden RT. Complications following adult cochlear implantation: experience in Manchester. J Laryngol Otol 2004;118:417-20.

2. Arnoldner C, Baumgartner WD, Gstoettner W, Hamzavi J. Surgical considerations in cochlear implantation in children and adults: a review of 342 cases in Vienna. Acta Otolaryngol 2005;125: 228-34.

3. Proops DW, Stoddart RL, Donaldson I. Medical, surgical and audiological complications of the first 100 adult cochlear implant patients in Birmingham. J Laryngol Otol 1999;113:14-7.

4. Cunningham CD 3rd, SlatteryWH3rd, Luxford WM. Postoperative infection in cochlear implant patients. Otolaryngol Head Neck Surg 2004;131:109-14.

5. Bhatia K, Gibbin KP, Nikolopoulos TP, O’Donoghue GM. Surgical complications and their management in a series of 300 consecutive pediatric cochlear implantations. Otol Neurotol 2004;25:730-9.

6. Black IM, BaileyCM, AlbertDM, Leighton SE, HartleyBE, Chatrath P, Patel N. The Great Ormond Street Hospital paediatric cochlear implant programme 1992-2004. A review of surgical complications. Cochlear Implants Int 2007;8:53-67.

7. Cohen NL, Hoffman RA, Stroschein M. Medical or surgical complications related to the Nucleus multichannel cochlear implant. Ann Otol Rhinol Laryngol Suppl 1988;135:8-13.

8. Dodson KM, Maiberger PG, Sismanis A. Intracranial complications of cochlear implantation. Otol Neurotol 2007;28:459-62.

9. Dutt SN, Ray J, Hadjihannas E, Cooper H, Donaldson I, Proops DW. Medical and surgical complications of the second 100 adult cochlear implant patients in Birmingham. J Laryngol Otol 2005;119:759-64.

10. Gysin C, Papsin BC, Daya H, Nedzelski J. Surgical outcome after paediatric cochlear implantation: diminution of complications with the evolution of new surgical techniques. J Otolaryngol 2000;29:285-9.

11. Kandogan T, Levent O, Gurol G. Complications of paediatric cochlear implantation: experience in Izmir. J Laryngol Otol 2005;119:606-10.

12. Kempf HG, Johann K, Weber BP, Lenarz T. Complications of cochlear implant surgery in children. Am J Otol 1997;18(6 Suppl):S62-3.

13. Kempf HG, Johann K, Lenarz T. Complications in pediatric cochlear implant surgery Eur Arch Otorhinolaryngol 1999;256:128-32.

14. Lassig AA, Zwolan TA, Telian SA. Cochlear implant failures and revision. Otol Neurotol 2005;26: 624-34.

15. Postelmans JT, Cleffken B, Stokroos RJ. Post-operative complications of cochlear implantation in adults and children: five years' experience in Maastricht. J Laryngol Otol 2007;121:318-23.

16. Ovesen T, Johansen LV. Post-operative problems and complications in 313 consecutive cochlear implantations. J Laryngol Otol. 2009;123:492-6.

17. Lin OYS, Lee FP, Peng SC. Complications in children with long term cochlear implants. ORL J Otorhinolaryngol Relat Spec 2006;68:237-42.

18. Kennedy RJ, Shelton C. Ventilation tubes and cochlear implants: what do we do? Otol Neurotol 2005;26:438-41.

19. Kempf HG, Stover T, Lenarz T. Mastoiditis and acute otitis media in children with cochlear implants: recommendations for medical management. Ann Otol Rhinol Laryngol Suppl 2000;185:25-7.

20. Luntz M, Hodges AV, Balkany T, Dolan-Ash S, Schloffman J. Otitis media in children with cochlear implants. Laryngoscope 1996;106:1403-5.

21. Bhatia K, Gibbin KP, Nikolopoulos TP, O'Donoghue GM. Surgical complications and their management in a series of 300 consecutive pediatric cochlear implantations. Otol Neurotol 2004;25:730-9.

22. Harada T, Ishida K, Endo M, Takahashi M, Sakai M. Recurrent extrusion of cochlear implant at an interval of 5 years. Otol Neurotol 2003;24:83-5.

23. Donnelly MJ, Pyman BC, Clark GM. Chronic middle ear disease and cochlear implantation. Ann Otol Rhinol Laryngol Suppl 1995;166:406-8.

24. Tamura Y, Shinkawa A, Ishida K, Sakai M. Cochlear implant after reconstruction of the external bony canal wall and tympanic cavity in radically mastoidectomized patients with cholesteatoma. Auris Nasus Larynx 1997;24:361-6. 
25. Manrique M, Cervera-Paz FJ, Espinosa JM, Perez N, Garcia-Tapia R. Cochlear implantation in radical cavities of mastoidectomy. Laryngoscope 1996;106:1562-5.

26. El-Kashlan HK, Arts HA, Telian SA: Cochlear implantation in chronic suppurative otitis media. Otol Neurotol 2002;23:53-5.

27. El-Kashlan HK, Arts HA, Telian SA: External auditory canal closure in cochlear implant surgery. Otol Neurotol 2003;24:404-8.

28. Gray RF, Irving RM: Cochlear implants in chronic suppurative otitis media. Am J Otol 1995;16:682-6.

29. Irving RM, Gray RF: Cochlear implants in chronic suppurative otitis media: preparing the septic ear for a sterile device. Am J Otol 1996;17:174-5.

30. Bibas A, Phillips S, Bailey CM, Papsin BC. Chronic suppurative otitis media following paediatric cochlear implantation. Cochlear Implants Int 2006;7:167-78.

31. Colletti V, Fiorino FG, Carner M, Pacini L. Basal turn cochleostomy via the middle fossa route for cochlear implant insertion. Am J Otol 1998;19:778-84.

32. Meyerhof WL, Stringer SP, Roland PS. Rambo procedure:modification and application. Laryngoscope 1988; 98:795-6.

33. Axon PR, Mawman DJ, Upile T, Ramsden RT. Cochlear implantation in the presence of chronic suppurative otitis media. J Laryngol Otol 1997;111:228-32.

34. Hamzavi J, Baumgartner W, Franz P, Plenk H Radical cavities and cochlear implantation. Acta Otolaryngol 2001;121:607-9.

35. Issing PR, Schönermark MP, Winkelmann S, Kempf HG, Ernst A. Cochlear implantation in patients with chronic otitis: indications for subtotal petrosectomy and obliteration of the middle ear. Skull Base Surg 1998;8:127-31.

36. Kronenberg J, Migirov L, Dagan T. Suprameatal approach: new surgical approach for cochlear implantation. J Laryngol Otol 2001;115:283-5.

37. Kronenberg J, Migirov L, Baumgartner WD. The suprameatal approach in cochlear implant surgery: our experience with 80 patients. ORL J Otorhinolaryngol Relat Spec 2002;64:403-5.

38. Kronenberg J, Baumgartner WD, Migirov L, Dagan T, Hildesheimer M. The suprameatal approach: an alternative surgical approach to cochlear implantation. Otol Neurotol 2004;25:41-5.

39. James C, Albegger K, Battmer R, Burdo S, Deggouj N, Deguine O, Dillier N, Gersdorff M, Laszig R, Lenarz T, Rodriguez MM, Mondain M, Offeciers E, Macías AR, Ramsden R, Sterkers O, Von Wallenberg E, Weber B, Fraysse B. Preservation of residual hearing with cochlear implantation: how and why. Acta Otolaryngol 2005;125:481-91.

40. Kiefer J, Gstoettner W, Baumgartner W, et al. Conservation of low-frequency hearing in cochlear implantation. Acta Otolaryngol 2004;123:272-80.

41. Balkany TJ, Hodges AV, Eshraghi AA, Butts S, Bricker K, Lingvai J, Polak M, King J. Cochlear implants in children - A review. Acta Otolaryngol 2002;122:356-62.

42. Gtoettner W, Adunka O, Hamzavi J, Lautischer M, Baumgartner W. Speech discrimination scores of post-lingually deaf cochlear-implant patients. Wien Klin Wochenschr 2000; 112: 487-91. (in German)

43. Helms J, Muller J, Schon F et al. Evaluation of performance with the COMBI 40 cochlear implant in adults: a multicentric study. ORL J Otorhinolaryngol Rel Spec 1997; 59:23-35.

44. Hodges AV, Schloffman J, Balkany T. Conservation of residual hearing with cochlear implantation. Am J Otol 1997;18:179-83

45. Balkany TJ, Hodges AV, Eshraghi AA, Butts S, Bricker K, Lingvai J, Polak M, King J. Cochlear implants in children- A review. Acta Otolaryngol 2002;122:356-62.

46. Gtoettner W, Adunka O, Hamzavi J, Lautischer M, Baumgartner W. Speech discrimination scores of post-lingually deaf cochlear-implant patients. Wien Klin Wochenschr 2000; 112: 487-91. (in German)

47. Helms J, Müller J, Schön F, Moser L, Arnold W, Janssen T, Ramsden R, von Ilberg C, Kiefer J, Pfennigdorf T, Gstöttner W, Baumgartner W, Ehrenberger K, Skarzynski H, Ribari O, Thumfart W, Stephan K, Mann W, Heinemann M, Zorowka P, Lippert KL, Zenner HP, Bohndord M, Hüttenbrink K, Hochmair-Desoyer I, et al. Evaluation of performance with the COMBI 40 cochlear implant in adults: a multicentric study. ORL J Otorhinolaryngol Rel Spec 1997; 59:23-35.

48. Kiefer J, von Ilberg C, Reimer B, Knecht R, Gall V, Diller G, Stürzebecher E, Pfennigdorff T, Spelsberg A.. Results of cochlear implantation in patients with severe to profound hearing loss- implications for the indications. Audiology 1998; 37:382-95. 
132 Chapter 8

49. Van Dijk JE, von Olphen AF,Langereis M, Mens L, Broks J, Smoorenburg G. Predictors of cochlear implant performance. Audiology 1999; 38:109-16.

50. Dahm MC, Xu J, Tykocinski M, Shepherd RK, Clark GM. Post mortem study of intracochlear position of the Nucleus Standard 22 electrode array. Proc 5th European Symposium on Peadiatric Cochlear implantation, Antwerp, Belgium, June 4-7, 2000.

51. Briggs RJ, Tykocinski M, Saunders E, Hellier W, Dahm M, Pyman B, Clark GM. Surgical implications of perimodiolar electrode design: avoiding intracochlear damage and scala vestibuli insertion. Cochlear Implant Int 2001;2:135-49.

52. Briggs R, Tykocinski M, Stidha K, Roberson J. Cochleostomy site: implications for electrode placement and hearing preservation. Acta Oto-Laryngol. 2005;125:870-6. 
() 133

\section{Samenvatting}


134 (2) 


\section{Samenvatting}

Een cochleair implantaat is een elektronische binnenoorprothese die is ontwikkeld om geluid om te zetten in elektrische pulsen om zodoende de functie van de beschadigde zintuigcellen in het slakkenhuis van het binnenoor over te nemen bij slechthorende en dove patiënten. In tegenstelling tot andere hoortoestellen (zoals luchtgeleidingstoestellen en beengeleiders) is een cochleair implantaat er toe in staat om geluid om te zetten in elektrische prikkels en deze door te geven aan de gehoorzenuw en de daarachter liggende zenuwbanen waarmee dove en slechthorende patiënten weer opnieuw kunnen horen.

Hoofdstuk 1 van dit proefschrift bevat een algemene introductie over de geschiedenis, verschillende chirurgische technieken en de postoperatieve complicaties bij cochleaire implantaties. Tevens geeft dit hoofdstuk een overzicht van de doelstellingen van dit proefschrift. De doelstellingen van dit proefschrift zijn:

1) Het evalueren van de postoperatieve complicaties na cochleaire implantatie in het Maastricht Universitair Medisch Centrum middels de mastoïdectomie met posterieure tympanotomie benadering.

2) Het toetsen van een chirurgisch algoritme welke kan worden toegepast bij cochleaire implantaties bij patiënten met een chronische ontsteking van het middenoor. Aangezien bij deze patiëntengroep een cochleair implantaat wordt geïmplanteerd in een chronisch ontstoken omgeving noodzaakt dit tot andere chirurgische implantatiestrategie.

3) Het vergelijken van twee verschillende chirurgische cochleaire implantatie technieken, namelijk de mastoïdectomie met posterieure tympanotomie benadering en suprameatale benadering, waarbij de uitkomstmaten de incidentie van postoperatieve complicaties en behoud van restgehoor waren na cochleaire implantatie.

In hoofdstuk 2 worden de postoperatieve complicaties besproken die in de eerste vijf jaar zijn opgetreden in het Maastricht Universitair Medisch Centrum. Het complicatiecijfer komt overeen met andere studies die de postoperatieve resultaten hebben beschreven betreffende cochleaire implantaties. Alle serieuze complicaties die in de eerste vijf jaren zijn geïdentificeerd hadden betrekking op wondinfecties en op het functioneren van het cochleair implantaat. Opmerkelijk in dit hoofdstuk waren de wondinfecties die optraden bij patiënten die allen gekend waren met een voorgeschiedenis van een chronische middenoorontsteking. Deze waarneming heeft er toe besloten om twee aanbevelingen te doen betreffende deze patiëntengroep. Ten eerste, kinderen die bekend zijn met recidiverende middenoorontstekingen zullen preoperatief middenoorbuisjes en verwijdering van de neusamandel ondergaan om wondinfecties na cochleaire implantatie postoperatief te voorkomen. Ten tweede, patiënten met een chronische middenoorontstekingen zullen aan de hand van de activiteit van de ziekte cochleaire implantatie òf in een keer ondergaan òf gefaseerd. Dit laatste betekent dat er eerst een sanerende operatie zal plaats vinden om de 
infectie in het middenoor te bestrijden en vervolgens na een half jaar het cochleair implantaat te implanteren.

Hoofdstuk 3 beschrijft de postoperatieve complicaties na cochleaire implantatie bij patiënten met een chronische middenoor ontsteking. Deze patiënten werden geopereerd volgens een bepaald chirurgisch algoritme. Alle patiënten waarbij aanwijzingen waren voor een actieve ontsteking werden in twee fasen geopereerd. Dit hield in dat eerst een sanerende operatie werd uitgevoerd gevolgd door het implanteren van het cochleair implantaat na 6 maanden. Bij alle patiënten met een inactieve ontsteking werd het cochleair implantaat en een eventuele sanerende operatie aaneensluitend uitgevoerd. De in hoofdstuk 3 beschreven complicatiecijfers zijn laag en in overeenstemming met de literatuur. Op basis hiervan kunnen we concluderen dat het bovengenoemde chirurgische implantatie algoritme succesvol kan worden gebruikt bij patiënten met een chronische middenoorontsteking.

Hoofdstuk 4 beschrijft de postoperatieve complicaties die zijn opgetreden na cochleaire implantaties middels de suprameatale benadering. Dit is een alternatieve chirurgische implantatietechniek die werd geïntroduceerd door Kronenberg in 1999. Deze techniek omzeilt een mastoïdectomie en posterieure tympanotomie welke gebruikelijk zijn bij de klassieke techniek om toegang te verkrijgen tot het middenoor en tot de plaats waar de cochleostomie wordt geboord. Het verkrijgen van deze toegang middels de klassieke techniek kan gepaard gaan met beschadiging van de aangezichtszenuw en smaakzenuw. Deze potentiële complicaties zijn de grootste drijfveer geweest om een andere implantatietechniek te bedenken waarbij dit kan worden verkomen en toch toegang te verkrijgen tot het middenoor. De suprameatale techniek die toegang tot het middenoor verschaft middels een suprameatale tunnel zou bovengenoemde risico's neutraliseren. Dit heeft het Amsterdam Medisch Centrum ertoe besloten om deze techniek te prefereren voor het bewerkstelligen van cochleaire implantaties. De in dit hoofdstuk beschreven incidentie van postoperatieve complicaties is equivalent aan de postoperatieve resultaten na cochleaire implantaties van andere studies die de klassieke implantatietechniek toepasten. Op basis van deze resultaten kunnen we concluderen dat deze techniek een veilige en goed uitvoerbare implantatietechniek is voor cochleaire implantatie.

Hoofdstuk 5 beschrijft de directe vergelijking tussen de postoperatieve complicaties en chirurgische operatietijd tussen de klassieke techniek en suprameatale benadering. De uitkomst van deze studie toont dat de incidentie van postoperatieve complicaties overeen komt met de beide technieken. Met betrekking tot de operatietijd werd er initieel een significant verschil gevonden tussen de operatietijd van beide technieken, waarbij de SMA techniek werd gekenmerkt met de kortste operatietijd. Dit significante verschil geldt alleen maar voor operateurs met beperkte ervaring in het uitvoeren van cochleaire implantaties. Hoe meer ervaren de operateur wordt hoe kleiner het verschil in operatietijd tussen beide technieken.

Dit hoofdstuk beschrijft ook de voor- en nadelen van de suprameatale benadering op een detailleerde wijze. Bescherming van de aangezichtszenuw, overzicht van het 
middenoor en verkorting van de initiële operatietijd worden als voordelen beschreven. Mogelijke nadelen van de suprameatale benadering worden in dit hoofdstuk betiteld als een loodrecht zicht op het interieur van de cochlea, cranialisatie van de elektrodetip en een afname van de beweeglijkheid van de gehoorbeenketen. In dit hoofdstuk wordt gespeculeerd dat deze nadelen een invloed kunnen hebben op het postoperatieve restgehoor betreffende het gebruik van de suprameatale benadering voor cochleaire implantaties.

Hoofdstuk 6 geeft een indruk over de mogelijkheden tot behoud van restgehoor na cochleaire implantatie middels de suprameatale benadering. De in dit hoofdstuk gemeten postoperatieve gehoordrempels tonen aan dat er wel degelijk behoud is van restgehoor na cochleaire implantatie bij deze techniek. Het berekenen van het percentage patiënten waarbij het gehoor behouden wordt is lastig uit te voeren aangezien de pre- en postoperatieve gehoordrempels rond de maximum liggen van de te meten gehoordrempels van de audiometer. Dit zorgt voor een zogenaamde "plafond effect" wat een overschatting geeft van het werkelijke behoud van restgehoor middels deze techniek. Met als doel het "plafond effect" te minimaliseren is het berekenen van het gehoorbehoud gedaan op basis van drie onafhankelijke rekenmethoden. Alle drie de rekenmethodes laten een behoud van restgehoor zien bij een deel van de patiënten welke cochleaire implantatie ondergingen. In vergelijking met de literatuur komen deze percentages van gehoorbehoud enigszins overeen met de eerdere gerapporteerde cijfers van restgehoor na cochleaire implantatie middels de klassieke techniek.

Hoofdstuk 7 toont de directe vergelijking van het behoud van restgehoor tussen de klassieke techniek en de suprameatale benadering. De uitkomst van deze vergelijking is dat er geen significant verschil is in het behoud van restgehoor tussen beide technieken. De reden dat geen evident verschil kan worden gevonden wordt veroorzaakt door het feit dat in een groot deel van de patiënten de postoperatieve gehoordrempels de maximale output van de audiometer overschreden. Om het effect van dit "plafond effect"te minimaliseren heeft een stratificatie plaatsgevonden voor de aanwezigheid van meetbare pre- en postoperatieve gehoordrempels. Deze aanvullende analyse toont wel een significant verschil in het behoud van restgehoor in het voordeel van de klassieke techniek. Echter beide technieken blijken niet in staat om bij patiënten met een gemiddeld restgehoor van $<90 \mathrm{~dB}$ een compleet behoud van restgehoor te realiseren.

In dit hoofdstuk passeren enkele hypothesen de revue die dit significante verschil in behoud van restgehoor kunnen verklaren. De belangrijkste hypothesen die worden genoemd zijn: de afwijkende route die de elektrode draad moet afleggen om in het gebied van de cochleostomie te kunnen komen. Deze afwijkende route kan resulteren in immobilisatie van de incus wanneer de elektrode draad tegen de incus komt te liggen. De immobilisatie van de incus zorgt dan voor conductief gehoorverlies die wordt gesuperponeerd op het al bekende perceptieve gehoorverlies. Een andere 
hypothese die het verschil in behoud van restgehoor kan verklaren ligt in het verlengde van het afwijkende beloop van de elektrode draad. Om de elektrode in het verlengde van de horizontale as van de scala tympani te laten komen wordt de cochleostomie mogelijk meer naar anterieur gemaakt ten opzichte van de klassieke techniek. Uit eerder onderzoek is gebleken dat een te ver naar anterieur geplaatst cochleostoma gepaard gaat met een trauma van het interieur van de cochlea wat aaneensluitend verlies van restgehoor bewerkstelligd.

Hoofdstuk 9 geeft een algemene discussie weer waarbij er vooral aandacht is voor het verschil van de aanvliegroute van de elektrode en de positionering van het cochleostoma van de SMA techniek ten opzichte van de klassieke techniek met betrekking op de invloed van het behoud van restgehoor. Een belangrijk punt is dat aanvullend onderzoek zal moeten worden verricht om bovengenoemde hypothesen te toetsen en zo een verbeterd inzicht te krijgen in de mechanismen die ten grondslag liggen aan het grotere verlies van restgehoor betreffende de suprameatale benadering. 
() 139

List of publications 
140 ( 


\section{List of publications}

Residual hearing preservation after cochlear implantation: comparison between two surgical techniques. Postelmans, JTF, Stokroos RJ, Spronsen van E, Grolman W, Tange RA, Maré MJ, Dreschler WA. University Center Amsterdam. Accepted with revision.

An evaluation of preservation of residual hearing using the suprameatal approach for cochlear implantation. Can this implantation technique be used for preservation of residual hearing? Postelmans JTF, Stokroos RJ, Spronsen van E, Grolman W, Tange RA, Maré MJ, Dreschler WA. Laryngoscope 2011 121:1794-9. University Center Amsterdam

The suprameatal approach: a safe alternative surgical technique for cochlear implantation. Postelmans JTF, Tange RA, Stokroos RJ, Grolman W. Otology Neurotology. 2010; 31:196-203. University Centre Amsterdam.

Comparison of two approaches to the surgical management of cochlear implantation. Postelmans JTF, Grolman W, Tange RA, Stokroos RJ. Laryngoscope. 2009; 119:1571-8. Maastricht University Medical Centre

Cochlear implantation in patient with chronic otitis media: seven years'experience in Maastricht. Postelmans, JTF, Stokroos RJ, Linmans J, Kremer B. Academisch ziekenhuis Maastricht. European Archives of Otorhinolaryngology. 2009; 266:1159-65. Maastricht University Medical Centre

Postoperative complications of cochlear implants in adults and children: five years experience in Maastricht. Postelmans JTF, Cleffken BI, Stokroos RJ, Journal of Laryngology and Otology. 2007;121:318-23. Maastricht University Medical Centre

Cochlear implantation in a patient with deafness induced by Charcot-Marie-Tooth Disease (Hereditary Motor Sensory Neuropathies). A case report. Postelmans JTF, Stokroos RJ. Journal of Laryngology and Otology. 2006;120:508-10. Maastricht University Medical Centre

Breast-conserving therapy for palpable and nonpalpable breast cancer: can surgical residents do the job irrespective of experience. Postelmans JTF, Cleffken BI, Schreutelkamp I, Nap M, Olde Damink SWM, Bijl van der H. World Journal of Surgery, 2007; 3:1731-6. Atrium Medical Centre, Heerlen. 

() 143

Dankwoord 
144 (2) 


\section{Dankwoord}

Bij het afronden van een proefschrift hoort ook het schrijven van een dankwoord om de verschillende personen te bedanken die een bijdrage hebben geleverd aan de totstandkoming van dit proefschrift.

Allereerst wil ik vanzelfsprekend beginnen bij mijn drie promotoren.

Professor dr. R. Stokroos, beste Robert, ik kan me nog goed onze eerste ontmoeting herinneren, waarbij ik je vroeg wat de beste manier was om KNO - arts te worden. Het kwam er op neer dat ik aantoonbare belangstelling moest hebben voor de KNO en jij wist wel iets om te onderzoeken. Een kleine zes jaar later ligt er nu een manuscript voor me op tafel over cochleaire implantaties waar ik met veel plezier aan heb gewerkt. Collega-assistenten waren altijd jaloers op mij op basis van het feit dat ik altijd mijn correcties binnen een of twee dagen terug had en dat er altijd veel vooruitgang in mijn onderzoek zat. Daarvoor wil ik je hartelijk bedanken. Ik kon altijd bij je aankloppen voor advies en steun.

Professor dr. B. Kremer, beste Bernd, ik wil jou, maar ook Robert bedanken dat jullie het met zijn tweeën hebben aangedurfd om mij zes jaar geleden aan te nemen voor de opleiding tot KNO - arts. Zonder jullie was ik geen KNO - arts geworden en was ik waarschijnlijk intensivist geworden. Ik kan me nog goed het telefoongesprek herinneren toen je zei dat ik met de opleiding mocht beginnen. Een van de laatste zinnen was "zorg er alsjeblieft voor dat ik hier geen spijt van krijg". Deze zin is mij altijd bijgebleven en heeft er voor gezorgd dat we beide trots kunnen zijn over het verloop van de afgelopen zes jaar. Buiten het feit dat je een geweldige opleider bent, heb ik ook veel respect voor het feit dat je veel tijd in de organisatie steekt van zowel je eigen afdeling, als ook de bestuurlijke functies die je in het MUMC bekleedt.

Beste professor dr. W. Grolman, beste Wilko, wij hebben elkaar pas later ontmoet toen de eerste twee artikelen van mijn proefschrift al af waren. Ik heb van jou het vertrouwen gekregen om de resultaten van de cochleaire implantaties door jou en $\mathrm{dr}$. R. Tange verricht te mogen opschrijven. Aangezien we redelijk ver uit elkaar wonen en werken hebben we veel over de telefoon gediscussieerd over de totstandkoming van de verschillende artikelen. Jouw directe manier van communiceren werkte zeer bij aan het vlotte beloop van mijn onderzoek. Je hebt me heel erg laten schrikken toen ik hoorde, niet zo heel lang geleden, dat je acuut was opgenomen in het ziekenhuis. Gelukkig is alles met je goed gekomen en ik wens je veel gezondheid toe.

Naast mijn promotoren ben ik uiteraard dank verschuldigd aan de beoordelingscommissie van dit proefschrift, voor de snelle en vakkundige beoordeling: professor $\mathrm{dr}$. Frijns, professor dr. H. Kingma, professor dr. van Dijk en professor dr. Temel.

Buiten deze hooggeleerde heren zijn er nog een aantal mensen die ik wil bedanken. Beste dr. R. Tange, beste Rinze, jij bent degene geweest die de suprameatale techniek 
in Nederland heeft geïntroduceerd. Je hebt me altijd gesteund tijdens mijn presentaties op de KNO dagen of elders waarbij collega's in de zaal soms wel eens kritische vragen stelde over mijn presentatie. Dit gaf een zeer vertrouwd gevoel en ik ben je daar erkentelijk voor.

Beste drs. E van Spronsen, beste Erik, wij zijn elkaar pas tegengekomen toen ik bezig was met het schrijven van de laatste twee artikelen. Jouw commentaar op de vele proefversies van de laatste twee artikelen was altijd erg origineel. De passage dat ik in 2D land woon is mij altijd bijgebleven. Ik wens je veel succes met het afronden van jouw proefschrift. Beste professor dr. W. Dreschler, beste Wouter, wij zijn met elkaar in contact gekomen tijdens het schrijven van de laatste twee artikelen. Ondanks je drukke werkzaamheden in het AMC was er altijd tijd om telefonisch advies te vragen over de audiologische data. In de gereviseerde versies zag ik vaak de opmerking "graag nuanceren" voorbij komen. Jouw kritiek en bijdrage heeft de artikelen naar een hoger niveau getild. Daarvoor dank.

Lieve Marèse Gordijn-Last, jij bent degene geweest die heeft gezegd dat ik het beste naar Robert kon om te horen hoe ik het beste KNO - arts kon worden. Dus wie is het allerbelangrijkste in de reeks van opgesomde namen...........als ik jou niet was tegengekomen....... Ik heb veel steun aan je gehad tijdens mijn opleidingstijd en mis onze conversaties bij het koffieapparaat.

Lieve Edith Berry - Maes, als ik weer eens een dagje vrij moest hebben voor mijn proefschrift of als ik iets weer te laat had ingeleverd was jij degene die het voor me regelde. Ik ken je nog als secretaresse bij het audiologisch centrum, maar net als ik, ben je gegroeid als persoon gedurende de afgelopen jaren. Je laat je niks wijs maken door iemand. Het is jammer dat we elkaar nu zo weinig zien.

Beste Mickey Chenault, wij kennen elkaar vanaf de eerste dag dat ik aan het proefschrift begon. Sterker nog, we zijn heel even kamergenoten geweest. Dank je wel voor het verrichten van de statistiek en het verbeteren van mijn Engelse schrijfstijl.

Beste Mirçea Rikers, ook jou ken ik vanaf het eerste moment. Ik dank je hartelijk voor al je hulp. Nogmaals gefeliciteerd met de geboorte van je zoon.

Mijn paranimfen, Jos, met jou ben ik oud geworden tijdens onze opleiding. Jij was mijn maatje en vertrouwenspersoon die iedereen nodig heeft om je opleiding tot medisch specialist af te ronden. Regelmatig gingen we even naar de bieb om de meest up-todate literatuur te bestuderen. Andrei, jou heb ik via Femke leren kennen toen ze nog AIO was. Naderhand hebben we velen gezellige avonden beleefd met onze dames. Ik heb je nog nooit chagrijnig gezien, ook niet eens toen Ellen net de Audi A3 in de 
vangrail had geparkeerd. Dat maakte ook niet uit want het raampje ging toch al niet meer naar beneden.

Mijn aankomende maten Gert Jan van Zeben, Tammo Zijlker, Henk Brinkhuis, Dirk Flikweert en Ewa Bergshoeff, het is een groot plezier om elke dag met jullie te mogen werken. Ik kijk er erg naar uit om in januari mijn steentje bij te dragen aan het succes van deze maatschap.

Mijn lieve ouders dank ik voor de opvoeding die ik heb gekregen. Het is niet vanzelfsprekend dat je een proefschrift en een opleiding tot medisch specialist in één afrond. Dit vergt enigszins discipline en doorzettingsvermogen wat ik van thuis mee heb gekregen.

Tot slot wil ik een aantal zinnen van dit dankwoord toewijden aan Femke. Jij ben al langer dan tien jaar mijn vriendinnetje en inmiddels ook al de trotse moeder van onze prachtige zoon Julius. Ik ben er trots op dat we op dezelfde dag promoveren en nog trotser dat je dit niet alleen doet maar met onze aanstaande zoon in je bolle buik. Ik hoop dat er nooit een einde zal komen aan ons succes verhaal. 

() 149

Curriculum Vitae 
150 ( 


\section{Curriculum Vitae}

Job Postelmans werd op 7 juni 1980 geboren te 's-Hertogenbosch. In 1999 werd het eindexamen Atheneum behaald aan het katholieke scholengemeenschap d'Oultremontcollege te Drunen. Datzelfde jaar werd begonnen met de studie Geneeskunde aan de Universiteit van Maastricht. Het artsexamen werd in 2005 behaald waarna klinische ervaring werd opgedaan als Arts-Niet-In-Opleiding op de Intensive Care van het Atrium Medisch Centrum. De opleiding tot Keel-, Neus- en Oorheelkunde werd in 2006 gestart in het Maastricht Universitair Medisch Centrum met als opleider prof. dr. B. Kremer en waarnemend opleider prof. dr. R.J Stokroos. De perifere opleidingsstages werden gedaan in het Elkerliek Ziekenhuis te Helmond, onder leiding van dr. P. Schuil en drs. H. Kahmann en in het Atrium Medisch Centrum te Heerlen, onder supervisie van dr. T. Zijlker en drs. H. Brinkhuis. Per 1 januari 2012 is hij als chef de clinique werkzaam in het Atrium Medisch Centrum te Heerlen. 